\title{
Two Revenue Sharing Contracts in a Three-echelon Supply Chain with a Risk-neutral or a Risk-averse Retailer
}

\author{
Yumei Hou ${ }^{1,2}$, Fangfang Wei ${ }^{1}$, Xin Tian ${ }^{3,4 *}$, Xiaoyun Liu ${ }^{1}$ \\ ${ }^{1}$ College of Economics and Management, Yanshan University, ${ }^{2}$ Institute of service operation and cooperative innovation, \\ Yanshan University, ${ }^{3}$ Research Center on Fictitious Economy and Data Science, Chinese Academy of Sciences, ${ }^{4}$ Key \\ Laboratory of Big Data Mining and Knowledge Management, Chinese Academy of Sciences (China) \\ bym@ysu.edu.cn,waferfang@126.com,*Corresponding_Author: tianx@ucas.ac.cn, 623536182@qq.com
}

Received: June 2015

Accepted: September 2015

\section{Abstract:}

Purpose: This paper compares the efficiency of two revenue-sharing contracts and discusses the members' preference for a three-echelon supply chain with the retailer's different risk attitude.

Design/methodology/approach: This paper focuses on a three-echelon supply chain with a manufacturer, a distributor and a retailer. If the retailer is risk-neutral, the coordination of the supply chain based on the two revenue-sharing contracts is comparatively studied. If the retailer is downside-risk-aversion, the supply chain performance is comparatively analyzed and a risk-sharing contract is designed to coordinate the supply chain. Finally, the two revenue-sharing contracts under the risk-sharing contract are still compared.

Findings: Although both the two revenue-sharing contracts can coordinate the supply chain with a risk-neutral retailer, they are not always able to coordinate the supply chain with a risk-averse retailer. It is interesting that the supply chain with a risk-averse retailer can be coordinated by executing a designed risk-sharing contract, which is based on any kind of revenue-sharing contract. Finally, any kind of revenue-sharing contracts is not absolutely better than another. Based on the risk-sharing contract, the retailer's preference is equivalent between 
the two contracts; but for the distributor and the manufacturer, their preferences between the two contracts are positively related to their own profit share in the supply chain.

Originality/value: Comprehensively comparing the two revenue-sharing contracts is the only presented research in the supply chain.

Keywords: supply chain, three-echelon, revenue-sharing contract, risk-aversion

\section{Introduction}

Revenue sharing contract is a supply chain contract between a manufacturer and a retailer, in which the manufacturer charges a low wholesale price to the retailer and shares a fraction of her revenue. It could induce the retailer to choose optimal actions in the supply chain (quantity and price) and also allocate channel profits among the supply chain members (Cachon \& Lariviere, 2005). It is widely adopted in variety of industries, such as the video rental industry (Mortimer, 2008), the mobile networks with independent content providers and mobile service supply chain (Lu, Lin \& Wang, 2010), the assembly systems with vendor-management inventory (Gerchak \& Wang, 2004), semiconductor industry supply chain (Bahinipati, Kanda \& Deshmukh, 2009), airline alliances (Hu, Caldentey \& Vulcano, 2013), and dairy supply chain (Qian, Zhang, Wu \& Pan, 2013).

In a multi-echelon supply chain, two revenue sharing contracts can be used. The first one, proposed by Giannoccaro and Pontrandolfo in 2004, is that the revenues are shared by all pairs of adjacent entities. The second one, proposed by Rhee, Veen, Venugopal and Nalla in 2010, is that the retailer simultaneously shares her revenues with all supply chain members. We call the first contract revenue sharing contract I and call the second one revenue sharing contract II. It is worth noting that Rhee et al. (2010) point that revenue sharing contract I implicitly assumes that all contracts between the pairs of entities are installed simultaneously, which is the key difficulty to implement the contract. However, with the high-speed developing of internet, the difficulty getting smaller, especially in a three-echelon supply chain which is composed of less member.

Managing risk in a supply chain has now been a more popular topic. Essentially, in a supply chain context, if there are some sources of uncertainty such as demand and supply, the performance of the supply chain will also be affected and become uncertain. As a result, risk emerges and supply chain agents have to make decision under risk. Then we focus on supply chain coordination with a risk-averse retailer based on two revenue sharing contracts.

Specifically, we focus on a three-echelon supply chain which is composed of a manufacturer, a distributor and a retailer. Based on the retailer's different risk attitude, we comparatively 
research supply chain coordination through two revenue sharing contracts. If the retailer is risk-neutral, the revenue sharing contract I and the revenue sharing contract II are the same for the supply chain, because both of them can maximize the total supply chain profit. Moreover, the performance of the members depends on the particular contract selected and no contract is absolutely preferred by all agents. If the retailer is risk-averse, her downside-risk is related to her profit share in the supply chain. And both the two revenue sharing contracts are not necessarily able to coordinate the supply chain, which is related to the retailer's degree of risk aversion. Moreover, any kind of revenue sharing contract is also not absolutely better than another, which is related to the retailer's degree of risk averse and the contract parameters.

Then, a modification of risk sharing contract of Gan, Sethi and Yan (2005) is analyzed to coordinate the supply chain and satisfy the retailer's risk constraint. The modification is because the retailer's downside-risk constraint cannot be satisfied if the retailer's cost is not zero in Gan et al. (2005). We have two kinds of risk sharing contracts based on the two revenue sharing contracts, because the risk sharing contract is a composite contract based on buyback contract and any kind of revenue sharing contract. Through comparatively analyzing the two risk sharing contracts, the comparison between the two revenue sharing contracts is very intuitive. For the whole supply chain and the downside-risk-retailer, the two revenue sharing contracts are equivalent. For the manufacturer and the distributor, their preferences between the two revenue sharing contracts are positively related to their own profit share in the supply chain.

The remainder of this paper is structured as follows. Section 2 reviews the relevant literature. Section 3 introduces two revenue sharing contracts with risk-neutral members and compares the two revenue sharing contracts. Section 4 comparative analyzes the supply chain performances with a risk-averse retailer under the different revenue sharing contracts. Then, in Section 5, the improved contracts of the two revenue sharing contracts are proposed to coordinate the supply chain with a risk-averse retailer. Finally, conclusion is presented in Section 6.

\section{Literature Review}

This paper incorporates three streams of research from the literature. The relevant areas include (1) two-echelon supply chain with revenue sharing contracts, (2) multi-echelon supply chain with revenue sharing contracts, and (3) supply chain coordination with risk-averse members. 


\section{(1) Two-echelon supply chain with revenue sharing contract}

A supply chain consists of several members that usually have different and conflicting objectives, which need to be coordinated by contracts. Many coordinating contracts, such as buy-back or return contract, revenue sharing contract, and quantity-flexibility contract, have been proposed to improve supply chain performance. A comprehensive review of contracts is presented in Govindan, Popiuc and Diabat (2013). Among the different kinds of contracts, revenue sharing contract is a popular contract which proved to be efficient for several industries. For example, revenue sharing contract increased the video industry's total profit by an estimated 7\% (Cachon \& Lariviere, 2005). Dana and Spier (2001) suggested the use of revenue sharing contract in a decentralized channel with a perfectly competitive downstream market and stochastic demand. They show that a revenue sharing contract could induce the downstream firms to choose a channel-optimal action. Zhang and Chen (2014) studied information sharing in a make-to-stock supply chain under wholesale contract and revenue sharing contract. They show that information sharing benefits the supplier, the retailer and the supply chain when revenue sharing contract is used. Hsueh (2014) proposed a new revenue sharing contract embedding corporate social responsibility to coordinate a two-tier supply chain.

\section{(2) Multi-echelon supply chains with revenue sharing contract}

In reality, supply chain consists of more than two echelons. So the research on the multi-echelon supply chain is a need. Some researchers focus on the coordination of multi-echelon supply chains, such as Jaber, Bonney and Guiffrida (2010). The research has been conducted on the coordination of multi-echelon supply chains with contracts such as price-only contract, quantity discount contract, buyback contract, and revenue sharing contract.

We notice that two revenue sharing contracts can be used in multi-echelon supply chain. The first one is that the revenues are shared by all pairs of adjacent entities, proposed by Giannoccaro and Pontrandolfo (2004), and is extended to study a three-echelon supply chain with surplus goods and credit losing by Ji, Liu and Han (2007). Then, it is expanded to study a three-echelon supply chain with the retailer's sales effort by Pang, Chen and Hu (2014). Moreover, the second one is that the retailer simultaneously shares her revenues with all supply chain members, proposed by Rhee et al. (2010), and is extended to study an N-stage supply chain with reliability considerations by Feng, Moon and Ryu (2014). Rhee et al. (2010) pointed out that the contract of Giannoccaro and Pontrandolfo (2004) has a key difficulty to implement, i.e., the contract implicitly assumes that all contracts between the pairs of entities are 
installed simultaneously. Jiang, Wang, Yan and Dai (2014) showed that the contract of Giannoccaro and Pontrandolfo (2004) may never be established in a three-echelon supply chain with competing manufacturers, where the members in the supply chain make decision sequentially. However, with the high-speed developing of internet, it is easily implemented that all contracts between the pairs of entities are installed simultaneously in a three-echelon supply chain. Jiang et al. (2014) focused on a three-echelon supply chain with the two revenue sharing contracts. But they don't analyze the member's risk attitude in the supply chain.

\section{(3) Supply chain coordination with risk-averse member}

Modeling risk-averse newsvendor problem has received considerable attention in recent years. Utility functions, mean-variance approach, value-at-risk (VaR) and conditional value-at-risk (CVaR) are four main research streams. We focus on the VaR approach, which is a financial risk measure that has emerged and been widely used in recent years. A distinct disadvantage of the standard VaR criterion is that it purely considers risk but not the expected profits. Although many supply chain members may be risk-averse, they still seek to attain a high (expected) profit. To reflect this, VaR can be used as a constraint, e.g., with a probability of $95 \%$ the realized profit is at least some fixed amount (Gan et al., 2005).

Gan, Sethi, and Yan (2004) first consider a supply chain coordination problem with risk-averse agent. According to Gan et al. (2004), we know that

'A contract coordinates a supply chain if under the contract, (1) the agents' reservation payoff constraints are satisfied, and (2) the agents' joint action under this contract is Pareto-optimal.'

In a companion paper (Gan et al., 2005), the definition of coordination was specialized for a supply chain with a risk-neutral supplier and a downside-risk constrained newsvendor.

To coordinate a supply chain with risk-averse members, some well-known contracts have been considered such as return policy, profit sharing contract, the target sales rebate contract and real option contract. Moreover, some new contracts have proposed to improve supply chain performance and achieve supply chain coordination, such as gain/loss sharing contract, advanced-purchase discount contract, buyback-setup-cost-sharing mechanism and risk sharing contract. In multi-echelon supply chain, Agrawal and Seshadri (2000) introduced risk-neutral intermediaries to offer mutually beneficial contracts to risk-averse retailers, and they demonstrated that an important role of an intermediary 
in distribution channels is to reduce the risk faced by retailers; $\mathrm{Xu}$, Meng and Shen (2013) proposed a tri-level programming model for a three-stage supply chain management based on Conditional Value-at-Risk measure, to improve the risk management of the supply chain. However, the two papers above did not consider the supply chain coordination. Gan et al. (2005) proposed a risk sharing contract to coordinate the supply chain with a risk-neutral supplier and a risk-averse retailer. The risk sharing contract is composed of buyback contract and revenue sharing contract, and its basic idea is to provide downside protection to the retailer by refunding a certain amount of unsold units. However, if the retailer's cost is not zero, the retailer's downside-risk constraint cannot be met by executing this risk sharing contract. So we improve the risk sharing contract in a three-echelon supply chain to satisfy the retailer's risk constraint and coordinate the supply chain.

\section{Two Revenue Sharing Contracts in the Supply Chain with a Risk-neutral Retailer}

In this section, we focus on a one-period supply chain model, which has a manufacturer (M), a distributor (D) and a retailer (R). The material, information, and financial flow are specified as plotting in Figure 1. There is just one kind of product selling in one-period. The lead-times of the order from both the retailer and the distributor are zero. Each member has an infinite capacity. The demand in one period, denoted by $X$, is stochastic random with the distribution function $F(\cdot)$ and the density function $f(\cdot)$. The unsatisfied demand in the end of the period is lost.

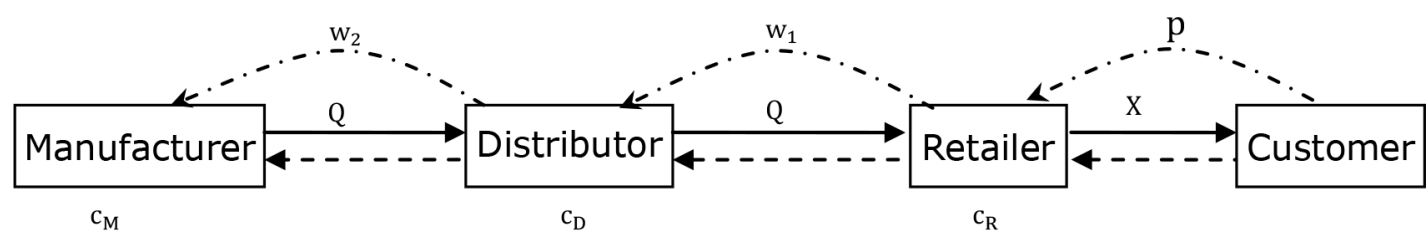

Notes:

Goods flow: $\longrightarrow$ Information flow: $---\rightarrow$ Capital flow:-·- - ->

Figure 1 . The three-echelon supply chain

In the supply chain, the following events will happen sequentially in one selling period: (1) at the beginning of the selling period, the manufacturer produces the product at the cost $\mathrm{c}_{M}$ per unit and the manufacturer announces the wholesale price $w_{2}$ per unit; (2) after observing the wholesale price from the manufacture, the distributor announces the wholesale price, denoted by $\mathrm{w}_{1}$ per unit; (3) the retailer makes order from the distributor and the order quantity is Q; (4) the distributor makes the same order as the retailer from the manufacturer and delivers products to the retailer immediately, her transferring cost for per unit of product is $C_{D} ;(5)$ the retailer has hold cost $C_{R}$ per unit for the arrived products. Economically, any supply chain 
member's pricing is greater than her cost. So three inequalities hold such as $w_{1}+c_{R}<p$, $C_{D}+w_{2}<w_{1}$ and $C_{M}<w_{2}$.

In fact, there are only two revenue sharing contracts in the three-echelon supply chain. The revenue sharing contract I, introduced in Section 3.1, was proposed by Giannoccaro and Pontrandolfo (2004) to coordinate a three-echelon supply chain. Moreover, the monitoring and controlling quality of the multi-echelon supply chain is very important such as food multi-echelon supply chain. The revenue sharing contract II, introduced in Section 3.2, is a good contract to monitor and control quality in the multi-echelon supply chain.

\subsection{The Revenue Sharing Contract I with a Risk-neutral Retailer}

The revenue sharing contract I (denoted by superscript I) $\left(\emptyset_{1}^{\mathrm{I}}, \emptyset_{2}^{\mathrm{I}}, \mathrm{w}_{1}^{\mathrm{I}}, \mathrm{w}_{2}^{\mathrm{I}}\right)$ in the three-echelon supply chain is shown in Figure 2. At the end of selling period, the retailer gives $\emptyset_{1}^{I}$ of her revenue to the distributor and the distributor gives $\emptyset_{2}^{\mathrm{I}}$ of her revenue to the manufacturer $\left(\emptyset_{1}^{\mathrm{I}}, \emptyset_{2}^{\mathrm{I}} \in[0,1]\right)$, where $\emptyset_{1}^{\mathrm{I}}$ and $\emptyset_{2}^{\mathrm{I}}$ represent the members' bargaining power in the supply chain. If the manufacturer's bargaining power is stronger, $\emptyset_{2}^{\mathrm{I}}$ is large; if the distributor's bargaining power is stronger, $\emptyset_{1}^{\mathrm{I}}$ is large and $\emptyset_{2}^{\mathrm{I}}$ is small; and if the retailer's bargaining power is stronger, $\emptyset_{1}^{\mathrm{I}}$ is small.

In the supply chain with the revenue sharing contract I, the expected profits of the retailer, the distributor and the manufacturer are as follows:

$$
\begin{gathered}
E\left[\Pi_{R}^{I}\left(w_{1}^{I}, Q\right)\right]=E\left[\left(1-\emptyset_{1}^{I}\right) \cdot p \cdot \min (X, Q)-w_{1}^{I} Q-c_{R} Q\right], \\
E\left[\Pi_{D}^{I}\left(w_{1}^{I}, w_{2}^{I}, Q\right)\right]=E\left[\left(1-\emptyset_{2}^{I}\right) \cdot\left(\emptyset_{1}^{I} \cdot p \cdot \min (X, Q)+w_{1}^{I} Q\right)-w_{2}^{I} Q-c_{D} Q\right]
\end{gathered}
$$

and

$$
\mathrm{E}\left[\Pi_{\mathrm{M}}^{\mathrm{I}}\left(\mathrm{w}_{1}^{\mathrm{I}}, \mathrm{w}_{2}^{\mathrm{I}}, \mathrm{Q}\right)\right]=\mathrm{E}\left[\emptyset_{2}^{\mathrm{I}} \cdot\left(\emptyset_{1}^{\mathrm{I}} \cdot \mathrm{p} \cdot \min (\mathrm{X}, \mathrm{Q})+\mathrm{w}_{1}^{\mathrm{I}} \mathrm{Q}\right)+\mathrm{w}_{2}^{\mathrm{I}} \mathrm{Q}-\mathrm{c}_{\mathrm{M}} \mathrm{Q}\right]
$$

The total expected profit of the supply chain is the sum of all the supply chain members' profit, i.e.,

$$
\mathrm{E}\left[\mathrm{n}_{\mathrm{SC}}(\mathrm{Q})\right]=\mathrm{E}\left[\mathrm{p} \cdot \min (\mathrm{X}, \mathrm{Q})-\left(\mathrm{c}_{\mathrm{R}}+\mathrm{c}_{\mathrm{D}}+\mathrm{c}_{\mathrm{M}}\right) \mathrm{Q}\right] .
$$




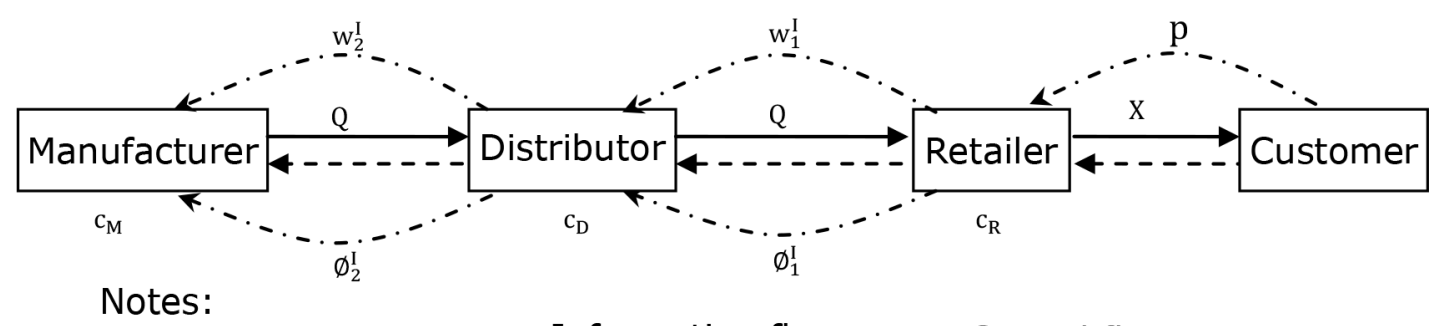

Goods flow: $\longrightarrow$ Information flow: $--\rightarrow$ Capital flow:- - - ->

Figure 2 . The three-echelon supply chain with the revenue sharing contract I

In the centralized supply chain, the total expected profit of the supply chain is concave with respect to $\mathrm{Q}$. So the retailer has the unique positive and optimal order quantity $\mathrm{Q}^{\mathrm{C}}$, i.e.,

$$
Q^{C}=F^{-1}\left(\left(p-c_{R}-c_{D}-c_{M}\right) / p\right)
$$

Combining Equations (4) and (5), the optimal total expected profit of the supply chain is

$$
\Pi_{S C}^{C}=\left(p-c_{R}-c_{D}-c_{M}\right) \cdot Q^{C}-p \cdot \int_{0}^{Q^{C}} F(x) d x
$$

According to Giannoccaro and Pontrandolfo (2004), for any given $\emptyset_{1}^{I}$ and $\emptyset_{2}^{I}$, the revenue sharing contract I with parameters

$$
\begin{gathered}
\mathrm{w}_{1}^{\mathrm{I}}=\left(1-\emptyset_{1}^{\mathrm{I}}\right) \cdot\left(\mathrm{c}_{\mathrm{D}}+\mathrm{c}_{\mathrm{M}}+\mathrm{c}_{\mathrm{R}}\right)-\mathrm{c}_{\mathrm{R}} \\
\mathrm{w}_{2}^{\mathrm{I}}=\mathrm{c}_{\mathrm{M}}-\emptyset_{2}^{\mathrm{I}} \cdot\left(\mathrm{c}_{\mathrm{D}}+\mathrm{c}_{\mathrm{M}}\right)
\end{gathered}
$$

coordinates the supply chain. With the coordinated revenue sharing contract I, the optimal profits of the three members are, respectively,

$$
\begin{gathered}
\Pi_{\mathrm{R}}^{\mathrm{I}}=\left(1-\emptyset_{1}^{\mathrm{I}}\right) \cdot \Pi_{\mathrm{SC}}^{\mathrm{C}}, \\
\Pi_{\mathrm{D}}^{\mathrm{I}}=\emptyset_{1}^{\mathrm{I}} \cdot\left(1-\emptyset_{2}^{\mathrm{I}}\right) \cdot \Pi_{\mathrm{SC}}^{\mathrm{C}}
\end{gathered}
$$

And

$$
\Pi_{\mathrm{M}}^{\mathrm{I}}=\emptyset_{1}^{\mathrm{I}} \cdot \emptyset_{2}^{\mathrm{I}} \cdot \Pi_{\mathrm{SC}}^{\mathrm{C}}
$$

In the coordinated supply chain with revenue sharing contract $I$, the members' profit allocations are determined by $\emptyset_{1}^{\mathrm{I}}$ and $\emptyset_{2}^{\mathrm{I}}$. Specifically, the retailer's profit share is $\left(1-\emptyset_{1}^{\mathrm{I}}\right)$, the distributor's profit share is $\emptyset_{1}^{I} \cdot\left(1-\emptyset_{2}^{I}\right)$ and the manufacturer's profit share is $\emptyset_{1}^{I} \cdot \emptyset_{2}^{I}$. Thus, the revenue sharing contract I not only coordinates the three-echelon supply chain but also arbitrarily allocates the profit among the members. If the retailer's bargaining power becomes stronger, the retailer would expect the decreasing of $\emptyset_{1}^{\mathrm{I}}$; if the distributor's bargaining power 
becomes stronger, the distributor would expect the increasing of $\emptyset_{1}^{\mathrm{I}}$ and the decreasing of $\emptyset_{2 i}^{\mathrm{I}}$; and if the manufacturer's bargaining power becomes stronger, the manufacturer would expect the increasing of both $\emptyset_{1}^{\mathrm{I}}$ and $\emptyset_{2}^{\mathrm{I}}$. It indicates that conflicts of interest exist among the three members.

Furthermore, the wholesale price $w_{1}^{I}$ is negative if $\frac{c_{D}+c_{M}}{c_{D}+c_{M}+c_{R}}<\emptyset_{1}^{I}<1$ and $w_{2}^{I}$ is negative if $\frac{c_{M}}{c_{D}+c_{M}}<\emptyset_{2}^{I}<1$. Therefore, if the manufacturer (the distributor) has a strong bargaining power, the manufacturer (the distributor) may set a negative wholesale price to the distributor (the retailer). This can be regarded as a principle-agent chain that the manufacturer (the distributor) entrusts the distributor (the retailer) to sell products through spending a certain cost. And the manufacturer (the distributor) gets a higher rebate from the distributor (the retailer) at the end of the selling period. Such a situation occurs in a commercial practice, i.e. a regular chain.

\subsection{The Revenue Sharing Contract II with a Risk-neutral Retailer}

The revenue sharing contract II (denoted by superscript II) $\left(\varnothing_{1}^{\mathrm{II}}, \emptyset_{2}^{\mathrm{II}}, \mathrm{w}_{1}^{\mathrm{II}}, \mathrm{w}_{2}^{\mathrm{II}}\right)$ in the three-echelon supply chain is shown in Figure 3 . At the end of selling period, the retailer gives $\emptyset_{1}^{\text {II }}$ of her revenue to the distributor, and gives $\emptyset_{2}^{\text {II }}$ of her revenue to the manufacturer, where $\emptyset_{1}^{\mathrm{II}}+\emptyset_{2}^{\mathrm{II}} \in[0,1]$. In the revenue sharing contract II, $\emptyset_{1}^{\mathrm{Il}}$ and $\emptyset_{2}^{\mathrm{Il}}$ represent the members' bargaining power in the supply chain. If the manufacturer's bargaining power is stronger, $\emptyset_{2}^{\text {Il }}$ is large; if the distributor's bargaining power is stronger, $\emptyset_{1}^{\mathrm{II}}$ is large; and if the retailer's bargaining power is stronger, both $\emptyset_{1}^{\mathrm{II}}$ and $\emptyset_{2}^{\mathrm{II}}$ are small.

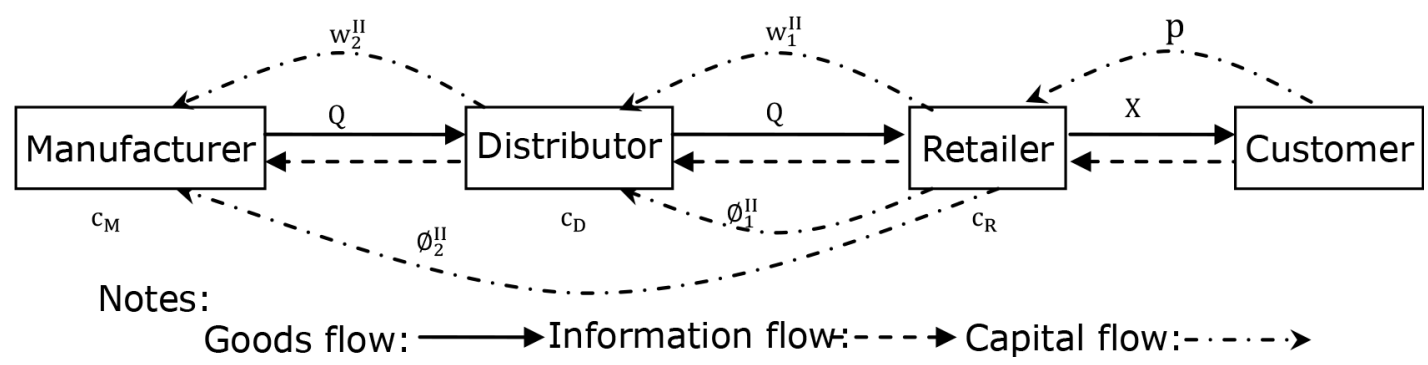

Figure 3. The three-echelon supply chain with the revenue sharing contract II

In the supply chain with the revenue sharing contract II, the expected profits of the retailer, the distributor and the manufacturer are as follows:

$$
\mathrm{E}\left[\Pi_{\mathrm{R}}^{\mathrm{II}}\left(\mathrm{w}_{1}^{\mathrm{II}}, \mathrm{Q}\right)\right]=\mathrm{E}\left[\left(1-\emptyset_{1}^{\mathrm{II}}-\emptyset_{2}^{\mathrm{II}}\right) \cdot \mathrm{p} \cdot \min (\mathrm{X}, \mathrm{Q})-\mathrm{w}_{1}^{\mathrm{II}} \mathrm{Q}-\mathrm{c}_{\mathrm{R}} \mathrm{Q}\right],
$$




$$
E\left[n_{D}^{\mathrm{II}}\left(w_{1}^{\mathrm{II}}, \mathrm{w}_{2}^{\mathrm{II}}, \mathrm{Q}\right)\right]=\mathrm{E}\left[\emptyset_{1}^{\mathrm{II}} \cdot \mathrm{p} \cdot \min (X, Q)+\mathrm{w}_{1}^{\mathrm{II}} \mathrm{Q}-\mathrm{w}_{2}^{\mathrm{II}} \mathrm{Q}-\mathrm{c}_{\mathrm{D}} \mathrm{Q}\right]
$$

and

$$
\mathrm{E}\left[\Pi_{\mathrm{M}}^{\mathrm{II}}\left(\mathrm{w}_{1}^{\mathrm{II}}, \mathrm{w}_{2}^{\mathrm{II}}, \mathrm{Q}\right)\right]=\mathrm{E}\left[\emptyset_{2}^{\mathrm{II}} \cdot \mathrm{p} \cdot \min (\mathrm{X}, \mathrm{Q})+\mathrm{w}_{2}^{\mathrm{II}} \mathrm{Q}-\mathrm{c}_{\mathrm{M}} \mathrm{Q}\right]
$$

Combining Equations (9), (10) and (11), the total expected profit of the supply chain is still $\mathrm{E}\left[\Pi_{\mathrm{SC}}(\mathrm{Q})\right]$ (See Equation (4)). So in the centralized supply chain, the optimal order quantity of the retailer is $\mathrm{Q}^{\mathrm{C}}$ and the optimal total expected profit of the supply chain is $\Pi_{\mathrm{SC}}^{\mathrm{C}}$.

According to Van der Rhee et al. (2010), for any given $\emptyset_{1}^{\mathrm{II}}$ and $\emptyset_{2}^{\mathrm{II}}$, the revenue sharing contract II with parameters

$$
\begin{gathered}
\mathrm{w}_{1}^{\mathrm{II}}=\left(1-\emptyset_{1}^{\mathrm{II}}-\emptyset_{2}^{\mathrm{II}}\right) \cdot\left(\mathrm{c}_{\mathrm{D}}+\mathrm{c}_{\mathrm{M}}+\mathrm{c}_{\mathrm{R}}\right)-\mathrm{c}_{\mathrm{R}} \\
\mathrm{w}_{2}^{\mathrm{II}}=\mathrm{c}_{\mathrm{M}}-\emptyset_{2}^{\mathrm{II}} \cdot\left(\mathrm{c}_{\mathrm{R}}+\mathrm{c}_{\mathrm{D}}+\mathrm{c}_{\mathrm{M}}\right)
\end{gathered}
$$

coordinates the supply chain. With the coordinated contract II, the optimal profits of the three supply chain members are, respectively,

$$
\begin{gathered}
\Pi_{\mathrm{R}}^{\mathrm{II}}=\left(1-\emptyset_{1}^{\mathrm{II}}-\emptyset_{2}^{\mathrm{II}}\right) \cdot \Pi_{\mathrm{SC}}^{\mathrm{C}}, \\
\Pi_{\mathrm{D}}^{\mathrm{II}}=\emptyset_{1}^{\mathrm{II}} \cdot \Pi_{\mathrm{SC}}^{\mathrm{C}}
\end{gathered}
$$

and

$$
\Pi_{\mathrm{M}}^{\mathrm{II}}=\emptyset_{2}^{\mathrm{II}} \cdot \Pi_{\mathrm{SC}}^{\mathrm{C}} \cdot
$$

In the coordinated supply chain with revenue sharing contract II, the retailer's profit share is $\left(1-\emptyset_{1}^{\mathrm{II}}-\emptyset_{2}^{\mathrm{II}}\right)$, the distributor's profit share is $\emptyset_{1}^{\mathrm{II}}$ and the manufacturer's profit share is $\emptyset_{2}^{\mathrm{II}}$. Thus, the revenue sharing contract II not only coordinates the supply chain but also arbitrarily allocates the supply chain profit among the members. If the retailer's bargaining power becomes stronger, the retailer would expect the decreasing of both $\emptyset_{1}^{\text {Il }}$ and $\emptyset_{2}^{\text {II; }}$ if the distributor's bargaining power becomes stronger, the distributor would expect the increasing of $\emptyset_{1}^{\text {II; }}$ and if the manufacturer's bargaining power becomes stronger, the manufacturer would expect the increasing of $\emptyset_{2}^{\mathrm{Il}}$. Thus, conflicts of interest exist among the three members in the supply chain.

Furthermore, the wholesale price $\mathrm{w}_{1}^{\mathrm{II}}$ is negative if $\frac{c_{\mathrm{D}}+\mathrm{c}_{\mathrm{M}}}{\mathrm{c}_{\mathrm{D}}+\mathrm{c}_{\mathrm{M}}+\mathrm{c}_{\mathrm{R}}}<\emptyset_{1}^{\mathrm{II}}+\emptyset_{2}^{\mathrm{II}}<1$ and $\mathrm{w}_{2}^{\mathrm{II}}$ is negative if $\frac{c_{M}}{c_{R}+c_{D}+c_{M}}<\emptyset_{2}^{\text {II }}<1-\emptyset_{1}^{\text {II }}$. Specifically, if $\emptyset_{1}^{\text {II }}=\frac{c_{D}}{c_{D}+c_{M}+c_{R}}$ and $\frac{c_{M}}{c_{R}+c_{D}+c_{M}}<\emptyset_{2}^{\text {II }}<\frac{c_{R}+c_{M}}{c_{D}+c_{M}+c_{R}}$, both $w_{1}^{I I}$ and $w_{2}^{\text {II }}$ are negative. That means that the manufacturer is a core enterprise in the three-echelon supply chain, she entrusts the retailer to sell the products and the distributor to distribute the products. 


\subsection{Compare the Coordinated Results between the Two Revenue Sharing Contracts}

According to the above subsections, both of the revenue sharing contracts can coordinate the three-echelon supply chain with coordinated parameters. However, the supply chain members' optimal profits are changed in the different revenue sharing contracts. For the supply chain, the problem is which contract will be preferred. We will focus on this problem in this subsection.

For the supply chain, the revenue sharing contract I and the revenue sharing contract II are the same because both of them can maximize the total supply chain profit. For each member of the supply chain, we compare their optimal profit in the revenue sharing contract I with that in the revenue sharing contract II, respectively. The comparative results are given in Table 1. In Table 1 , the parameters $\emptyset_{1}^{\mathrm{I}}, \emptyset_{2}^{\mathrm{I}}, \emptyset_{1}^{\text {II }}$ and $\emptyset_{2}^{\text {II }}$ value in thirteen different areas, so there are thirteen different comparative results accordingly. According to the comparative results, we have the proposition as follows.

Proposition 1. If $\emptyset_{1}^{\mathrm{II}}=\emptyset_{1}^{\mathrm{I}} \cdot\left(1-\emptyset_{2}^{\mathrm{I}}\right)$ and $\emptyset_{2}^{\mathrm{II}}=\emptyset_{1}^{\mathrm{I}} \cdot \emptyset_{2}^{\mathrm{I}}$, the revenue sharing contract I is the same as the revenue sharing contract II. Otherwise, any kind of revenue sharing contracts is not absolutely better than another.

Proposition 1 can be obtained by observing Table 1, so we omit the proof.

According to Proposition 1, the members' preferences between the two revenue sharing contracts depend on the parameters $\emptyset_{1}^{\mathrm{I}}, \emptyset_{2}^{\mathrm{I}}, \emptyset_{1}^{\mathrm{II}}$ and $\emptyset_{2}^{\text {II }}$. Furthermore, under the conditions (1)-(12) in Table 1, the members cannot reach a consensus preference. Therefore, which contract is employed in the supply chain is determined by the choice of the core enterprise. For example, if the retailer is the core enterprise, she has the ability to persuade the other members to choice the revenue sharing contract II under the condition (1). In this case, the retailer should give the distributor and the manufacturer some subsidies to make up their loss in the revenue sharing contract II. 


\begin{tabular}{|c|c|c|c|}
\hline Conditión Contrast Item & $\begin{array}{c}\text { Compare } \\
\Pi_{\mathrm{R}}^{\mathrm{I}} \text { with } \Pi_{\mathrm{R}}^{\mathrm{II}}\end{array}$ & $\begin{array}{c}\text { Compare } \\
\Pi_{\mathrm{D}}^{\mathrm{I}} \text { with } \Pi_{\mathrm{D}}^{\mathrm{II}}\end{array}$ & $\begin{array}{c}\text { Compare } \\
\Pi_{\mathrm{M}}^{\mathrm{L}} \text { with } \Pi_{\mathrm{M}}^{\mathrm{II}}\end{array}$ \\
\hline (1) $\left\{\begin{array}{c}0<\emptyset_{1}^{\mathrm{II}}<\emptyset_{1}^{\mathrm{I}} \cdot\left(1-\emptyset_{2}^{\mathrm{I}}\right) \\
0<\emptyset_{2}^{\mathrm{II}}<\emptyset_{1}^{\mathrm{I}} \cdot \emptyset_{2}^{\mathrm{I}}\end{array}\right.$ & $\Pi_{\mathrm{R}}^{\mathrm{I}}<\Pi_{\mathrm{R}}^{\mathrm{II}}$ & $\Pi_{\mathrm{D}}^{\mathrm{I}}>\Pi_{\mathrm{D}}^{\mathrm{II}}$ & $\Pi_{\mathrm{M}}^{\mathrm{I}}>\Pi_{\mathrm{M}}^{\mathrm{II}}$ \\
\hline (2) $\left\{\begin{array}{c}\emptyset_{1}^{\mathrm{II}}=\emptyset_{1}^{\mathrm{I}} \cdot\left(1-\emptyset_{2}^{\mathrm{I}}\right) \\
0<\emptyset_{2}^{\mathrm{II}}<\emptyset_{1}^{\mathrm{I}} \cdot \emptyset_{2}^{\mathrm{I}}\end{array}\right.$ & $\Pi_{\mathrm{R}}^{\mathrm{I}}<\Pi_{\mathrm{R}}^{\mathrm{II}}$ & $\Pi_{\mathrm{D}}^{\mathrm{I}}=\Pi_{\mathrm{D}}^{\mathrm{II}}$ & $\Pi_{\mathrm{M}}^{\mathrm{I}}>\Pi_{\mathrm{M}}^{\mathrm{II}}$ \\
\hline (3) $\left\{\begin{array}{c}\emptyset_{1}^{\mathrm{I}} \cdot\left(1-\emptyset_{2}^{\mathrm{I}}\right)<\emptyset_{1}^{\mathrm{II}}<\emptyset_{1}^{\mathrm{I}}-\emptyset_{2}^{\mathrm{II}} \\
0<\emptyset_{2}^{\mathrm{II}}<\emptyset_{1}^{\mathrm{I}} \cdot \emptyset_{2}^{\mathrm{I}}\end{array}\right.$ & $\Pi_{\mathrm{R}}^{\mathrm{I}}<\Pi_{\mathrm{R}}^{\mathrm{II}}$ & $\Pi_{\mathrm{D}}^{\mathrm{I}}<\Pi_{\mathrm{D}}^{\mathrm{II}}$ & $\Pi_{\mathrm{M}}^{\mathrm{I}}>\Pi_{\mathrm{M}}^{\mathrm{II}}$ \\
\hline (4) $\left\{\begin{array}{c}\emptyset_{1}^{\mathrm{I}}=\emptyset_{1}^{\mathrm{II}}+\emptyset_{2}^{\mathrm{II}} \\
0<\emptyset_{2}^{\mathrm{II}}<\emptyset_{1}^{\mathrm{I}} \cdot \emptyset_{2}^{\mathrm{I}}\end{array}\right.$ & $\Pi_{\mathrm{R}}^{\mathrm{I}}=\Pi_{\mathrm{R}}^{\mathrm{II}}$ & $\Pi_{\mathrm{D}}^{\mathrm{I}}<\Pi_{\mathrm{D}}^{\mathrm{II}}$ & $\Pi_{\mathrm{M}}^{\mathrm{I}}>\Pi_{\mathrm{M}}^{\mathrm{II}}$ \\
\hline (5) $\left\{\begin{array}{c}\emptyset_{1}^{\mathrm{I}}-\emptyset_{2}^{\mathrm{II}}<\emptyset_{1}^{\mathrm{II}}<1-\emptyset_{2}^{\mathrm{II}} \\
0<\emptyset_{2}^{\mathrm{II}}<\emptyset_{1}^{\mathrm{I}} \cdot \emptyset_{2}^{\mathrm{I}}\end{array}\right.$ & $\Pi_{\mathrm{R}}^{\mathrm{I}}>\Pi_{\mathrm{R}}^{\mathrm{II}}$ & $\Pi_{\mathrm{D}}^{\mathrm{I}}<\Pi_{\mathrm{D}}^{\mathrm{II}}$ & $\Pi_{\mathrm{M}}^{\mathrm{I}}>\Pi_{\mathrm{M}}^{\mathrm{II}}$ \\
\hline (6) $\left\{\begin{array}{c}\emptyset_{1}^{\mathrm{I}}-\emptyset_{2}^{\mathrm{II}}<\emptyset_{1}^{\mathrm{II}}<1-\emptyset_{2}^{\mathrm{II}} \\
\emptyset_{2}^{\mathrm{II}}=\emptyset_{1}^{\mathrm{I}} \cdot \emptyset_{2}^{\mathrm{I}}\end{array}\right.$ & $\Pi_{\mathrm{R}}^{\mathrm{I}}>\Pi_{\mathrm{R}}^{\mathrm{II}}$ & $\Pi_{\mathrm{D}}^{\mathrm{I}}<\Pi_{\mathrm{D}}^{\mathrm{II}}$ & $\Pi_{\mathrm{M}}^{\mathrm{I}}=\Pi_{\mathrm{M}}^{\mathrm{II}}$ \\
\hline (7) $\left\{\begin{array}{c}\emptyset_{1}^{\mathrm{I}} \cdot\left(1-\emptyset_{2}^{\mathrm{I}}\right)<\emptyset_{1}^{\mathrm{II}}<1-\emptyset_{2}^{\mathrm{II}} \\
\emptyset_{1}^{\mathrm{I}} \cdot \emptyset_{2}^{\mathrm{I}}<\emptyset_{2}^{\mathrm{II}}<1-\emptyset_{1}^{\mathrm{II}}\end{array}\right.$ & $\Pi_{\mathrm{R}}^{\mathrm{I}}>\Pi_{\mathrm{R}}^{\mathrm{II}}$ & $\Pi_{\mathrm{D}}^{\mathrm{I}}<\Pi_{\mathrm{D}}^{\mathrm{II}}$ & $\Pi_{\mathrm{M}}^{\mathrm{I}}<\Pi_{\mathrm{M}}^{\mathrm{II}}$ \\
\hline (8) $\left\{\begin{array}{c}\emptyset_{1}^{\mathrm{II}}=\emptyset_{1}^{\mathrm{I}} \cdot\left(1-\emptyset_{2}^{\mathrm{I}}\right) \\
\emptyset_{1}^{\mathrm{I}}-\emptyset_{1}^{\mathrm{II}}<\emptyset_{2}^{\mathrm{II}}<1-\emptyset_{1}^{\mathrm{II}}\end{array}\right.$ & $\Pi_{\mathrm{R}}^{\mathrm{I}}>\Pi_{\mathrm{R}}^{\mathrm{II}}$ & $\Pi_{\mathrm{D}}^{\mathrm{I}}=\Pi_{\mathrm{D}}^{\mathrm{II}}$ & $\Pi_{\mathrm{M}}^{\mathrm{I}}<\Pi_{\mathrm{M}}^{\mathrm{II}}$ \\
\hline (9) $\left\{\begin{array}{c}0<\emptyset_{1}^{\mathrm{II}}<\emptyset_{1}^{\mathrm{I}} \cdot\left(1-\emptyset_{2}^{\mathrm{I}}\right) \\
\emptyset_{1}^{\mathrm{I}}-\emptyset_{1}^{\mathrm{II}}<\emptyset_{2}^{\mathrm{II}}<1-\emptyset_{1}^{\mathrm{II}}\end{array}\right.$ & $\Pi_{\mathrm{R}}^{\mathrm{I}}>\Pi_{\mathrm{R}}^{\mathrm{II}}$ & $\Pi_{D}^{I}>\Pi_{D}^{I I}$ & $\Pi_{\mathrm{M}}^{\mathrm{I}}<\Pi_{\mathrm{M}}^{\mathrm{II}}$ \\
\hline (10) $\left\{\begin{array}{c}0<\emptyset_{1}^{\mathrm{II}}<\emptyset_{1}^{\mathrm{I}} \cdot\left(1-\emptyset_{2}^{\mathrm{I}}\right) \\
\emptyset_{1}^{\mathrm{I}}=\emptyset_{1}^{\mathrm{II}}+\emptyset_{2}^{\mathrm{II}}\end{array}\right.$ & $\Pi_{\mathrm{R}}^{\mathrm{I}}=\Pi_{\mathrm{R}}^{\mathrm{II}}$ & $\Pi_{\mathrm{D}}^{\mathrm{I}}>\Pi_{\mathrm{D}}^{\mathrm{II}}$ & $\Pi_{\mathrm{M}}^{\mathrm{I}}<\Pi_{\mathrm{M}}^{\mathrm{II}}$ \\
\hline (11) $\left\{\begin{array}{l}0<\emptyset_{1}^{I I}<\emptyset_{1}^{I} \cdot\left(1-\emptyset_{2}^{I}\right) \\
\emptyset_{1}^{I} \cdot \emptyset_{2}^{I}<\emptyset_{2}^{I I}<\emptyset_{1}^{I}-\emptyset_{1}^{I I}\end{array}\right.$ & $\Pi_{\mathrm{R}}^{\mathrm{I}}<\Pi_{\mathrm{R}}^{\mathrm{II}}$ & $\Pi_{D}^{I}>\Pi_{D}^{I I}$ & $\Pi_{\mathrm{M}}^{\mathrm{I}}<\Pi_{\mathrm{M}}^{\mathrm{II}}$ \\
\hline (12) $\left\{\begin{array}{c}0<\emptyset_{1}^{\mathrm{II}}<\emptyset_{1}^{\mathrm{I}} \cdot\left(1-\emptyset_{2}^{\mathrm{I}}\right) \\
\emptyset_{2}^{\mathrm{II}}=\emptyset_{1}^{\mathrm{I}} \cdot \emptyset_{2}^{\mathrm{I}}\end{array}\right.$ & $\Pi_{\mathrm{R}}^{\mathrm{I}}<\Pi_{\mathrm{R}}^{\mathrm{II}}$ & $\Pi_{\mathrm{D}}^{\mathrm{I}}>\Pi_{\mathrm{D}}^{\mathrm{II}}$ & $\Pi_{M}^{\mathrm{I}}=\Pi_{\mathrm{M}}^{\mathrm{II}}$ \\
\hline (13) $\left\{\begin{array}{c}\emptyset_{1}^{\mathrm{II}}=\emptyset_{1}^{\mathrm{I}} \cdot\left(1-\emptyset_{2}^{\mathrm{I}}\right) \\
\emptyset_{2}^{\mathrm{II}}=\emptyset_{1}^{\mathrm{I}} \cdot \emptyset_{2}^{\mathrm{I}}\end{array}\right.$ & $\Pi_{\mathrm{R}}^{\mathrm{I}}=\Pi_{\mathrm{R}}^{\mathrm{II}}$ & $\Pi_{\mathrm{D}}^{\mathrm{I}}=\Pi_{\mathrm{D}}^{\mathrm{II}}$ & $\Pi_{\mathrm{M}}^{\mathrm{I}}=\Pi_{\mathrm{M}}^{\mathrm{II}}$ \\
\hline
\end{tabular}

Table 1. Comparisons $\Pi_{\mathrm{R}}^{\mathrm{I}}$ with $\Pi_{\mathrm{R}}^{\mathrm{II}} \Pi_{\mathrm{D}}^{\mathrm{I}}$ with $\Pi_{\mathrm{D}}^{\mathrm{II}}$ and $\Pi_{\mathrm{M}}^{\mathrm{I}}$ with $\Pi_{\mathrm{M}}^{\mathrm{II}}$

\section{Two Revenue Sharing Contracts in the Supply Chain with a Risk-averse Retailer}

In some supply chains with smaller retailer, both the manufacturer and the distributor can transfer their risk downside and the smaller retailer prefers to risk-averse. In this kind of case can the revenue sharing contracts still coordinate the three-echelon supply chain? Based on the question, the performance of the supply chain with a risk-averse retailer is focused on the rest of the paper. Furthermore, the comparative analysis of the supply chain performances with different revenue sharing contract is conducted.

The downside risk measure is the probability that the return is below a target level. Its pioneering definition was introduced by Fishburn (1977) and was reset by Gan et al. (2005) in a newsvendor model. According to Gan et al. (2005), letting $a_{R}$ be the target profit of the risk-averse retailer, for 
any given order quantity $\mathrm{Q}$ and random demand realized value $\mathrm{X}$, the retailer's downside risk is the probability that her profit is not greater than $a_{R}$, i.e., $\left.P\left\{n_{R}(Q, X) \leq a_{R}\right)\right\}$. Hence for any given target profit level $a_{R}$ and upper bound of the downside risk $\beta_{R}\left(0<\beta_{R}<1\right)$, the risk-averse retailer makes an order quantity $\mathrm{Q}^{\mathrm{j}^{*}}(\mathrm{j}=\mathrm{I}$ or II) to maximize her expected profit, while her profit doesn't fall below her target profit level $a_{R}$ and the downside risk doesn't exceed a specified $\beta_{R}\left(0<\beta_{R}<1\right)$. The downside-risk-averse retailer's decision problem is

$$
\begin{gathered}
\max _{Q \geq 0} E\left[n_{R}^{j}(Q, X)\right], \\
\text { s.t. } P\left\{n_{R}^{j}(Q, X) \leq a_{R}\right\} \leq \beta_{R^{\prime}} j=\text { I or II. }
\end{gathered}
$$

The retailer's extent of risk-aversion is measured by risk-aversion pair $\left(a_{R}, \beta_{R}\right)$. For two risk-aversion pairs $\left(a_{R}^{1}, \beta_{R}^{1}\right)$ and $\left(a_{R}^{2}, \beta_{R}^{2}\right)$, if $a_{R}^{1} \leq a_{R}^{2}$ and $\beta_{R}^{1} \geq \beta_{R}^{2}$ then the second pair means a higher aversion to risk than does the first. Hence, the pair $\left(a_{R}, \beta_{R}\right)$ can be called the retailer's risk-averse level.

\subsection{The Revenue Sharing Contract I with a Risk-averse Retailer}

In the three-echelon supply chain with the revenue sharing contract I, the risk-averse retailer's optimal order quantity and the retailer's downside risk are discussed, which the wholesale prices $w_{1}^{I}$ and $w_{2}^{I}$ in the revenue sharing contract I are given by Equations (7a) and (7b).

Proposition 2. For any given target profit level $a_{R}$, the risk-averse retailer has a critical order quantity

$$
Q^{10}=a_{R} /\left(\left(1-\emptyset_{1}^{I}\right) \cdot\left(p-c_{D}-c_{M}-c_{R}\right)\right)
$$

For the critical order quantity $\mathrm{Q}^{10}$ the retailer's downside risk is

$$
P\left\{\Pi_{R}^{I}(Q, X) \leq a_{R}\right\}= \begin{cases}1 & Q \leq Q^{10} \\ F\left(\frac{a_{R}+\left(1-\emptyset_{1}^{I}\right) \cdot\left(c_{D}+c_{M}+c_{R}\right) \cdot Q}{\left(1-\emptyset_{1}^{I}\right) \cdot p}\right) & Q>Q^{I 0}\end{cases}
$$

Furthermore, if $\mathrm{Q}>\mathrm{Q}^{\mathrm{I0}}$, the retailer's downside risk increases with respect to $\mathrm{Q}$.

Proposition 2 is similar to Proposition 2.1 in Gan et al. (2005). Furthermore, according to Proposition 2, the upper bound and lower bound of the optimal order quantity $\mathrm{Q}^{\mathrm{I}^{*}}$ are $\mathrm{Q}^{\mathrm{C}}$ and $\mathrm{Q}^{\mathrm{I0}}$, respectively, given by Lemma 1 . 
Lemma 1. $\mathrm{Q}^{\mathrm{I} 0}<\mathrm{Q}^{\mathrm{I}^{*}} \leq \mathrm{Q}^{\mathrm{C}}$.

With the upper and lower bound in hands, the retailer's optimal order quantity $\mathrm{Q}^{\mathrm{I}^{*}}$ is given by Proposition 3.

Proposition 3. For any given risk-aversion level $\left(a_{R}, \beta_{R}\right)$, the retailer's optimal order quantity is

$$
Q^{I *}=\left\{\begin{array}{lc}
Q^{C} & F\left(Y^{I}\right) \leq \beta_{R} \\
\frac{\left(1-\phi_{1}^{I}\right) p \cdot F^{-1}\left(\beta_{R}\right)-a_{R}}{\left(1-\emptyset_{1}^{I}\right) \cdot\left(c_{D}+c_{M}+c_{R}\right)} & F\left(Q^{I 0}\right)<\beta_{R}<F\left(Y^{I}\right), \\
\text { has no feasible solution } & \beta_{R} \leq F\left(Q^{I 0}\right)
\end{array}\right.
$$

where $Y^{I}=\frac{a_{R}+\left(1-\phi_{1}^{I}\right) \cdot\left(c_{D}+c_{M}+c_{R}\right) \cdot Q^{C}}{\left(1-\phi_{1}^{I}\right) \cdot p}$.

The Proposition 3 indicates that if $\mathrm{Q}^{\mathrm{C}}$ satisfies the downside risk constraint $(14 \mathrm{~b})$, then the retailer's optimal order quantity $\mathrm{Q}^{\mathrm{I}^{*}}$ is $\mathrm{Q}^{\mathrm{C}}$ exactly. Moreover, if $\mathrm{F}\left(\mathrm{Q}^{\mathrm{I0}}\right)<\beta_{\mathrm{R}}<\mathrm{F}\left(\mathrm{Y}^{\mathrm{I}}\right)$, then the retailer's optimal order quantity $\mathrm{Q}^{\mathrm{I}^{*}}$ is defined by the formula $\mathrm{P}\left\{\Pi_{\mathrm{R}}^{\mathrm{I}}\left(\mathrm{Q}^{\mathrm{I}}, \mathrm{X}\right) \leq \alpha_{\mathrm{R}}\right\}=\beta_{\mathrm{R}}$; and if $\beta_{R} \leq F\left(Q^{I 0}\right)$, the risk-averse retailer would not order product.

Then we have the following theorem based on the definition of the supply chain coordination given by Cachon (2003).

Theorem 1. For any given risk-aversion level $\left(a_{R}, \beta_{R}\right)$, if $F\left(Y^{I}\right) \leq \beta_{R}$, the three-echelon supply chain can be coordinated by the revenue sharing contract I with the wholesale prices $\left(\mathrm{w}_{1}^{\mathrm{I}}, \mathrm{w}_{2}^{\mathrm{I}}\right)$; and if $\beta_{R}<F\left(Y^{I}\right)$, the three-echelon supply chain cannot be coordinated by the revenue sharing contract I.

According to Proposition 3, the members' optimal expected profits can be derived. The optimal expected profit of member $i(i=R, D$ or $M)$ and the total profit of the supply chain are $E\left[\pi_{i}^{I}\left(Q^{I *}\right)\right]$ and $\mathrm{E}\left[\pi_{\mathrm{SC}}\left(\mathrm{Q}^{\mathrm{I}}\right)\right]$, respectively.

Proposition 4. For any given risk-aversion level $\left(a_{R}, \beta_{R}\right)$,

(1) if $F\left(Y^{I}\right) \leq \beta_{R}$, the optimal expected profits of the supply chain member $i$ are equal to $\pi_{i}^{I}(i=R$, $\mathrm{D}$ or $\mathrm{M})$, respectively, which are given by Equations $(8 \mathrm{a})-(8 \mathrm{c})$;

(2) if $F\left(Q^{10}\right)<\beta_{R}<F\left(Y^{I}\right)$, then the optimal expected profits of the retailer, the distributor and the manufacturer are 


$$
\begin{gathered}
E\left[\pi_{R}^{\mathrm{I}}\left(Q^{\mathrm{I} *}\right)\right]=\left(1-\emptyset_{1}^{\mathrm{I}}\right) \cdot \mathrm{E}\left[\pi_{S C}\left(Q^{\mathrm{I} *}\right)\right] \\
\mathrm{E}\left[\pi_{\mathrm{D}}^{\mathrm{I}}\left(\mathrm{Q}^{\mathrm{I} *}\right)\right]=\emptyset_{1}^{\mathrm{I}} \cdot\left(1-\emptyset_{2}^{\mathrm{I}}\right) \cdot \mathrm{E}\left[\pi_{\mathrm{SC}}\left(\mathrm{Q}^{\mathrm{I} *}\right)\right]
\end{gathered}
$$

and

$$
\mathrm{E}\left[\pi_{\mathrm{M}}^{\mathrm{I}}\left(\mathrm{Q}^{\mathrm{I}}\right)\right]=\emptyset_{1}^{\mathrm{I}} \cdot \emptyset_{2}^{\mathrm{I}} \cdot \mathrm{E}\left[\pi_{\mathrm{SC}}\left(\mathrm{Q}^{\mathrm{I} *}\right)\right]
$$

respectively. Furthermore, $\mathrm{E}\left[\pi_{\mathrm{SC}}\left(\mathrm{Q}^{\mathrm{I} *}\right)\right]<\pi_{\mathrm{SC}}^{\mathrm{C}}, \mathrm{E}\left[\pi_{\mathrm{R}}^{\mathrm{I}}\left(\mathrm{Q}^{\mathrm{I}}\right)\right]<\pi_{\mathrm{R}}^{\mathrm{I}}, \mathrm{E}\left[\pi_{\mathrm{D}}^{\mathrm{I}}\left(\mathrm{Q}^{\mathrm{I} *}\right)\right]<\pi_{\mathrm{D}}^{\mathrm{I}}$ and $\mathrm{E}\left[\pi_{\mathrm{M}}^{\mathrm{I}}\left(\mathrm{Q}^{\mathrm{I}}\right)\right]<\pi_{\mathrm{M}}^{\mathrm{I}}$;

(3) if $\beta_{R} \leq F\left(Q^{10}\right)$, all the members' optimal expected profits are zero.

According to Proposition 4, the members do not change their profit shares in the supply chain with the revenue sharing contract I even if the retailer's risk attitude has changed. This is because the retailer's risk attitude cannot affect the members' bargaining powers. Moreover, if $\mathrm{F}\left(\mathrm{Q}^{\mathrm{I}}\right)<\beta_{\mathrm{R}}<\mathrm{F}\left(\mathrm{Y}^{\mathrm{I}}\right)$, all the members' optimal expected profits in the supply chain with the risk-averse retailer are less than that in the supply chain with the risk-neutral retailer, and the retailer's optimal decision cannot maximize the total expected profit of the supply chain by executing the revenue sharing contract I. The reason is that the retailer does not want to bear high risk and makes a low order quantity such that $\mathrm{Q}^{\mathrm{I}^{*}}<\mathrm{Q}^{\mathrm{C}}$.

\subsection{The Revenue Sharing Contract II with a Risk-averse Retailer}

Similar to the subsection 4.1 , based on the revenue sharing contract II, we analyze the performance of the supply chain with the risk-averse retailer, which the wholesale prices $w_{1}^{\text {II }}$ and $w_{2}^{\mathrm{II}}$ in the revenue sharing contract II are given by Equations (12a) and (12b).

Proposition 5. For any given target profit level $a_{R}$, the risk-averse retailer has a critical order quantity

$$
\mathrm{Q}^{\mathrm{II0}}=\alpha_{\mathrm{R}} /\left(\left(1-\emptyset_{1}^{\mathrm{II}}-\emptyset_{2}^{\mathrm{II}}\right) \cdot\left(\mathrm{p}-\mathrm{c}_{\mathrm{D}}-\mathrm{c}_{\mathrm{M}}-\mathrm{c}_{\mathrm{R}}\right)\right)
$$

For the critical order quantity $\mathrm{Q}^{\mathrm{II}}$, the retailer's downside risk is

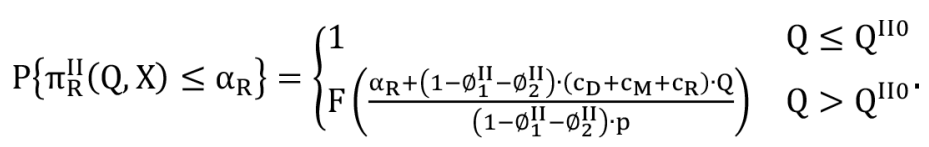

Furthermore, if $\mathrm{Q}>\mathrm{Q}^{\mathrm{II} 0}$, then the retailer's downside risk increases with respect to $\mathrm{Q}$.

Similar to Lemma 1, the upper bound and lower bound of the retailer's optimal order quantity $\mathrm{Q}^{\mathrm{II}}$, are $\mathrm{Q}^{\mathrm{C}}$ and $\mathrm{Q}^{\mathrm{II}}$, respectively. 
Lemma 2. $\mathrm{Q}^{\mathrm{II0}}<\mathrm{Q}^{\mathrm{II}} \leq \mathrm{Q}^{\mathrm{C}}$.

With the upper and lower bound in hands, we can derive the retailer's optimal order quantity.

Proposition 6. For any given risk-aversion level $\left(a_{R}, \beta_{R}\right)$, the retailer's optimal order quantity is given by

$$
Q^{I I *}=\left\{\begin{array}{lc}
Q^{C} & F\left(\gamma^{I I}\right) \leq \beta_{R} \\
\frac{\left(1-\emptyset_{1}^{I I}-\emptyset_{2}^{I I}\right) p \cdot F^{-1}\left(\beta_{R}\right)-\alpha_{R}}{\left(1-\emptyset_{1}^{I I}-\emptyset_{2}^{I I}\right) \cdot\left(c_{D}+c_{M}+c_{R}\right)} & F\left(Q^{I I 0}\right)<\beta_{R}<F\left(\gamma^{I I}\right), \\
\text { has no feasible solution } & \beta_{R} \leq F\left(Q^{I I 0}\right)
\end{array}\right.
$$

where $\gamma^{\mathrm{II}}=\frac{\alpha_{\mathrm{R}}+\left(1-\phi_{1}^{\mathrm{II}}-\emptyset_{2}^{\mathrm{II}}\right) \cdot\left(c_{D}+c_{M}+c_{R}\right) \cdot Q^{\mathrm{C}}}{\left(1-\emptyset_{1}^{\mathrm{II}}-\emptyset_{2}^{\mathrm{II}}\right) \cdot p}$.

Proposition 6 indicates that if $F\left(Y^{I I}\right) \leq \beta_{R}$, the risk-neutral retailer's optimal order quantity $Q^{C}$ satisfies the downside risk constraint (14b), hence the risk-averse retailer's optimal order quantity is exactly $\mathrm{Q}^{\mathrm{C}}$. Moreover, if $\mathrm{F}\left(\mathrm{Q}^{\mathrm{II}}\right)<\beta_{\mathrm{R}}<\mathrm{F}\left(\mathrm{Y}^{\mathrm{II}}\right)$, then the risk-averse retailer's optimal order quantity $\mathrm{Q}^{\mathrm{II} *}$ is defined by the formula $\mathrm{P}\left\{\pi_{\mathrm{R}}^{\mathrm{II}}\left(\mathrm{Q}^{\mathrm{II} *}, \mathrm{X}\right) \leq \alpha_{\mathrm{R}}\right\}=\beta_{\mathrm{R}}$; and if $\beta_{\mathrm{R}} \leq \mathrm{F}\left(\mathrm{Q}^{\mathrm{II} 0}\right)$, then the risk-averse retailer would not order any product.

Similar to Theorem 1, we have the following results.

Theorem 2. For any given risk-aversion level $\left(a_{R}, \beta_{R}\right)$, if $F\left(\gamma^{I I}\right) \leq \beta_{R}$, the three-echelon supply chain can be coordinated by the revenue sharing contract II with ( $\left.w_{1}^{\mathrm{II}}, w_{2}^{\mathrm{II}}\right)$; if $F\left(Y^{\mathrm{II}}\right)>\beta_{\mathrm{R}}$, the three-echelon supply chain cannot be coordinated by the revenue sharing contract II.

The optimal expected profit of member $i(i=R, D$ or $M)$ and the total profit of the supply chain are denoted by $\mathrm{E}\left[\pi_{\mathrm{i}}^{\mathrm{II}}\left(\mathrm{Q}^{\mathrm{II*}}\right)\right]$ and $\mathrm{E}\left[\pi_{\mathrm{SC}}\left(\mathrm{Q}^{\mathrm{II} *}\right)\right]$. We have the similar results as Proposition 4 given in Proposition 7.

Proposition 7. For any given risk-aversion level $\left(a_{R}, \beta_{R}\right)$,

(1) if $F\left(Y^{\text {II }}\right) \leq \beta_{R}$, the optimal profits of the retailer, the distributor and the manufacturer in supply chain with risk-averse retailer are Equations (13a), (13b) and (13c), respectively;

(2) if $F\left(Q^{I I 0}\right)<\beta_{R}<F\left(Y^{I I}\right)$, the optimal profits of the retailer, the distributor and the manufacturer are

$$
\mathrm{E}\left[\pi_{\mathrm{R}}^{\mathrm{II}}\left(\mathrm{Q}^{\mathrm{II} *}\right)\right]=\left(1-\emptyset_{1}^{\mathrm{II}}-\emptyset_{2}^{\mathrm{II}}\right) \cdot \mathrm{E}\left[\pi_{\mathrm{SC}}\left(\mathrm{Q}^{\mathrm{II} *}\right)\right],
$$




$$
\mathrm{E}\left[\pi_{\mathrm{D}}^{\mathrm{II}}\left(\mathrm{Q}^{\mathrm{II} *}\right)\right]=\emptyset_{1}^{\mathrm{II}} \cdot \mathrm{E}\left[\pi_{\mathrm{SC}}\left(\mathrm{Q}^{\mathrm{II} *}\right)\right]
$$

and

$$
\mathrm{E}\left[\pi_{\mathrm{M}}^{\mathrm{II}}\left(\mathrm{Q}^{\mathrm{II} *}\right)\right]=\emptyset_{2}^{\mathrm{II}} \cdot \mathrm{E}\left[\pi_{\mathrm{SC}}\left(\mathrm{Q}^{\mathrm{II} *}\right)\right],
$$

respectively. Furthermore, $\mathrm{E}\left[\pi_{\mathrm{SC}}\left(\mathrm{Q}^{\mathrm{II} *}\right)\right]<\pi_{\mathrm{SC}}^{\mathrm{C}}, \mathrm{E}\left[\pi_{\mathrm{R}}^{\mathrm{II}}\left(\mathrm{Q}^{\mathrm{II} *}\right)\right]<\pi_{\mathrm{R}}^{\mathrm{II}}, \mathrm{E}\left[\pi_{\mathrm{D}}^{\mathrm{II}}\left(\mathrm{Q}^{\mathrm{II} *}\right)\right]<\pi_{\mathrm{D}}^{\mathrm{II}}$ and $\mathrm{E}\left[\pi_{\mathrm{M}}^{\mathrm{II}}\left(\mathrm{Q}^{\mathrm{II} *}\right)\right]<\pi_{\mathrm{M}}^{\mathrm{II}}$;

(3) if $F\left(Q^{I I 0}\right) \geq \beta_{R}$, all the members' optimal expected profits are zero.

According to Proposition 7, the retailer's profit share is $\left(1-\emptyset_{1}^{\mathrm{II}}-\emptyset_{2}^{\mathrm{II}}\right)$, the distributor's profit share is $\emptyset_{1}^{\text {Il }}$ and the manufacturer's profit share is $\emptyset_{2}^{\text {Il }}$. So even if the retailer's risk attitude has changed, the members' profit shares are no change in the supply chain with the revenue sharing contract II. Moreover, if $F\left(Q^{\mathrm{II} 0}\right)<\beta_{R}<F\left(Y^{\mathrm{II}}\right)$, any member's optimal expected profit in the supply chain with the risk-averse retailer is less than that in the supply chain with the risk-neutral retailer, and the retailer's optimal decision cannot maximize the total expected profit of the supply chain by executing the revenue sharing contract II.

\subsection{Compare the Supply Chain Performance between the Two Revenue Sharing Contracts}

We analyze the differences between the two revenue sharing contracts on the performance of the supply chain. The comparative analysis is discussed in three aspects, the retailers' downside-risk, the retailer's optimal order quantity and the members' expected profits.

\subsubsection{Comparative Analysis on the Retailer's Downside-risk}

\section{Lemma 3}

If $\emptyset_{1}^{\mathrm{I}}>\emptyset_{1}^{\mathrm{II}}+\emptyset_{2}^{\mathrm{II}}$, then $\mathrm{Q}^{\mathrm{I0}}>\mathrm{Q}^{\mathrm{II} 0}$ and $\mathrm{F}\left(\mathrm{Q}^{\mathrm{I0}}\right)>\mathrm{F}\left(\mathrm{Q}^{\mathrm{II}}\right)$;

if $\emptyset_{1}^{\mathrm{I}}=\emptyset_{1}^{\mathrm{II}}+\emptyset_{2}^{\mathrm{II}}$, then $\mathrm{Q}^{\mathrm{I0}}=\mathrm{Q}^{\mathrm{II0}}$ and $\mathrm{F}\left(\mathrm{Q}^{\mathrm{I0}}\right)=\mathrm{F}\left(\mathrm{Q}^{\mathrm{II}}\right)$; and

if $\emptyset_{1}^{\mathrm{I}}<\emptyset_{1}^{\mathrm{II}}+\emptyset_{2}^{\mathrm{II}}$, then $\mathrm{Q}^{\mathrm{IO}}<\mathrm{Q}^{\mathrm{IIO}}$ and $\mathrm{F}\left(\mathrm{Q}^{\mathrm{I0}}\right)<\mathrm{F}\left(\mathrm{Q}^{\mathrm{II}}\right)$.

Lemma 3 can be obtained by observing Equations (15) and (19), so we omit the proof.

For any given $\beta_{R}$, let $\lambda=\frac{\left(1-\phi_{1}^{\mathrm{I}}\right) \cdot \mathrm{p} \cdot \mathrm{F}^{-1}\left(\beta_{R}\right)-\alpha_{R}}{\left(1-\phi_{1}^{\mathrm{I}}\right) \cdot\left(c_{D}+c_{M}+c_{R}\right)}$ and $\mu=\frac{\left(1-\phi_{1}^{\mathrm{II}}-\phi_{2}^{\mathrm{II}}\right) \cdot p \cdot \mathrm{F}^{-1}\left(\beta_{R}\right)-\alpha_{R}}{\left(1-\phi_{1}^{\mathrm{II}}-\phi_{2}^{\Phi}\right) \cdot\left(c_{D}+c_{M}+c_{R}\right)}$. With Lemma 3 in hand and refer to Figure 1 in Gan et al. (2005), if $\emptyset_{1}^{\mathrm{I}}>\emptyset_{1}^{\mathrm{II}}+\emptyset_{2}^{\mathrm{II}}$, we draw Figure 4; if $\emptyset_{1}^{\mathrm{I}}<\emptyset_{1}^{\mathrm{II}}+\emptyset_{2}^{\mathrm{II}}$, we draw Figure 5. According to Figure 4 and Figure 5, we get Proposition 8. 


\section{Proposition 8}

(1) The retailer's downside-risk increases with the order quantity $Q$ in the two revenue sharing contracts if $\mathrm{Q}>\mathrm{Q}^{\mathrm{I0}}$ and $\mathrm{Q}>\mathrm{Q}^{\mathrm{II} 0}$.

(2) If $\emptyset_{1}^{\mathrm{I}}=\emptyset_{1}^{\mathrm{II}}+\emptyset_{2}^{\mathrm{II}}$, the retailer's downside-risks in the two revenue sharing contracts are the same;

if $\emptyset_{1}^{\mathrm{I}}>\emptyset_{1}^{\mathrm{II}}+\emptyset_{2}^{\mathrm{II}}$, the retailer's downside-risk in the revenue sharing contract I is not smaller than that in the revenue sharing contract II; and

if $\emptyset_{1}^{\mathrm{I}}<\emptyset_{1}^{\mathrm{II}}+\emptyset_{2}^{\mathrm{II}}$, the retailer's downside-risk in the revenue sharing contract I is not greater than that in the revenue sharing contract II.

According to Proposition 8, the retailer's downside-risk is related to her profit share in the supply chain based on any kind of revenue sharing contract.

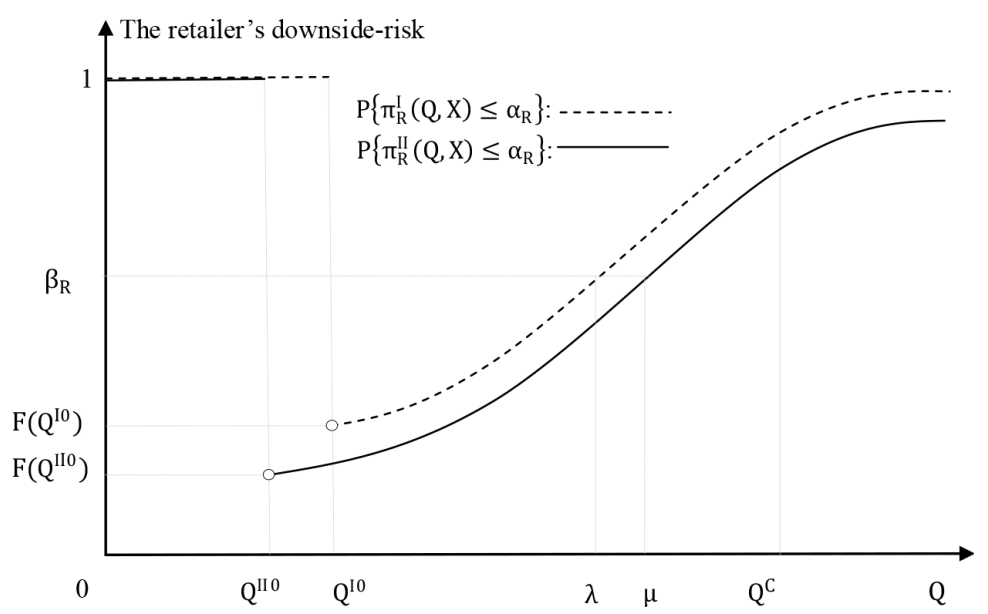

Figure 4. The retailer's downside-risks when $\emptyset_{1}^{\mathrm{I}}>\emptyset_{1}^{\mathrm{II}}+\emptyset_{2}^{\text {II }}$

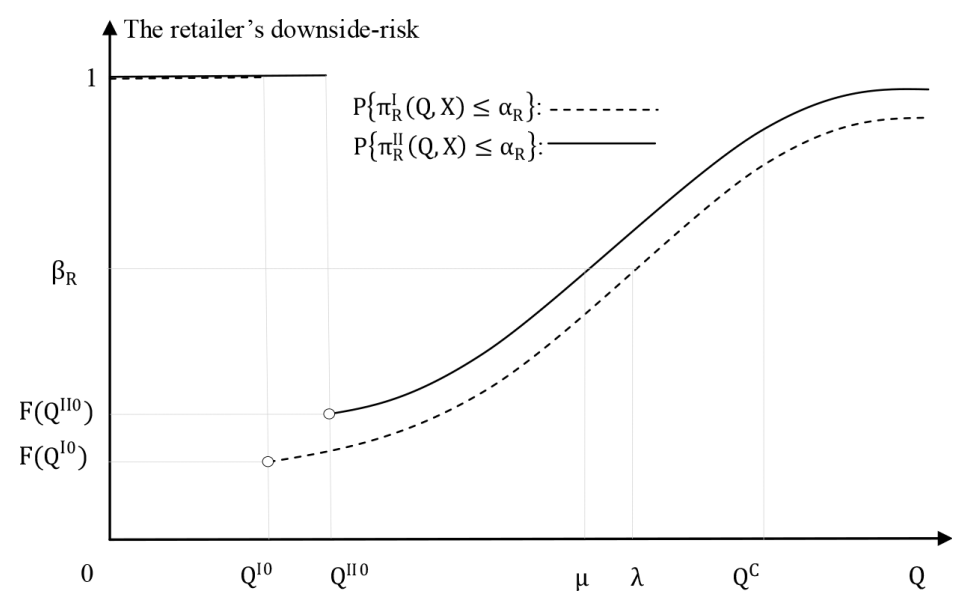

Figure 5. The retailer's downside-risks when $\emptyset_{1}^{\mathrm{I}}<\emptyset_{1}^{\mathrm{II}}+\emptyset_{2}^{\text {II }}$ 


\subsubsection{Comparative Analysis on the Retailer's Optimal Order}

Equations (17) and (21), and Figures 4 and 5 indicate that there is an order relation between the retailer's optimal order quantities in different models. Hence, according to Lemma 3, we have results as follows.

\section{Proposition 9}

(1) For $\emptyset_{1}^{\mathrm{I}}=\emptyset_{1}^{\mathrm{II}}+\emptyset_{2}^{\mathrm{II}}$, then $\mathrm{Q}^{\mathrm{I}}=\mathrm{Q}^{\mathrm{II}}$.

(2) For $\emptyset_{1}^{\mathrm{I}}>\emptyset_{1}^{\mathrm{II}}+\emptyset_{2}^{\mathrm{II}}$, if $\mathrm{F}\left(\mathrm{Q}^{\mathrm{IIO}}\right)<\beta_{\mathrm{R}}<\mathrm{F}\left(\mathrm{Y}^{\mathrm{I}}\right)$, then $\mathrm{Q}^{\mathrm{I}^{*}}<\mathrm{Q}^{\mathrm{II}}$; if $\mathrm{F}\left(\mathrm{Y}^{\mathrm{I}}\right) \leq \beta_{\mathrm{R}}$, then $\mathrm{Q}^{\mathrm{I}^{*}}=\mathrm{Q}^{\mathrm{II}}=\mathrm{Q}^{\mathrm{C}}$.

(3) For $\emptyset_{1}^{\mathrm{I}}<\emptyset_{1}^{\mathrm{II}}+\emptyset_{2}^{\mathrm{II}}$, if $\mathrm{F}\left(\mathrm{Q}^{\mathrm{I0}}\right)<\beta_{\mathrm{R}}<\mathrm{F}\left(\mathrm{Y}^{\mathrm{II}}\right)$, then $\mathrm{Q}^{\mathrm{I}^{*}}>\mathrm{Q}^{\mathrm{II}}$; if $\mathrm{F}\left(\mathrm{Y}^{\mathrm{II}}\right) \leq \beta_{\mathrm{R}}$, then $\mathrm{Q}^{\mathrm{I}^{*}}=\mathrm{Q}^{\mathrm{II}}=\mathrm{Q}^{\mathrm{C}}$.

According to Proposition 9, the retailer's optimal order quantity is confined by her risk aversion level $\left(a_{R}, \beta_{R}\right)$ as well as the contract parameters $\emptyset_{1}^{I}, \emptyset_{1}^{\text {II }}$ and $\emptyset_{2}^{\text {II }}$ in the supply chain. Therefore, if the retailer's profit share is the same (Proposition 9(1)), the supply chain gets the same profit in the two contracts. Besides that, with different revenue sharing contracts, the total profit of the supply chain is different. We have the corollaries as follows.

Corollary 1. For the whole supply chain, the two revenue sharing contracts are equivalent if

(1) $\emptyset_{1}^{\mathrm{I}}=\emptyset_{1}^{\mathrm{II}}+\emptyset_{2}^{\mathrm{II}}$; or if

(2) $\emptyset_{1}^{\mathrm{I}}>\emptyset_{1}^{\mathrm{II}}+\emptyset_{2}^{\mathrm{II}}$ and $F\left(\gamma^{\mathrm{I}}\right) \leq \beta_{\mathrm{R}}$; or if

(3) $\emptyset_{1}^{\mathrm{I}}<\emptyset_{1}^{\mathrm{II}}+\emptyset_{2}^{\mathrm{II}}$ and $\mathrm{F}\left(\mathrm{\gamma}^{\mathrm{II}}\right) \leq \beta_{\mathrm{R}}$.

Corollary 2. For the whole supply chain, the revenue sharing contract $I$ is superior to the revenue sharing contract II if $\emptyset_{1}^{\mathrm{I}}<\emptyset_{1}^{\mathrm{II}}+\emptyset_{2}^{\mathrm{II}}$ and $\mathrm{F}\left(\mathrm{Q}^{\mathrm{IO}}\right)<\beta_{\mathrm{R}}<\mathrm{F}\left(\mathrm{Y}^{\mathrm{II}}\right)$.

Corollary 3. For the whole supply chain, the revenue sharing contract II is superior to the revenue sharing contract I if $\emptyset_{1}^{\mathrm{I}}>\emptyset_{1}^{\mathrm{II}}+\emptyset_{2}^{\mathrm{II}}$ and $\mathrm{F}\left(\mathrm{Q}^{\mathrm{II0}}\right)<\beta_{\mathrm{R}}<\mathrm{F}\left(\mathrm{Y}^{\mathrm{I}}\right)$.

According to Corollaries 1-3, for the whole supply chain, the efficiency of the two revenue sharing contracts is different, which is related to the retailer's profit share and the upper bound of the retailer's downside risk. 


\subsubsection{Comparative Analysis on the Members' Expected Profits}

Similar to the analyses on the retailer's order quantity, we discuss the members' expected profits in the two revenue sharing contracts.

Proposition 10. For the retailer, the distributor and the manufacturer, comparative results of their optimal expected profit under the two revenue sharing contracts are shown in Table 2, Table 3 and Table 4, respectively.

According to Proposition 10, we get three corollaries as follows.

Corollary 4. For all the members, the two revenue sharing contracts are equivalent if

(1) $\emptyset_{1}^{\mathrm{I}}=\emptyset_{1}^{\mathrm{II}}+\emptyset_{2}^{\mathrm{II}}$ and $\beta_{\mathrm{R}} \leq \mathrm{F}\left(\mathrm{Q}^{\mathrm{I0}}\right)$; or if

(2) $\emptyset_{1}^{\mathrm{I}}=\emptyset_{1}^{\mathrm{II}}+\emptyset_{2}^{\mathrm{II}}$ and $F\left(\gamma^{\mathrm{I}}\right) \leq \beta_{\mathrm{R}}$; or if

(3) $\emptyset_{1}^{\mathrm{I}}>\emptyset_{1}^{\mathrm{II}}+\emptyset_{2}^{\mathrm{II}}$ and $\mathrm{F}\left(\gamma^{\mathrm{I}}\right) \leq \beta_{\mathrm{R}}$; or if

(4) $\emptyset_{1}^{\mathrm{I}}<\emptyset_{1}^{\mathrm{II}}+\emptyset_{2}^{\mathrm{II}}$ and $\mathrm{F}\left(\mathrm{Y}^{\mathrm{II}}\right) \leq \beta_{\mathrm{R}}$.

Corollary 5. For all the members, the revenue sharing contract I is superior to the revenue sharing contract II if

(1) $\emptyset_{1}^{\mathrm{I}}<\emptyset_{1}^{\mathrm{II}}+\emptyset_{2}^{\mathrm{II}}$ and $\mathrm{F}\left(\mathrm{Q}^{\mathrm{I0}}\right)<\beta_{\mathrm{R}} \leq \mathrm{F}\left(\mathrm{Q}^{\mathrm{II}}\right)$; or if

(2) $\emptyset_{1}^{\mathrm{I}}<\emptyset_{1}^{\mathrm{II}}+\emptyset_{2}^{\mathrm{II}}$ and $\mathrm{F}\left(\mathrm{Q}^{\mathrm{II} 0}\right)<\beta_{\mathrm{R}}<\mathrm{F}\left(\mathrm{Y}^{\mathrm{II}}\right)$ and $\emptyset_{1}^{\mathrm{I}} \cdot\left(1-\emptyset_{2}^{\mathrm{I}}\right) \geq \emptyset_{1}^{\mathrm{II}}$ and $\emptyset_{1}^{\mathrm{I}} \cdot \emptyset_{2}^{\mathrm{I}} \cdot \mathrm{E}\left[\Pi_{\mathrm{SC}}\left(\mathrm{Q}^{\mathrm{I} *}\right)\right]>\emptyset_{2}^{\mathrm{II}} \cdot \mathrm{E}\left[\mathrm{n}_{\mathrm{SC}}\left(\mathrm{Q}^{\mathrm{II} *}\right)\right]$ or if

(3) $\emptyset_{1}^{\mathrm{I}}<\emptyset_{1}^{\mathrm{II}}+\emptyset_{2}^{\mathrm{II}}$ and $\mathrm{F}\left(\mathrm{Q}^{\mathrm{II}}\right)<\beta_{\mathrm{R}}<\mathrm{F}\left(\mathrm{Y}^{\mathrm{II}}\right)$ and $\emptyset_{1}^{\mathrm{I}} \cdot \emptyset_{2}^{\mathrm{I}} \geq \emptyset_{2}^{\mathrm{II}}$ and $\emptyset_{1}^{\mathrm{I}} \cdot\left(1-\emptyset_{2}^{\mathrm{I}}\right) \cdot \mathrm{E}\left[\Pi_{\mathrm{SC}}\left(Q^{\mathrm{I} *}\right)\right] \geq \emptyset_{1}^{\mathrm{II}} \cdot \mathrm{E}\left[\Pi_{\mathrm{SC}}\left(Q^{\mathrm{II} *}\right)\right]$.

Corollary 6. For all the members, the revenue sharing contract II is superior to the revenue sharing contract I if

(1) $\emptyset_{1}^{\mathrm{I}}>\emptyset_{1}^{\mathrm{II}}+\emptyset_{2}^{\mathrm{II}}$ and $\mathrm{F}\left(\mathrm{Q}^{\mathrm{II}}\right)<\beta_{\mathrm{R}} \leq \mathrm{F}\left(\mathrm{Q}^{\mathrm{IO}}\right)$; or if

(2) $\emptyset_{1}^{\mathrm{I}}>\emptyset_{1}^{\mathrm{II}}+\emptyset_{2}^{\mathrm{II}}$ and $\mathrm{F}\left(\mathrm{Q}^{\mathrm{IO}}\right)<\beta_{\mathrm{R}}<\mathrm{F}\left(\mathrm{Y}^{\mathrm{I}}\right)$ and $\emptyset_{1}^{\mathrm{I}} \cdot\left(1-\emptyset_{2}^{\mathrm{I}}\right) \leq \emptyset_{1}^{\mathrm{II}}$ and $\emptyset_{1}^{\mathrm{I}} \cdot \emptyset_{2}^{\mathrm{I}} \cdot \mathrm{E}\left[\mathrm{n}_{\mathrm{SC}}\left(\mathrm{Q}^{\mathrm{I} *}\right)\right]<\emptyset_{2}^{\mathrm{II}} \cdot \mathrm{E}\left[\Pi_{\mathrm{SC}}\left(\mathrm{Q}^{\mathrm{II} *}\right)\right]$; or if 
(3) $\emptyset_{1}^{\mathrm{I}}>\emptyset_{1}^{\mathrm{II}}+\emptyset_{2}^{\mathrm{II}}$ and $\mathrm{F}\left(\mathrm{Q}^{\mathrm{I0}}\right)<\beta_{\mathrm{R}}<\mathrm{F}\left(\mathrm{Y}^{\mathrm{I}}\right)$ and $\emptyset_{1}^{\mathrm{I}} \cdot \emptyset_{2}^{\mathrm{I}} \leq \emptyset_{2}^{\mathrm{II}}$ and $\emptyset_{1}^{\mathrm{I}} \cdot\left(1-\emptyset_{2}^{\mathrm{I}}\right) \cdot \mathrm{E}\left[\Pi_{\mathrm{SC}}\left(\mathrm{Q}^{\mathrm{I} *}\right)\right] \leq \emptyset_{1}^{\mathrm{II}} \cdot \mathrm{E}\left[\Pi_{\mathrm{SC}}\left(\mathrm{Q}^{\mathrm{II} *}\right)\right]$.

According to corollaries 4-6, for all the supply chain members, the efficiency of the two revenue sharing contracts is also different, which is related to each member's profit share, the retailer's target profit level, and the upper bound of the retailer's downside risk.

\begin{tabular}{|c|c|c|}
\hline \multicolumn{2}{|c|}{ Constraint conditions } & Comparative results \\
\hline \multirow{2}{*}{$\emptyset_{1}^{\mathrm{I}}=\emptyset_{1}^{\mathrm{II}}+\emptyset_{2}^{\mathrm{II}}$} & $\mathrm{E}\left[\Pi_{\mathrm{R}}^{\mathrm{I}}\left(Q^{\mathrm{I} *}\right)\right]=\mathrm{E}\left[\Pi_{\mathrm{R}}^{\mathrm{II}}\left(\mathrm{Q}^{\mathrm{II}}\right)\right]$ \\
\hline \multirow{2}{*}{$\emptyset_{1}^{\mathrm{I}}>\emptyset_{1}^{\mathrm{II}}+\emptyset_{2}^{\mathrm{II}}$} & $\mathrm{F}\left(\mathrm{Q}^{\mathrm{II}}\right)<\beta_{\mathrm{R}}<\mathrm{F}\left(\mathrm{Y}^{\mathrm{I}}\right)$ & $\mathrm{E}\left[\Pi_{\mathrm{R}}^{\mathrm{I}}\left(\mathrm{Q}^{\mathrm{I} *}\right)\right]<\mathrm{E}\left[\Pi_{\mathrm{R}}^{\mathrm{II}}\left(\mathrm{Q}^{\mathrm{II}}\right)\right]$ \\
\cline { 2 - 3 } & $\mathrm{F}\left(\mathrm{Y}^{\mathrm{I}}\right) \leq \beta_{\mathrm{R}}$ & $\mathrm{E}\left[\Pi_{\mathrm{R}}^{\mathrm{I}}\left(\mathrm{Q}^{\mathrm{I} *}\right)\right]=\mathrm{E}\left[\Pi_{\mathrm{R}}^{\mathrm{II}}\left(\mathrm{Q}^{\mathrm{II} *}\right)\right]$ \\
\hline \multirow{2}{*}{$\emptyset_{1}^{\mathrm{I}}<\emptyset_{1}^{\mathrm{II}}+\emptyset_{2}^{\mathrm{II}}$} & $\mathrm{F}\left(\mathrm{Q}^{\mathrm{II}}\right)<\beta_{\mathrm{R}}<\mathrm{F}\left(\mathrm{Y}^{\mathrm{II}}\right)$ & $\mathrm{E}\left[\Pi_{\mathrm{R}}^{\mathrm{I}}\left(\mathrm{Q}^{\mathrm{I} *}\right)\right]>\mathrm{E}\left[\Pi_{\mathrm{R}}^{\mathrm{II}}\left(\mathrm{Q}^{\mathrm{II} *}\right)\right]$ \\
\cline { 2 - 3 } & $\mathrm{F}\left(\mathrm{Y}^{\mathrm{II}}\right) \leq \beta_{\mathrm{R}}$ & $\mathrm{E}\left[\Pi_{\mathrm{R}}^{\mathrm{I}}\left(\mathrm{Q}^{\mathrm{I} *}\right)\right]=\mathrm{E}\left[\Pi_{\mathrm{R}}^{\mathrm{II}}\left(\mathrm{Q}^{\mathrm{II} *}\right)\right]$ \\
\hline
\end{tabular}

Table 2. Comparisons $\mathrm{E}\left[\Pi_{\mathrm{R}}^{\mathrm{I}}\left(\mathrm{Q}^{\mathrm{I} *}\right)\right]$ with $\mathrm{E}\left[\Pi_{\mathrm{R}}^{\mathrm{II}}\left(\mathrm{Q}^{\mathrm{II} *}\right)\right]$

\begin{tabular}{|c|c|c|c|}
\hline \multicolumn{3}{|c|}{ Constraint conditions } & Comparative results \\
\hline \multirow{5}{*}{$\emptyset_{1}^{\mathrm{I}}=\emptyset_{1}^{\mathrm{II}}+\emptyset_{2}^{\mathrm{II}}$} & \multicolumn{2}{|c|}{$\beta_{\mathrm{R}} \leq \mathrm{F}\left(\mathrm{Q}^{\mathrm{I0}}\right)$} & $\mathrm{E}\left[n_{\mathrm{D}}^{\mathrm{I}}\left(\mathrm{Q}^{\mathrm{I} *}\right)\right]=\mathrm{E}\left[\Pi_{\mathrm{D}}^{\mathrm{II}}\left(\mathrm{Q}^{\mathrm{II} *}\right)\right]$ \\
\hline & \multirow{3}{*}{$\mathrm{F}\left(\mathrm{Q}^{\mathrm{I0}}\right)<\beta_{\mathrm{R}}<\mathrm{F}\left(\mathrm{Y}^{\mathrm{I}}\right)$} & $\emptyset_{1}^{\mathrm{I}} \cdot\left(1-\emptyset_{2}^{\mathrm{I}}\right)<\emptyset_{1}^{\mathrm{II}}$ & $\mathrm{E}\left[\Pi_{\mathrm{D}}^{\mathrm{I}}\left(\mathrm{Q}^{\mathrm{I} *}\right)\right]<\mathrm{E}\left[\Pi_{\mathrm{D}}^{\mathrm{II}}\left(\mathrm{Q}^{\mathrm{II} *}\right)\right]$ \\
\hline & & $\emptyset_{1}^{\mathrm{I}} \cdot\left(1-\emptyset_{2}^{\mathrm{I}}\right)=\emptyset_{1}^{\mathrm{II}}$ & $E\left[n_{D}^{I}\left(Q^{I *}\right)\right]=E\left[n_{D}^{I I}\left(Q^{I I *}\right)\right]$ \\
\hline & & $\emptyset_{1}^{\mathrm{I}} \cdot\left(1-\emptyset_{2}^{\mathrm{I}}\right)>\emptyset_{1}^{\mathrm{II}}$ & $\mathrm{E}\left[\Pi_{\mathrm{D}}^{\mathrm{I}}\left(\mathrm{Q}^{\mathrm{I} *}\right)\right]>\mathrm{E}\left[\Pi_{\mathrm{D}}^{\mathrm{II}}\left(\mathrm{Q}^{\mathrm{II} *}\right)\right]$ \\
\hline & \multicolumn{2}{|c|}{$F\left(\gamma^{\mathrm{I}}\right) \leq \beta_{R}$} & $E\left[n_{D}^{I}\left(Q^{I *}\right)\right]=E\left[n_{D}^{I I}\left(Q^{I I *}\right)\right]$ \\
\hline \multirow{4}{*}{$\emptyset_{1}^{\mathrm{I}}>\emptyset_{1}^{\mathrm{II}}+\emptyset_{2}^{\mathrm{II}}$} & \multicolumn{2}{|c|}{$F\left(Q^{\mathrm{II0}}\right)<\beta_{\mathrm{R}} \leq \mathrm{F}\left(\mathrm{Q}^{\mathrm{I0}}\right)$} & $\mathrm{E}\left[\Pi_{\mathrm{D}}^{\mathrm{I}}\left(\mathrm{Q}^{\mathrm{I} *}\right)\right]<\mathrm{E}\left[n_{\mathrm{D}}^{\mathrm{II}}\left(\mathrm{Q}^{\mathrm{II} *}\right)\right]$ \\
\hline & \multirow{2}{*}{$F\left(Q^{10}\right)<\beta_{R}<F\left(Y^{1}\right)$} & $\emptyset_{1}^{\mathrm{I}} \cdot\left(1-\emptyset_{2}^{\mathrm{I}}\right) \leq \emptyset_{1}^{\mathrm{II}}$ & $\mathrm{E}\left[\Pi_{\mathrm{D}}^{\mathrm{I}}\left(\mathrm{Q}^{\mathrm{I} *}\right)\right]<\mathrm{E}\left[\Pi_{\mathrm{D}}^{\mathrm{II}}\left(\mathrm{Q}^{\mathrm{II*}}\right)\right]$ \\
\hline & & $\emptyset_{1}^{\mathrm{I}} \cdot\left(1-\emptyset_{2}^{\mathrm{I}}\right)>\emptyset_{1}^{\mathrm{II}}$ & Uncertainty \\
\hline & \multicolumn{2}{|c|}{$F\left(\gamma^{\mathrm{I}}\right) \leq \beta_{R}$} & $\mathrm{E}\left[\Pi_{\mathrm{D}}^{\mathrm{I}}\left(\mathrm{Q}^{\mathrm{I} *}\right)\right]=\mathrm{E}\left[\Pi_{\mathrm{D}}^{\mathrm{II}}\left(\mathrm{Q}^{\mathrm{II} *}\right)\right]$ \\
\hline \multirow{4}{*}{$\emptyset_{1}^{\mathrm{I}}<\emptyset_{1}^{\mathrm{II}}+\emptyset_{2}^{\mathrm{II}}$} & \multicolumn{2}{|c|}{$\mathrm{F}\left(\mathrm{Q}^{\mathrm{I0}}\right)<\beta_{\mathrm{R}} \leq \mathrm{F}\left(\mathrm{Q}^{\mathrm{II}}\right)$} & $\mathrm{E}\left[n_{\mathrm{D}}^{\mathrm{I}}\left(\mathrm{Q}^{\mathrm{I} *}\right)\right]>\mathrm{E}\left[\Pi_{\mathrm{D}}^{\mathrm{II}}\left(\mathrm{Q}^{\mathrm{II} *}\right)\right]$ \\
\hline & \multirow{2}{*}{$\mathrm{F}\left(\mathrm{Q}^{\mathrm{IIO}}\right)<\beta_{\mathrm{R}}<\mathrm{F}\left(\mathrm{Y}^{\mathrm{II}}\right)$} & $\emptyset_{1}^{\mathrm{I}} \cdot\left(1-\emptyset_{2}^{\mathrm{I}}\right) \geq \emptyset_{1}^{\mathrm{II}}$ & $\mathrm{E}\left[\Pi_{\mathrm{D}}^{\mathrm{I}}\left(\mathrm{Q}^{\mathrm{I} *}\right)\right]>\mathrm{E}\left[\Pi_{\mathrm{D}}^{\mathrm{II}}\left(\mathrm{Q}^{\mathrm{II} *}\right)\right]$ \\
\hline & & $\emptyset_{1}^{I} \cdot\left(1-\emptyset_{2}^{I}\right)<\emptyset_{1}^{I I}$ & Uncertainty \\
\hline & \multicolumn{2}{|c|}{$F\left(Y^{I I}\right) \leq \beta_{R}$} & $\mathrm{E}\left[\Pi_{\mathrm{D}}^{\mathrm{I}}\left(\mathrm{Q}^{\mathrm{I} *}\right)\right]=\mathrm{E}\left[\Pi_{\mathrm{D}}^{\mathrm{II}}\left(\mathrm{Q}^{\mathrm{II} *}\right)\right]$ \\
\hline
\end{tabular}

Table 3. Comparisons $\mathrm{E}\left[\Pi_{\mathrm{D}}^{\mathrm{I}}\left(\mathrm{Q}^{\mathrm{I}}\right)\right]$ with $\mathrm{E}\left[\Pi_{\mathrm{D}}^{\mathrm{II}}\left(\mathrm{Q}^{\mathrm{II}}\right)\right]$ 


\begin{tabular}{|c|c|c|c|}
\hline \multicolumn{3}{|c|}{ Constraint conditions } & Comparative results \\
\hline \multirow{5}{*}{$\emptyset_{1}^{\mathrm{I}}=\emptyset_{1}^{\mathrm{II}}+\emptyset_{2}^{\mathrm{II}}$} & \multicolumn{2}{|c|}{$\beta_{R} \leq F\left(Q^{10}\right)$} & $\mathrm{E}\left[\Pi_{\mathrm{M}}^{\mathrm{I}}\left(\mathrm{Q}^{\mathrm{I} *}\right)\right]=\mathrm{E}\left[\Pi_{\mathrm{M}}^{\mathrm{II}}\left(\mathrm{Q}^{\mathrm{II} *}\right)\right]$ \\
\hline & \multirow{3}{*}{$\mathrm{F}\left(\mathrm{Q}^{\mathrm{I0}}\right)<\beta_{\mathrm{R}}<\mathrm{F}\left(\mathrm{Y}^{\mathrm{I}}\right)$} & $\emptyset_{1}^{\mathrm{I}} \cdot \emptyset_{2}^{\mathrm{I}}<\emptyset_{2}^{\mathrm{II}}$ & $\mathrm{E}\left[\Pi_{\mathrm{M}}^{\mathrm{I}}\left(\mathrm{Q}^{\mathrm{I} *}\right)\right]<\mathrm{E}\left[\Pi_{\mathrm{M}}^{\mathrm{II}}\left(\mathrm{Q}^{\mathrm{II} *}\right)\right]$ \\
\hline & & $\emptyset_{1}^{\mathrm{I}} \cdot \emptyset_{2}^{\mathrm{I}}=\emptyset_{2}^{\mathrm{II}}$ & $\mathrm{E}\left[\Pi_{\mathrm{M}}^{\mathrm{I}}\left(\mathrm{Q}^{\mathrm{I}}\right)\right]=\mathrm{E}\left[\Pi_{\mathrm{M}}^{\mathrm{II}}\left(\mathrm{Q}^{\mathrm{II} *}\right)\right]$ \\
\hline & & $\emptyset_{1}^{\mathrm{I}} \cdot \emptyset_{2}^{\mathrm{I}}>\emptyset_{2}^{\mathrm{II}}$ & $\mathrm{E}\left[\Pi_{\mathrm{M}}^{\mathrm{I}}\left(Q^{\mathrm{I} *}\right)\right]>\mathrm{E}\left[\Pi_{\mathrm{M}}^{\mathrm{II}}\left(Q^{\mathrm{I} *}\right)\right]$ \\
\hline & \multicolumn{2}{|c|}{$F\left(\gamma^{I}\right) \leq \beta_{R}$} & $\mathrm{E}\left[\Pi_{\mathrm{M}}^{\mathrm{I}}\left(\mathrm{Q}^{\mathrm{I} *}\right)\right]=\mathrm{E}\left[\Pi_{\mathrm{M}}^{\mathrm{II}}\left(\mathrm{Q}^{\mathrm{II} *}\right)\right]$ \\
\hline \multirow{4}{*}{$\emptyset_{1}^{\mathrm{I}}>\emptyset_{1}^{\mathrm{II}}+\emptyset_{2}^{\mathrm{II}}$} & \multicolumn{2}{|c|}{$\mathrm{F}\left(\mathrm{Q}^{\mathrm{IIO}}\right)<\beta_{\mathrm{R}} \leq \mathrm{F}\left(\mathrm{Q}^{\mathrm{I0}}\right)$} & $\mathrm{E}\left[\Pi_{\mathrm{M}}^{\mathrm{I}}\left(\mathrm{Q}^{\mathrm{I} *}\right)\right]<\mathrm{E}\left[\Pi_{\mathrm{M}}^{\mathrm{II}}\left(\mathrm{Q}^{\mathrm{II} *}\right)\right]$ \\
\hline & \multirow{2}{*}{$\mathrm{F}\left(\mathrm{Q}^{10}\right)<\beta_{\mathrm{R}}<\mathrm{F}\left(\mathrm{Y}^{\mathrm{I}}\right)$} & $\emptyset_{1}^{\mathrm{I}} \cdot \emptyset_{2}^{\mathrm{I}} \leq \emptyset_{2}^{\mathrm{II}}$ & $\mathrm{E}\left[\Pi_{\mathrm{M}}^{\mathrm{I}}\left(\mathrm{Q}^{\mathrm{I} *}\right)\right]<\mathrm{E}\left[\Pi_{\mathrm{M}}^{\mathrm{II}}\left(\mathrm{Q}^{\mathrm{II} *}\right)\right]$ \\
\hline & & $\emptyset_{1}^{\mathrm{I}} \cdot \emptyset_{2}^{\mathrm{I}}>\emptyset_{2}^{\mathrm{II}}$ & Uncertainty \\
\hline & \multicolumn{2}{|c|}{$F\left(\gamma^{I}\right) \leq \beta_{R}$} & $\mathrm{E}\left[\Pi_{\mathrm{M}}^{\mathrm{I}}\left(\mathrm{Q}^{\mathrm{I} *}\right)\right]=\mathrm{E}\left[\Pi_{\mathrm{M}}^{\mathrm{II}}\left(\mathrm{Q}^{\mathrm{II} *}\right)\right]$ \\
\hline \multirow{4}{*}{$\emptyset_{1}^{\mathrm{I}}<\emptyset_{1}^{\mathrm{II}}+\emptyset_{2}^{\mathrm{II}}$} & \multicolumn{2}{|c|}{$\mathrm{F}\left(\mathrm{Q}^{\mathrm{I0}}\right)<\beta_{\mathrm{R}} \leq \mathrm{F}\left(\mathrm{Q}^{\mathrm{IIO}}\right)$} & $\mathrm{E}\left[\Pi_{\mathrm{M}}^{\mathrm{I}}\left(Q^{\mathrm{I} *}\right)\right]>\mathrm{E}\left[n_{\mathrm{M}}^{\mathrm{II}}\left(Q^{\mathrm{II} *}\right)\right]$ \\
\hline & \multirow{2}{*}{$\mathrm{F}\left(\mathrm{Q}^{\mathrm{IIO}}\right)<\beta_{\mathrm{R}}<\mathrm{F}\left(\mathrm{Y}^{\mathrm{II}}\right)$} & $\emptyset_{1}^{\mathrm{I}} \cdot \emptyset_{2}^{\mathrm{I}} \geq \emptyset_{2}^{\mathrm{II}}$ & $\mathrm{E}\left[\Pi_{\mathrm{M}}^{\mathrm{I}}\left(\mathrm{Q}^{\mathrm{I} *}\right)\right]>\mathrm{E}\left[\Pi_{\mathrm{M}}^{\mathrm{II}}\left(\mathrm{Q}^{\mathrm{II}}\right)\right]$ \\
\hline & & $\emptyset_{1}^{\mathrm{I}} \cdot \emptyset_{2}^{\mathrm{I}}<\emptyset_{2}^{\mathrm{II}}$ & Uncertainty \\
\hline & \multicolumn{2}{|c|}{$F\left(Y^{\mathrm{II}}\right) \leq \beta_{R}$} & $\mathrm{E}\left[\Pi_{\mathrm{M}}^{\mathrm{I}}\left(\mathrm{Q}^{\mathrm{I}}\right)\right]=\mathrm{E}\left[\Pi_{\mathrm{M}}^{\mathrm{II}}\left(\mathrm{Q}^{\mathrm{II}}\right)\right]$ \\
\hline
\end{tabular}

Table 4. Comparisons $\mathrm{E}\left[\Pi_{\mathrm{M}}^{\mathrm{I}}\left(\mathrm{Q}^{\mathrm{I} *}\right)\right]$ with $\mathrm{E}\left[\Pi_{\mathrm{M}}^{\mathrm{II}}\left(\mathrm{Q}^{\mathrm{II} *}\right)\right]$

\section{The Improved Contracts of the Two Revenue Sharing Contracts in the Supply Chain with a Risk-averse Retailer}

According to Theorem 1 and Theorem 2, both the two revenue sharing contracts are not necessarily able to coordinate the supply chain with a risk-averse retailer. Hence, in this section, we will improve the two revenue sharing contracts to coordinate the supply chain and continue to compare the two contracts.

In the three-echelon supply chain with the revenue sharing contract $j(j=I, I I)$, the retailer's downside risk and her expected profit increase with the order quantity $\mathrm{Q}$ when $\mathrm{Q}^{\mathrm{j}^{*}}<\mathrm{Q} \leq \mathrm{Q}^{\mathrm{C}}$. Here, the supply chain coordinates if the retailer ignores the risk constraint and makes an order such that $\mathrm{Q}=\mathrm{Q}^{\mathrm{c}}$. However, the retailer would make an order $\mathrm{Q}^{\mathrm{j}^{*}}$ less than $\mathrm{Q}^{\mathrm{C}}$ to avoid the risk. Hence, to enhance the performance of the supply chain, both the manufacturer and the distributor would stimulate the risk-averse retailer to increase her ordering quantity from $\mathrm{Q}^{\mathrm{j}^{*}}$ up to $\mathrm{Q}^{\mathrm{C}}$ by providing the required downside protection to the retailer. The downside protection will be provided in the form of buyback for the unsold products.

The stimulation is a modification of risk sharing contract of Gan et al. (2005). In Gan et al. (2005) (the symbols in Gan et al. (2005) continue to be used in the analysis of this paragraph), the retailer would not order a quantity $\mathrm{q}$ which $\mathrm{q}<\mathrm{q}^{*}$ or $\hat{\mathrm{q}}<\mathrm{q}$. Moreover, if $\mathrm{q}^{*} \leq \mathrm{q} \leq \hat{\mathrm{q}}$, then the retailer's profit trajectory is 


$$
\Pi_{r}(X)=\left\{\begin{array}{lc}
\Pi_{r}^{0}\left(q^{*}, X\right) & \text { if } X \leq q^{*} \\
\Pi_{r}^{0}\left(q^{*}, X\right)+\left(p-w^{\prime}\right)\left(X-q^{*}\right) & \text { if } q^{*}<X<q \\
\Pi_{r}^{0}\left(q^{*}, X\right)+\left(p-w^{\prime}\right)\left(q-q^{*}\right) & \text { if } X \geq q
\end{array}\right.
$$

and the retailer's downside-risk constraint is met, where the retailer's procurement cost is assumed to be zero (A detailed description referred to Gan et al. (2005)). If the retailer's unit procurement cost $C_{R}$ is not zero $\left(C_{R}>0\right)$, then the retailer's profit trajectory becomes

$$
\Pi_{\mathrm{r}}^{\prime}(X)=\left\{\begin{array}{lc}
\Pi_{\mathrm{r}}^{0}\left(\mathrm{q}^{*}, X\right)-c_{\mathrm{R}} \cdot\left(\mathrm{q}-\mathrm{q}^{*}\right) & \text { if } X \leq \mathrm{q}^{*} \\
\Pi_{\mathrm{r}}^{0}\left(\mathrm{q}^{*}, X\right)-\mathrm{c}_{\mathrm{R}} \cdot\left(\mathrm{q}-\mathrm{q}^{*}\right)+\left(\mathrm{p}-\mathrm{w}^{\prime}\right)\left(X-\mathrm{q}^{*}\right) & \text { if } \mathrm{q}^{*}<X<\mathrm{q}, \\
\Pi_{\mathrm{r}}^{0}\left(\mathrm{q}^{*}, X\right)-\mathrm{c}_{\mathrm{R}} \cdot\left(\mathrm{q}-\mathrm{q}^{*}\right)+\left(\mathrm{p}-\mathrm{w}^{\prime}\right)\left(\mathrm{q}-\mathrm{q}^{*}\right) & \text { if } X \geq \mathrm{q}
\end{array}\right.
$$

and if $X \leq \mathrm{q}^{*}$, we have

$$
\begin{gathered}
\mathrm{P}\left\{\boldsymbol{n}_{\mathrm{r}}{ }^{\prime}(\mathrm{X}) \leq \mathrm{a}_{\mathrm{r}}\right\} \geq \mathrm{P}\left\{\left[\mathrm{n}_{\mathrm{r}}{ }^{\prime}(\mathrm{X}) \leq \mathrm{a}_{\mathrm{r}}\right] \cap\left[\mathrm{X} \leq \mathrm{q}^{*}\right]\right\} \\
=\mathrm{P}\left\{\boldsymbol{n}_{\mathrm{r}}^{0}\left(\mathrm{q}^{*}, \mathrm{X}\right)-\mathrm{c}_{\mathrm{R}} \cdot\left(\mathrm{q}-\mathrm{q}^{*}\right) \leq \mathrm{a}_{\mathrm{r}}\right\} \\
>\mathrm{P}\left\{\boldsymbol{n}_{\mathrm{r}}^{0}\left(\mathrm{q}^{*}, \mathrm{X}\right) \leq \mathrm{a}_{\mathrm{r}}\right\}=\beta_{\mathrm{r}} .
\end{gathered}
$$

This result indicates that the retailer's downside-risk constraint cannot be met. So the retailer also would not order a quantity $\mathrm{q}$ such that $\mathrm{q}^{*} \leq \mathrm{q} \leq \hat{\mathrm{q}}$. It means that no trading happens in the supply chain with the risk sharing contract in Gan et al. (2005).

According to the above description, the risk sharing contract $j(j=I, I I)$ is modified to make downside protection for the retailer and coordinate the supply chain. Here, the risk sharing contract $j$ is an improved contract of the revenue sharing contract $j$, so the revenue sharing contract $j$ is called the initial contract of the risk sharing contract $j$.

The risk sharing contract $\mathrm{j}$ is defined as follows and its basic structure is given in Figure 6:

(i) If the retailer's order quantity $Q$ is less than or equal to $Q^{j^{*}}$, the initial contract is executed.

(ii) If the retailer's order quantity $\mathrm{Q}$ is greater than $\mathrm{Q}^{\mathrm{j}}$ but not greater than $\mathrm{Q}^{\mathrm{C}}$, then in addition to execute the initial contract, the retailer receives a refund (denoted by $b_{1}^{j}$ ) from the distributor for each unsold unit product in excess of $\mathrm{Q}^{\mathrm{j}^{*}}$, and the distributor receives a refund (denoted by $\mathrm{b}_{2}^{\mathrm{j}}$ ) from the manufacturer for each unit of return product.

(iii) If the retailer's order quantity $Q$ is greater than $Q^{C}$, the terms of the contract are the same as that in (ii) except that the refundable unsold product are not exceed $\left(Q^{C}-Q^{j^{*}}\right)$.

To investigate the coordination of the three-echelon supply chain with the risk sharing contract, we adopt the definition of coordination proposed by Gan et al. (2005). 
Definition 1. (Gan et al., 2005 ). The supply chain is coordinated if the following conditions are satisfied:

(1) all the members get payoffs not less than their respective reservation payoffs,

(2) the retailer's downside risk constraint is met, and

(3) the supply chain's expected profit is maximized.

(i)

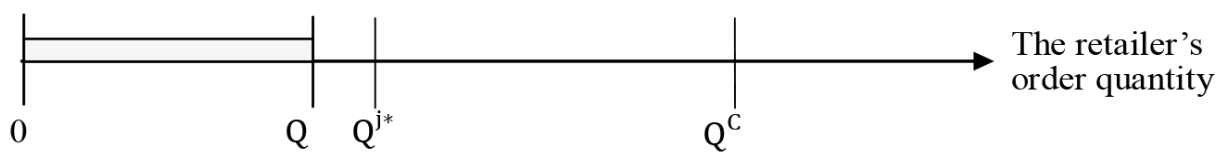

(ii)

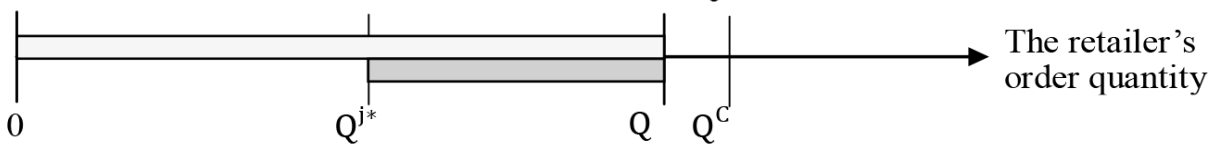

(iii)

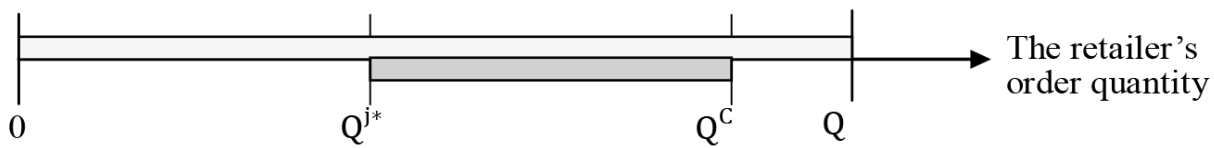

Executing the initial contract

Executing the return policy

Figure 6 . The basic structure of the risk sharing contract

In this paper the reservation payoff of member $i$ is $E\left[n_{i}^{j}\left(Q^{j *}, X\right)\right](i=R, D, M ; j=I, I I)$, which is the member i's optimal expected profit in the supply chain with the risk-averse retailer under the revenue-sharing contract $j$.

\subsection{The Risk Sharing Contract I with a Risk-averse Retailer}

In the risk sharing contract $I$, the refund parameters, $b_{1}^{\mathrm{I}}$ and $\mathrm{b}_{2}^{\mathrm{I}}$, will be discussed first. If they satisfy $b_{1}^{I}>w_{1}^{I}+c_{R}$ and $b_{2}^{I}>w_{2}^{I}+c_{D}$, the retailer and the distributor gain profit from the unsold products. This inspires the retailer to magnify the demand and results in a heavy bullwhip effect. Thus, it is reasonable that the refund parameters are limited to $b_{1}^{L} \in\left(0, w_{1}^{I}+c_{R}\right]$ and $\mathrm{b}_{2}^{\mathrm{I}} \in\left(0, \mathrm{w}_{2}^{\mathrm{I}}+\mathrm{c}_{\mathrm{D}}\right]$, i.e.,

$$
\mathrm{b}_{1}^{\mathrm{I}} \in\left(0,\left(1-\emptyset_{1}^{\mathrm{I}}\right)\left(\mathrm{c}_{\mathrm{D}}+\mathrm{c}_{\mathrm{M}}+\mathrm{c}_{\mathrm{R}}\right)\right]
$$

and

$$
\mathrm{b}_{2}^{\mathrm{I}} \in\left(0,\left(1-\emptyset_{2}^{\mathrm{I}}\right) \cdot\left(\mathrm{c}_{\mathrm{D}}+\mathrm{c}_{\mathrm{M}}\right)\right],
$$

respectively. 
For any given risk-aversion level $\left(a_{R}, \beta_{R}\right)$, if $F\left(Y^{I}\right) \leq \beta_{R}$, the revenue sharing contract I with $w_{1}^{I}$ and $\mathrm{w}_{2}^{\mathrm{I}}$ has been able to coordinate the supply chain; and if $\beta_{\mathrm{R}}<\mathrm{F}\left(\mathrm{Q}^{\mathrm{I0}}\right)$, the retailer never orders to avoid the risk. So we analyze the member i's profit trajectory $\Pi_{i}^{I r}(Q, X)(i=M, D, R)$ in the risk sharing contract I only when $\mathrm{F}\left(\mathrm{Q}^{\mathrm{I0}}\right)<\beta_{\mathrm{R}}<\mathrm{F}\left(\mathrm{Y}^{\mathrm{I}}\right)$.

If the retailer's order satisfies $\mathrm{Q} \leq \mathrm{Q}^{\mathrm{I}^{*}}$, the member $\mathrm{i}^{\prime} \mathrm{s}$ expected profit is no greater than her reservation profit, i.e., $\mathrm{E}\left[\Pi_{\mathrm{i}}^{\mathrm{I}}(\mathrm{Q}, \mathrm{X})\right] \leq \mathrm{E}\left[\Pi_{\mathrm{i}}^{\mathrm{I}}\left(\mathrm{Q}^{\mathrm{I}}, \mathrm{X}\right)\right]$. This leads all the members do not want to participate in the risk sharing contract I.

If the retailer's order satisfies $Q>Q^{c}$, the retailer's profit trajectory is

$$
\begin{array}{cc}
\Pi_{\mathrm{R}}^{\mathrm{Ir}}(\mathrm{Q}, \mathrm{X})= & \\
\left\{\begin{array}{lc}
\Pi_{\mathrm{R}}^{\mathrm{I}}\left(\mathrm{Q}^{\mathrm{I}}, \mathrm{X}\right)-\left(\mathrm{w}_{1}^{\mathrm{I}}+\mathrm{c}_{\mathrm{R}}\right)\left(\mathrm{Q}-\mathrm{Q}^{\mathrm{I}}\right)+\mathrm{b}_{1}^{\mathrm{I}}\left(\mathrm{Q}^{\mathrm{C}}-\mathrm{Q}^{\mathrm{I}}\right) & \text { if } \mathrm{X} \leq \mathrm{Q}^{\mathrm{I} *} \\
\Pi_{\mathrm{R}}^{\mathrm{I}}\left(\mathrm{Q}^{\mathrm{I}}, \mathrm{X}\right)-\left(\mathrm{w}_{1}^{\mathrm{I}}+\mathrm{c}_{\mathrm{R}}\right)\left(\mathrm{Q}-\mathrm{Q}^{\mathrm{I} *}\right)+\left(1-\emptyset_{1}^{\mathrm{I}}\right) \mathrm{p}\left(\mathrm{X}-\mathrm{Q}^{\mathrm{I}}\right)+\mathrm{b}_{1}^{\mathrm{I}}\left(\mathrm{Q}^{\mathrm{C}}-\mathrm{X}\right)^{+} & \text {if } \mathrm{Q}^{\mathrm{I} *}<X<Q, \\
\Pi_{\mathrm{R}}^{\mathrm{I}}\left(\mathrm{Q}^{\mathrm{I}}, \mathrm{X}\right)-\left(\mathrm{w}_{1}^{\mathrm{I}}+\mathrm{c}_{\mathrm{R}}\right)\left(\mathrm{Q}-\mathrm{Q}^{\mathrm{I}}\right)+\left(1-\emptyset_{1}^{\mathrm{I}}\right) \mathrm{p}\left(\mathrm{Q}-\mathrm{Q}^{\mathrm{I}}\right) & \text { if } \mathrm{Q} \leq \mathrm{X}
\end{array}\right.
\end{array}
$$

where

$$
\left(Q^{C}-X\right)^{+}= \begin{cases}Q^{C}-X & \text { if } Q^{C}>X \\ 0 & \text { if } Q^{C} \leq X\end{cases}
$$

According to Equations (7a) and (24), we have

$$
\begin{gathered}
P\left\{\Pi_{\mathrm{R}}^{\mathrm{Ir}}(\mathrm{Q}, \mathrm{X}) \leq \mathrm{a}_{\mathrm{R}}\right\} \geq \mathrm{P}\left\{\left[\Pi_{\mathrm{R}}^{\mathrm{Ir}}(\mathrm{Q}, \mathrm{X}) \leq \mathrm{a}_{\mathrm{R}}\right] \cap\left[\mathrm{X} \leq \mathrm{Q}^{\mathrm{I} *}\right]\right\} \\
=\mathrm{P}\left\{\begin{array}{c}
\Pi_{\mathrm{R}}^{\mathrm{I}}\left(\mathrm{Q}^{\mathrm{I}}, \mathrm{X}\right)-\left(1-\emptyset_{1}^{\mathrm{I}}\right) \cdot\left(\mathrm{c}_{\mathrm{D}}+\mathrm{c}_{\mathrm{M}}+\mathrm{c}_{\mathrm{R}}\right) \cdot\left(\mathrm{Q}-\mathrm{Q}^{\mathrm{C}}\right) \\
-\left(\left(1-\emptyset_{1}^{\mathrm{I}}\right) \cdot\left(\mathrm{c}_{\mathrm{D}}+\mathrm{c}_{\mathrm{M}}+\mathrm{c}_{\mathrm{R}}\right)-\mathrm{b}_{1}\right) \cdot\left(\mathrm{Q}^{\mathrm{C}}-\mathrm{Q}^{\mathrm{I} *}\right) \leq \mathrm{a}_{\mathrm{R}}
\end{array}\right\} \\
>P\left\{\Pi_{\mathrm{R}}^{\mathrm{I}}\left(\mathrm{Q}^{\mathrm{I} *}, \mathrm{X}\right) \leq \mathrm{a}_{\mathrm{R}}\right\}=\beta_{\mathrm{R}} .
\end{gathered}
$$

Therefore, the retailer's downside-risk constraint cannot be met. In this case, the retailer would not order any quantity $\mathrm{Q}$ such that $\mathrm{Q}>\mathrm{Q}^{\mathrm{C}}$.

Next, if the retailer's order satisfies $\mathrm{Q}^{\mathrm{I}^{*}}<\mathrm{Q} \leq \mathrm{Q}^{\mathrm{C}}$, the member's profit trajectory is analyzed. First, the retailer's profit trajectory is

$$
\begin{array}{cl}
\Pi_{R}^{I r}(Q, X)= & \\
\begin{cases}\Pi_{R}^{I}\left(Q^{I *}, X\right)-\left(w_{1}^{I}+c_{R}\right) \cdot\left(Q-Q^{I *}\right)+b_{1}^{I} \cdot\left(Q-Q^{I *}\right) & \text { if } X \leq Q^{I *} \\
\Pi_{R}^{I}\left(Q^{I *}, X\right)-\left(w_{1}^{I}+c_{R}\right) \cdot\left(Q-Q^{I *}\right)+\left(1-\emptyset_{1}^{I}\right) \cdot p \cdot\left(X-Q^{I *}\right)+b_{1}^{I} \cdot(Q-X) & \text { if } Q^{I *}<X<Q . \\
\Pi_{R}^{I}\left(Q^{I *}, X\right)-\left(w_{1}^{I}+c_{R}\right) \cdot\left(Q-Q^{I *}\right)+\left(1-\emptyset_{1}^{I}\right) \cdot p \cdot\left(Q-Q^{I *}\right) & \text { if } Q \leq X\end{cases}
\end{array}
$$

We have $P\left\{\Pi_{R}^{I r}(Q, X) \leq a_{R}\right\} \leq P\left\{\Pi_{R}^{I}\left(Q^{I *}, X\right) \leq a_{R}\right\}=\beta_{R}$ if and only if $\Pi_{R}^{I r}(Q, X) \geq_{s t} \Pi_{R}^{I}\left(Q^{I *}, X\right)$. So the retailer's downside-risk constraint is met if $b_{1}^{I} \geq w_{1}^{I}+c_{R}$, i.e., $b_{1}^{I} \geq\left(1-\emptyset_{1}^{I}\right)\left(c_{D}+c_{M}+c_{R}\right)$. Combining the range of $b_{1}^{\mathrm{I}}$ in Equation (23a), we have

$$
\mathrm{b}_{1}^{\mathrm{I}}=\left(1-\emptyset_{1}^{\mathrm{I}}\right)\left(\mathrm{c}_{\mathrm{D}}+\mathrm{c}_{\mathrm{M}}+\mathrm{c}_{\mathrm{R}}\right)
$$


Second, the distributor's profit trajectory is

$$
\begin{aligned}
& \Pi_{\mathrm{D}}^{\mathrm{Ir}}(\mathrm{Q}, \mathrm{X})= \\
& \left\{\begin{array}{lc}
\Pi_{D}^{\mathrm{I}}\left(Q^{I^{*}}, X\right)-c_{D} \cdot\left(Q-Q^{I^{*}}\right)+\left(\left(1-\emptyset_{2}^{I}\right) w_{1}^{I}-w_{2}^{I}\right)\left(Q-Q^{I^{*}}\right)+\left(b_{2}^{I}-b_{1}^{I}\right) \cdot\left(Q-Q^{I^{*}}\right) & \text { if } X \leq Q^{I^{*}} \\
\pi_{D}^{I}\left(Q^{I^{*}}, X\right)-c_{D} \cdot\left(Q-Q^{I^{*}}\right)+\left(\left(1-\emptyset_{2}^{I}\right) w_{1}^{I}-w_{2}^{I}\right)\left(Q-Q^{I^{*}}\right)+\emptyset_{1}^{I}\left(1-\emptyset_{2}^{I}\right) p \cdot\left(X-Q^{I^{*}}\right)+\left(b_{2}^{I}-b_{1}^{I}\right)(Q-X) & \text { if } Q^{I^{*}}<X<Q \\
n_{D}^{I}\left(Q^{I^{*}}, X\right)-c_{D} \cdot\left(Q-Q^{I^{*}}\right)+\left(\emptyset_{1}^{I}\left(1-\emptyset_{2}^{I}\right) p+\left(1-\emptyset_{2}^{I}\right) \cdot w_{1}^{I}-w_{2}^{I}\right)\left(Q-Q^{I^{*}}\right) & \text { if } Q \leq X
\end{array}\right.
\end{aligned}
$$

and the manufacturer's profit trajectory is

$$
\begin{array}{cc}
\Pi_{M}^{\mathrm{Ir}}(\mathrm{Q}, \mathrm{X})= & \\
\left\{\begin{array}{lc}
\Pi_{M}^{\mathrm{I}}\left(\mathrm{Q}^{\mathrm{I}^{*}}, \mathrm{X}\right)-\mathrm{c}_{M} \cdot\left(\mathrm{Q}-\mathrm{Q}^{\mathrm{I}^{*}}\right)+\left(\emptyset_{2}^{\mathrm{I}} \mathrm{w}_{1}^{\mathrm{I}}+\mathrm{w}_{2}^{\mathrm{I}}\right) \cdot\left(\mathrm{Q}-\mathrm{Q}^{\mathrm{I}^{*}}\right)-\mathrm{b}_{2}^{\mathrm{I}} \cdot\left(\mathrm{Q}-\mathrm{Q}^{\mathrm{I}^{*}}\right) & \text { if } \mathrm{X} \leq \mathrm{Q}^{\mathrm{I}^{*}} \\
\Pi_{M}^{\mathrm{I}}\left(\mathrm{Q}^{\mathrm{I}^{*}}, \mathrm{X}\right)-\mathrm{c}_{M} \cdot\left(\mathrm{Q}-\mathrm{Q}^{\mathrm{I}^{*}}\right)+\left(\emptyset_{2}^{\mathrm{I}} \mathrm{w}_{1}^{\mathrm{I}}+\mathrm{w}_{2}^{\mathrm{I}}\right) \cdot\left(\mathrm{Q}-\mathrm{Q}^{\mathrm{I}^{*}}\right)+\emptyset_{1}^{\mathrm{I}} \phi_{2}^{\mathrm{I}} \cdot \mathrm{p} \cdot\left(\mathrm{X}-\mathrm{Q}^{\mathrm{I}^{*}}\right)-\mathrm{b}_{2}^{\mathrm{I}} \cdot(\mathrm{Q}-\mathrm{X}) & \text { if } \mathrm{Q}^{\mathrm{I}^{*}}<\mathrm{X}<\mathrm{Q} . \\
\Pi_{M}^{\mathrm{I}}\left(\mathrm{Q}^{\mathrm{I}^{*}}, \mathrm{X}\right)-\mathrm{c}_{M} \cdot\left(\mathrm{Q}-\mathrm{Q}^{\mathrm{I}^{*}}\right)+\left(\emptyset_{1}^{\mathrm{I}} \phi_{2}^{\mathrm{I}} \cdot \mathrm{p}+\emptyset_{2}^{\mathrm{I}} \cdot \mathrm{w}_{1}^{\mathrm{I}}+\mathrm{w}_{2}^{\mathrm{I}}\right) \cdot\left(\mathrm{Q}-\mathrm{Q}^{\mathrm{I}^{*}}\right) & \text { if } \mathrm{Q} \leq \mathrm{X}
\end{array}\right.
\end{array}
$$

Then, according to Equations (7a), (7b) and (25), the expected profits of the retailer, the distributor and the manufacturer are

$$
\begin{gathered}
E\left[\Pi_{R}^{\mathrm{Ir}}(\mathrm{Q}, \mathrm{X})\right]=\mathrm{E}\left[\Pi_{R}^{\mathrm{I}}\left(\mathrm{Q}^{\mathrm{I}}, \mathrm{X}\right)\right]+\left(1-\emptyset_{1}^{\mathrm{I}}\right) \cdot\left(\mathrm{p}-\mathrm{c}_{\mathrm{R}}-\mathrm{c}_{\mathrm{D}}-\mathrm{c}_{\mathrm{M}}\right) \cdot\left(\left(\mathrm{Q}-\mathrm{Q}^{\mathrm{I} *}\right)-\int_{\mathrm{Q}^{\mathrm{I*}}}^{\mathrm{Q}} \mathrm{F}(\mathrm{x}) \mathrm{dx}\right) \\
\mathrm{E}\left[\Pi_{\mathrm{D}}^{\mathrm{Ir}}(\mathrm{Q}, \mathrm{X})\right]=\mathrm{E}\left[\Pi_{\mathrm{D}}^{\mathrm{I}}\left(\mathrm{Q}^{\mathrm{I}}, \mathrm{X}\right)\right]+\emptyset_{1}^{\mathrm{I}} \cdot\left(1-\emptyset_{2}^{\mathrm{I}}\right) \cdot\left(\mathrm{p}-\mathrm{c}_{\mathrm{R}}-\mathrm{c}_{\mathrm{D}}-\mathrm{c}_{\mathrm{M}}\right) \cdot\left(\mathrm{Q}-\mathrm{Q}^{\mathrm{I} *}\right)-\left(\emptyset_{1}^{\mathrm{I}}\left(1-\emptyset_{2}^{\mathrm{I}}\right) \cdot \mathrm{p}+\right. \\
\left.\left(1-\emptyset_{1}^{\mathrm{I}}\right) \cdot\left(\mathrm{c}_{\mathrm{D}}+\mathrm{c}_{\mathrm{M}}+\mathrm{c}_{\mathrm{R}}\right)-\mathrm{b}_{2}^{\mathrm{I}}\right) \cdot \int_{\mathrm{Q}^{\mathrm{I}}}^{\mathrm{Q}} \mathrm{F}(\mathrm{x}) \mathrm{dx}
\end{gathered}
$$

and

$$
E\left[\Pi_{M}^{I r}(Q, X)\right]=E\left[\Pi_{M}^{I}\left(Q^{I *}, X\right)\right]+\emptyset_{1}^{I} \emptyset_{2}^{I} \cdot\left(p-c_{R}-c_{D}-c_{M}\right)\left(Q-Q^{I *}\right)-\left(\emptyset_{1}^{I} \emptyset_{2}^{I} p+b_{2}^{I}\right) \cdot \int_{Q^{I *}}^{Q} F(x) d x,
$$

respectively.

Thus, we obtain a lower bound and an upper bound of $b_{2}^{I}$ in the following proposition.

Proposition 11. If the risk-aversion level $\left(a_{R}, \beta_{R}\right)$ satisfies $F\left(Q^{10}\right)<\beta_{R}<F\left(Y^{I}\right)$, to encourage all the members to participate into the risk sharing contract $\mathrm{I}$, the refund parameter $\mathrm{b}_{1}^{\mathrm{I}}$ is given by $b_{1}^{I}=\left(1-\emptyset_{1}^{I}\right)\left(c_{D}+c_{M}+c_{R}\right)$, and the lower bound and the upper bound of the refund parameter $b_{2}^{\mathrm{I}}$ are

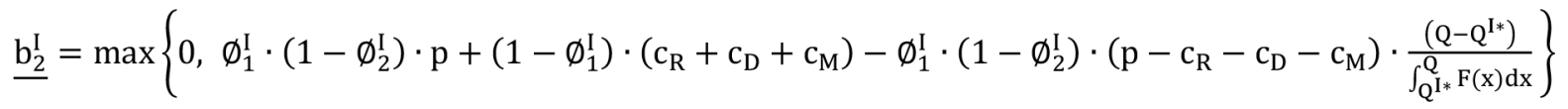

and

$$
\overline{b_{2}^{I}}=\min \left\{\left(1-\emptyset_{2}^{I}\right) \cdot\left(c_{D}+c_{M}\right), \emptyset_{1}^{I} \emptyset_{2}^{I} \cdot\left(p-c_{R}-c_{D}-c_{M}\right) \cdot \frac{\left(Q-Q^{I *}\right)}{\int_{Q^{I *}}^{Q} F(x) d x}-\emptyset_{1}^{I} \emptyset_{2}^{I} p\right\}
$$


respectively, where $\mathrm{Q}^{\mathrm{I}^{*}}<\mathrm{Q} \leq \mathrm{Q}^{\mathrm{C}}$.

If $\mathrm{b}_{1}^{\mathrm{I}}=\left(1-\emptyset_{1}^{\mathrm{I}}\right)\left(\mathrm{c}_{\mathrm{D}}+\mathrm{c}_{\mathrm{M}}+\mathrm{c}_{\mathrm{R}}\right)$ and $\mathrm{b}_{2}^{\mathrm{I}} \in\left[\underline{\mathrm{b}_{2}^{\mathrm{I}}}, \overline{\mathrm{b}_{2}^{\mathrm{I}}}\right]$, the retailer's downside-risk constraint is met and all the members would participate into the risk sharing contract $\mathrm{I}$, where the retailer's order quantity satisfies $\mathrm{Q}^{\mathrm{I}^{*}}<\mathrm{Q} \leq \mathrm{Q}^{\mathrm{C}}$. Hence, according to Definition 1, we get the theorem as follows.

Theorem 3. The risk sharing contract I coordinates the supply chain if the risk-aversion level $\left(a_{R}, \beta_{R}\right)$ satisfies $F\left(Q^{I 0}\right)<\beta_{R}<F\left(Y^{I}\right)$ and the refund parameters satisfy $b_{1}^{I}=\left(1-\emptyset_{1}^{I}\right)\left(c_{D}+c_{M}+c_{R}\right)$ and $\mathrm{b}_{2}^{\mathrm{I}} \in\left[\underline{\mathrm{b}_{2}^{\mathrm{I}}}, \overline{\mathrm{b}_{2}^{\mathrm{I}}}\right]$.

According to Theorem 3, if $b_{1}^{\mathrm{I}}=\left(1-\emptyset_{1}^{\mathrm{I}}\right)\left(\mathrm{c}_{\mathrm{D}}+\mathrm{c}_{\mathrm{M}}+\mathrm{c}_{\mathrm{R}}\right)$ and $\mathrm{b}_{2}^{\mathrm{I}} \in\left[\underline{\mathrm{b}_{2}^{\mathrm{I}}}, \overline{\mathrm{b}_{2}^{\mathrm{I}}}\right]$, the retailer would order $\mathrm{Q}^{\mathrm{C}}$ such that the supply chain coordinates. So the optimal expected profits of the retailer, the distributor and the manufacturer in the risk sharing contract I are,

$$
\begin{gathered}
\pi_{R}^{\mathrm{Ir}}=\left(1-\emptyset_{1}^{\mathrm{I}}\right) \cdot \pi_{\mathrm{SC}}^{\mathrm{C}}+\left(1-\emptyset_{1}^{\mathrm{I}}\right)\left(c_{\mathrm{R}}+\mathrm{c}_{\mathrm{D}}+\mathrm{c}_{\mathrm{M}}\right) \int_{\mathrm{Q}^{\mathrm{I}^{*}}}^{\mathrm{Q}^{\mathrm{C}} \mathrm{F}(\mathrm{x}) \mathrm{dx},} \\
\pi_{\mathrm{D}}^{\mathrm{Ir}}=\emptyset_{1}^{\mathrm{I}}\left(1-\emptyset_{2}^{\mathrm{I}}\right) \cdot \pi_{\mathrm{SC}}^{\mathrm{C}}-\left(\left(1-\emptyset_{1}^{\mathrm{I}}\right)\left(\mathrm{c}_{\mathrm{R}}+\mathrm{c}_{\mathrm{D}}+\mathrm{c}_{\mathrm{M}}\right)-\mathrm{b}_{2}^{\mathrm{I}}\right) \int_{\mathrm{Q}^{*}}^{\mathrm{Q}^{\mathrm{C}} \mathrm{F}} \mathrm{F}(\mathrm{x}) \mathrm{dx}
\end{gathered}
$$

and

$$
\pi_{\mathrm{M}}^{\mathrm{Ir}}=\emptyset_{1}^{\mathrm{I}} \emptyset_{2}^{\mathrm{I}} \cdot \pi_{\mathrm{SC}}^{\mathrm{C}}-\mathrm{b}_{2}^{\mathrm{I}} \cdot \int_{\mathrm{Q}^{*}}^{\mathrm{Q}^{\mathrm{C}}} \mathrm{F}(\mathrm{x}) \mathrm{dx}
$$

respectively.

\subsection{The Risk Sharing Contract II with a Risk-averse Retailer}

Similar to the subsection 5.1 , the refund parameters, $\mathrm{b}_{1}^{\mathrm{II}}$ and $\mathrm{b}_{2}^{\mathrm{II}}$, will be discussed first. To avoid a heavy bullwhip effect, we have

$$
b_{1}^{\mathrm{II}} \in\left(0,\left(1-\emptyset_{1}^{\mathrm{II}}-\emptyset_{2}^{\mathrm{II}}\right)\left(\mathrm{c}_{\mathrm{D}}+\mathrm{c}_{\mathrm{M}}+\mathrm{c}_{\mathrm{R}}\right)\right]
$$

and

$$
\mathrm{b}_{2}^{\mathrm{II}} \in\left(0, \mathrm{c}_{\mathrm{D}}+\mathrm{c}_{\mathrm{M}}-\emptyset_{2}^{\mathrm{II}} \cdot\left(\mathrm{c}_{\mathrm{R}}+\mathrm{c}_{\mathrm{D}}+\mathrm{c}_{\mathrm{M}}\right)\right]
$$

For any given risk-aversion level $\left(a_{R}, \beta_{R}\right)$, we study the member i's profit trajectory $\pi_{i}^{\operatorname{IIr}}(Q, X)$ $(i=R, D, M)$ only if $F\left(Q^{I I 0}\right)<\beta_{R}<F\left(Y^{I I}\right)$ to avoid two insignificant cases. First, the supply chain has been coordinated by executing the revenue sharing contract II with $w_{1}^{\text {II }}$ and $w_{2}^{\text {II }}$ if $F\left(Y^{I I}\right) \leq \beta_{R}$; and second, the retailer never orders to avoid the risk if $\beta_{R}<F\left(Q^{I I 0}\right)$. 
If the retailer's order satisfies $\mathrm{Q} \leq \mathrm{Q}^{\mathrm{II}}{ }^{*}$, we have $\mathrm{E}\left[\pi_{\mathrm{i}}^{\mathrm{II}}(\mathrm{Q}, \mathrm{X})\right] \leq \mathrm{E}\left[\pi_{\mathrm{i}}^{\mathrm{II}}\left(\mathrm{Q}^{\mathrm{II} *}, \mathrm{X}\right)\right]$. All the members do not want to participate in the risk sharing contract II.

If the retailer's order satisfies $Q>Q^{c}$, the retailer's profit trajectory is

$$
\begin{aligned}
& \pi_{\mathrm{R}}^{\mathrm{IIr}}(\mathrm{Q}, \mathrm{X})=
\end{aligned}
$$

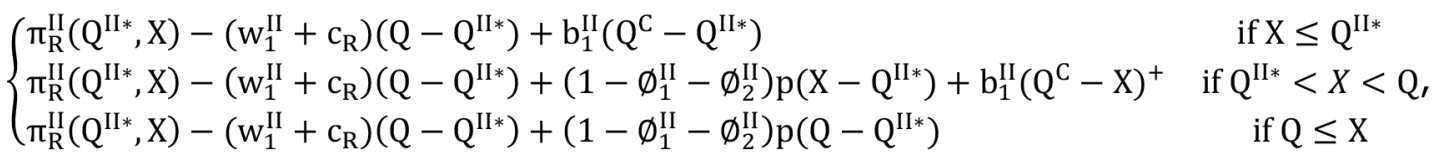

where $\left(Q^{C}-X\right)^{+}=\left\{\begin{array}{cl}Q^{C}-X & \text { if } Q^{C}>X \\ 0 & \text { if } Q^{C} \leq X\end{array}\right.$. According to Equations (12a) and (29), we have

$$
\begin{gathered}
\mathrm{P}\left\{\pi_{\mathrm{R}}^{\mathrm{IIr}}(\mathrm{Q}, \mathrm{X}) \leq \alpha_{\mathrm{R}}\right\} \geq \mathrm{P}\left\{\left[\pi_{\mathrm{R}}^{\mathrm{IIr}}(\mathrm{Q}, \mathrm{X}) \leq \alpha_{\mathrm{R}}\right] \cap\left[\mathrm{X} \leq \mathrm{Q}^{\mathrm{II} *}\right]\right\} \\
=\mathrm{P}\left\{\pi_{\mathrm{R}}^{\mathrm{II}}\left(\mathrm{Q}^{\mathrm{II} *}, \mathrm{X}\right)-\left(\left(1-\emptyset_{1}^{\mathrm{II}}-\emptyset_{2}^{\mathrm{II}}\right) \cdot\left(\mathrm{c}_{\mathrm{D}}+\mathrm{c}_{\mathrm{M}}+\mathrm{c}_{\mathrm{R}}\right)-\mathrm{b}_{1}^{\mathrm{II}}\right)\left(\mathrm{Q}-\mathrm{Q}^{\mathrm{II} *}\right)-\mathrm{b}_{1}^{\mathrm{II}}\left(\mathrm{Q}-\mathrm{Q}^{\mathrm{C}}\right) \leq \alpha_{\mathrm{R}}\right\} \\
>P\left\{\pi_{\mathrm{R}}^{\mathrm{II}}\left(\mathrm{Q}^{\mathrm{II} *}, \mathrm{X}\right) \leq \alpha_{\mathrm{R}}\right\}=\beta_{\mathrm{R}} .
\end{gathered}
$$

Hence, the retailer's downside-risk constraint cannot be met, and she would not order any quantity $\mathrm{Q}$ such that $\mathrm{Q}>\mathrm{Q}^{\mathrm{C}}$.

Next, if the retailer's order satisfies $\mathrm{Q}^{\mathrm{II} *}<\mathrm{Q} \leq \mathrm{Q}^{\mathrm{C}}$, the retailer's profit trajectory is

$$
\begin{aligned}
& \pi_{\mathrm{R}}^{\mathrm{IIr}}(\mathrm{Q}, \mathrm{X})= \\
& \left\{\begin{array}{lc}
\pi_{R}^{\mathrm{II}}\left(Q^{\mathrm{II} *}, X\right)-\left(w_{1}^{\mathrm{II}}+c_{\mathrm{R}}\right)\left(\mathrm{Q}-\mathrm{Q}^{\mathrm{II} *}\right)+\mathrm{b}_{1}^{\mathrm{II}} \cdot\left(\mathrm{Q}-\mathrm{Q}^{\mathrm{II} *}\right) & \text { if } X \leq Q^{\mathrm{II} *} \\
\pi_{\mathrm{R}}^{\mathrm{II}}\left(\mathrm{Q}^{\mathrm{II} *}, \mathrm{X}\right)-\left(\mathrm{w}_{1}^{\mathrm{II}}+\mathrm{c}_{\mathrm{R}}\right)\left(\mathrm{Q}-\mathrm{Q}^{\mathrm{II} *}\right)+\left(1-\emptyset_{1}^{\mathrm{II}}-\emptyset_{2}^{\mathrm{II}}\right) \cdot \mathrm{p} \cdot\left(\mathrm{X}-\mathrm{Q}^{\mathrm{II} *}\right)+\mathrm{b}_{1}^{\mathrm{II}}(\mathrm{Q}-\mathrm{X}) & \text { if } \mathrm{Q}^{\mathrm{II} *}<X<Q . \\
\pi_{\mathrm{R}}^{\mathrm{II}}\left(\mathrm{Q}^{\mathrm{II}}, \mathrm{X}\right)-\left(\mathrm{w}_{1}^{\mathrm{II}}+\mathrm{c}_{\mathrm{R}}\right)\left(\mathrm{Q}-\mathrm{Q}^{\mathrm{II} *}\right)+\left(1-\emptyset_{1}^{\mathrm{II}}-\emptyset_{2}^{\mathrm{II}}\right) \cdot \mathrm{p} \cdot\left(\mathrm{Q}-\mathrm{Q}^{\mathrm{II} *}\right) & \text { if } \mathrm{Q} \leq \mathrm{X}
\end{array}\right.
\end{aligned}
$$

Similar to the discuss in the risk sharing contract I, the retailer's downside-risk constraint is met if

$$
b_{1}^{\mathrm{II}}=\left(1-\emptyset_{1}^{\mathrm{II}}-\emptyset_{2}^{\mathrm{II}}\right) \cdot\left(\mathrm{c}_{\mathrm{D}}+\mathrm{c}_{\mathrm{M}}+\mathrm{c}_{\mathrm{R}}\right)
$$

The distributor's profit trajectory is

$$
\begin{aligned}
& \pi_{\mathrm{D}}^{\mathrm{IIr}}(\mathrm{Q}, \mathrm{X})= \\
& \left\{\begin{array}{lc}
n_{\mathrm{D}}^{\mathrm{II}}\left(\mathrm{Q}^{\mathrm{II}}, \mathrm{X}\right)+\left(\mathrm{w}_{1}^{\mathrm{II}}-\mathrm{w}_{2}^{\mathrm{II}}-\mathrm{c}_{\mathrm{D}}\right)\left(\mathrm{Q}-\mathrm{Q}^{\mathrm{II} *}\right)+\left(\mathrm{b}_{2}^{\mathrm{II}}-\mathrm{b}_{1}^{\mathrm{II}}\right)\left(\mathrm{Q}-\mathrm{Q}^{\mathrm{II} *}\right) & \text { if } \mathrm{X} \leq \mathrm{Q}^{\mathrm{II} *} \\
\Pi_{\mathrm{D}}^{\mathrm{II}}\left(\mathrm{Q}^{\mathrm{II}}, \mathrm{X}\right)+\left(\mathrm{w}_{1}^{\mathrm{II}}-\mathrm{w}_{2}^{\mathrm{II}}-\mathrm{c}_{\mathrm{D}}\right)\left(\mathrm{Q}-\mathrm{Q}^{\mathrm{II} *}\right)+\emptyset_{1}^{\mathrm{II}} \mathrm{p} \cdot\left(\mathrm{X}-\mathrm{Q}^{\mathrm{II} *}\right)+\left(\mathrm{b}_{2}^{\mathrm{II}}-\mathrm{b}_{1}^{\mathrm{II}}\right)(\mathrm{Q}-\mathrm{X}) & \text { if } \mathrm{Q}^{\mathrm{II} *}<\mathrm{X}<\mathrm{Q} . \\
n_{\mathrm{D}}^{\mathrm{II}}\left(\mathrm{Q}^{\mathrm{II}}, \mathrm{X}\right)+\left(\mathrm{w}_{1}^{\mathrm{II}}-\mathrm{w}_{2}^{\mathrm{II}}-\mathrm{c}_{\mathrm{D}}\right)\left(\mathrm{Q}-\mathrm{Q}^{\mathrm{II} *}\right)+\emptyset_{1}^{\mathrm{II}} \mathrm{p} \cdot\left(\mathrm{Q}-\mathrm{Q}^{\mathrm{II} *}\right) & \text { if } \mathrm{Q} \leq \mathrm{X}
\end{array}\right.
\end{aligned}
$$

The manufacturer's profit trajectory is

$$
\begin{aligned}
& \pi_{\mathrm{M}}^{\mathrm{IIr}}(\mathrm{Q}, \mathrm{X})=
\end{aligned}
$$

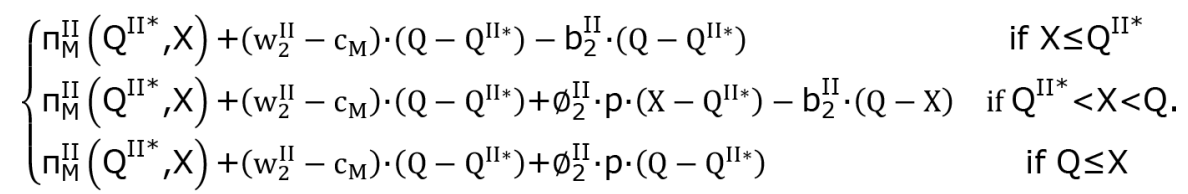


According to Equations (12a), (12b) and (30), the expected profits of the retailer, the distributor and the manufacturer are

$$
\begin{gathered}
E\left[\pi_{R}^{\mathrm{IIr}}(\mathrm{Q}, \mathrm{X})\right]=\mathrm{E}\left[\pi_{\mathrm{R}}^{\mathrm{II}}\left(\mathrm{Q}^{\mathrm{II} *}, \mathrm{X}\right)\right]+\left(1-\emptyset_{1}^{\mathrm{II}}-\emptyset_{2}^{\mathrm{II}}\right) \cdot\left(\mathrm{p}-\mathrm{c}_{\mathrm{R}}-\mathrm{c}_{\mathrm{D}}-\mathrm{c}_{\mathrm{M}}\right) \cdot\left(\left(\mathrm{Q}-\mathrm{Q}^{\mathrm{II} *}\right)-\int_{\mathrm{Q}^{\mathrm{II}}}^{\mathrm{Q}} \mathrm{F}(\mathrm{x}) \mathrm{dx}\right) \\
\mathrm{E}\left[\pi_{\mathrm{D}}^{\mathrm{IIr}}(\mathrm{Q}, \mathrm{X})\right]=\mathrm{E}\left[\pi_{\mathrm{D}}^{\mathrm{II}}\left(\mathrm{Q}^{\mathrm{II} *}, \mathrm{X}\right)\right]+\emptyset_{1}^{\mathrm{II}} \cdot\left(\mathrm{p}-\mathrm{c}_{\mathrm{R}}-\mathrm{c}_{\mathrm{D}}-\mathrm{c}_{\mathrm{M}}\right) \cdot\left(\mathrm{Q}-\mathrm{Q}^{\mathrm{II} *}\right)-\left(\emptyset_{1}^{\mathrm{II}} \mathrm{p}+\left(1-\emptyset_{1}^{\mathrm{II}}-\emptyset_{2}^{\mathrm{II}}\right)\right. \\
\left.\left(\mathrm{c}_{\mathrm{D}}+\mathrm{c}_{\mathrm{M}}+\mathrm{c}_{\mathrm{R}}\right)-\mathrm{b}_{2}^{\mathrm{II}}\right) \cdot \int_{\mathrm{Q}^{\mathrm{II} *} \mathrm{~F}(\mathrm{x}) \mathrm{dx}}
\end{gathered}
$$

and

$$
E\left[\pi_{M}^{\mathrm{IIr}}(\mathrm{Q}, \mathrm{X})\right]=E\left[\pi_{\mathrm{M}}^{\mathrm{II}}\left(\mathrm{Q}^{\mathrm{II} *}, \mathrm{X}\right)\right]+\emptyset_{2}^{\mathrm{II}} \cdot\left(\mathrm{p}-\mathrm{c}_{\mathrm{R}}-\mathrm{c}_{\mathrm{D}}-\mathrm{c}_{\mathrm{M}}\right)\left(\mathrm{Q}-\mathrm{Q}^{\mathrm{II} *}\right)-\left(\emptyset_{2}^{\mathrm{II}} \mathrm{p}+\mathrm{b}_{2}^{\mathrm{II}}\right) \cdot \int_{\mathrm{Q}^{\mathrm{II}}}^{\mathrm{Q}} \mathrm{F}(\mathrm{x}) \mathrm{dx},
$$

respectively.

Thus, we get a lower bound and an upper bound for $b_{2}^{I I}$ in the following proposition.

Proposition 12. If the risk-aversion level $\left(a_{R}, \beta_{R}\right)$ satisfies $F\left(Q^{I I 0}\right)<\beta_{R}<F\left(\gamma^{I I}\right)$, to encourage all the members to participate into the risk sharing contract II, the refund parameter $\mathrm{b}_{1}^{\mathrm{II}}$ is given by $b_{1}^{\mathrm{II}}=\left(1-\emptyset_{1}^{\mathrm{II}}-\emptyset_{2}^{\mathrm{II}}\right) \cdot\left(c_{D}+c_{M}+c_{R}\right)$, and the lower bound and the upper bound of the refund parameter $b_{2}^{\text {II }}$ are

$$
\underline{\mathrm{b}_{2}^{\mathrm{II}}}=\max \left\{0, \emptyset_{1}^{\mathrm{II}} \mathrm{p}+\left(1-\emptyset_{1}^{\mathrm{II}}-\emptyset_{2}^{\mathrm{II}}\right)\left(\mathrm{c}_{\mathrm{D}}+\mathrm{c}_{\mathrm{M}}+\mathrm{c}_{\mathrm{R}}\right)-\emptyset_{1}^{\mathrm{II}} \cdot\left(\mathrm{p}-\mathrm{c}_{\mathrm{R}}-\mathrm{c}_{\mathrm{D}}-\mathrm{c}_{\mathrm{M}}\right) \cdot \frac{\left(\mathrm{Q}-\mathrm{Q}^{\mathrm{II} *}\right)}{\int_{\mathrm{Q}^{\mathrm{II}} \mathrm{F}}^{\mathrm{F}(\mathrm{x}) \mathrm{dx}}}\right\}
$$

and

$$
\overline{b_{2}^{I I}}=\min \left\{c_{D}+c_{M}-\emptyset_{2}^{I I} \cdot\left(c_{R}+c_{D}+c_{M}\right), \emptyset_{2}^{I I} \cdot\left(p-c_{R}-c_{D}-c_{M}\right) \cdot \frac{\left(Q-Q^{I I *}\right)}{\int_{Q^{I I}}^{Q} F(x) d x}-\emptyset_{2}^{I I} p\right\},
$$

respectively, where $\mathrm{Q}^{\mathrm{II}} \leq \mathrm{Q} \leq \mathrm{Q}^{\mathrm{C}}$.

If $b_{1}^{\text {II }}$ and $b_{2}^{\text {II }}$ satisfy the conditions in Proposition 12 , the retailer's downside-risk constraint is met and all the members would participate into the risk sharing contract II if the retailer's order satisfies $\mathrm{Q}^{\mathrm{I}{ }^{*}}<\mathrm{Q} \leq \mathrm{Q}^{\mathrm{C}}$. Furthermore, we have the following theorem.

Theorem 4. The risk sharing contract II coordinates the supply chain if the risk-aversion level $\left(a_{R}, \beta_{R}\right)$ satisfies $F\left(Q^{I I 0}\right)<\beta_{R}<F\left(Y^{I I}\right)$ and the refund parameters satisfy $\mathrm{b}_{1}^{\mathrm{II}}=\left(1-\emptyset_{1}^{\mathrm{II}}-\emptyset_{2}^{\mathrm{II}}\right) \cdot\left(\mathrm{c}_{\mathrm{D}}+\mathrm{c}_{\mathrm{M}}+\mathrm{c}_{\mathrm{R}}\right)$ and $\mathrm{b}_{2}^{\mathrm{II}} \in\left[\underline{\mathrm{b}_{2}^{\mathrm{II}}}, \overline{\mathrm{b}_{2}^{\mathrm{II}}}\right]$. 
According to Theorem 4, if $b_{1}^{\mathrm{II}}=\left(1-\emptyset_{1}^{\mathrm{II}}-\emptyset_{2}^{\mathrm{II}}\right) \cdot\left(\mathrm{c}_{\mathrm{D}}+\mathrm{c}_{\mathrm{M}}+\mathrm{c}_{\mathrm{R}}\right)$ and $\mathrm{b}_{2}^{\mathrm{II}} \in\left[\underline{\mathrm{b}_{2}^{\mathrm{II}}}, \overline{\mathrm{b}_{2}^{\mathrm{II}}}\right]$, the retailer would order $\mathrm{Q}^{\mathrm{C}}$ such that the supply chain coordinates. So the optimal profits of the retailer, the distributor and the manufacturer in the risk sharing contract II are

$$
\begin{gathered}
\pi_{R}^{\mathrm{IIr}}=\left(1-\emptyset_{1}^{\mathrm{II}}-\emptyset_{2}^{\mathrm{II}}\right) \cdot \pi_{\mathrm{SC}}^{\mathrm{C}}+\left(1-\emptyset_{1}^{\mathrm{II}}-\emptyset_{2}^{\mathrm{II}}\right)\left(\mathrm{c}_{\mathrm{R}}+\mathrm{c}_{\mathrm{D}}+\mathrm{c}_{\mathrm{M}}\right) \cdot \int_{\mathrm{Q}^{\mathrm{I} *} \mathrm{~F}}^{\mathrm{Q}^{\mathrm{C}} \mathrm{F}(\mathrm{x}) \mathrm{dx}} \\
\pi_{\mathrm{D}}^{\mathrm{IIr}}=\emptyset_{1}^{\mathrm{II}} \cdot \pi_{\mathrm{SC}}^{\mathrm{C}}-\left(\left(1-\emptyset_{1}^{\mathrm{II}}-\emptyset_{2}^{\mathrm{II}}\right)\left(\mathrm{c}_{\mathrm{D}}+\mathrm{c}_{\mathrm{M}}+\mathrm{c}_{\mathrm{R}}\right)-\mathrm{b}_{2}^{\mathrm{II}}\right) \cdot \int_{\mathrm{Q}^{\mathrm{II}}}^{\mathrm{Q}^{\mathrm{C}} \mathrm{F}}(\mathrm{x}) \mathrm{dx}
\end{gathered}
$$

and

$$
\pi_{\mathrm{M}}^{\mathrm{IIr}}=\emptyset_{2}^{\mathrm{II}} \cdot \pi_{\mathrm{SC}}^{\mathrm{C}}-\mathrm{b}_{2}^{\mathrm{II}} \cdot \int_{\mathrm{Q}^{\mathrm{II}}}^{\mathrm{Q}} \mathrm{F}(\mathrm{x}) \mathrm{dx},
$$

respectively.

\subsection{Compare the Coordinated Results between the Two Risk Sharing Contracts}

For the whole supply chain, the two risk sharing contracts are equivalent if the risk-aversion level $\left(a_{R}, \beta_{R}\right)$ satisfies $F\left(Q^{I 0}\right)<\beta_{R}<F\left(Y^{I}\right)$ and $F\left(Q^{I I 0}\right)<\beta_{R}<F\left(Y^{I I}\right)$, because both of the contracts are not only able to coordinate the supply chain, but also to meet the retailer's downside-risk constraint.

For the each member, her optimal expected profit is different between the two risk sharing contracts. In order to clearly distinguish the two revenue sharing contracts, the refunds in the two risk sharing contracts should be the same, i.e., $b_{1}^{\mathrm{I}}=b_{1}^{\mathrm{II}}$ and $b_{2}^{\mathrm{I}}=b_{2}^{\mathrm{II}}$. Thus the refund parameter $b_{1}^{j}(j=I$ or $I I)$ is

$$
\mathrm{b}_{1}^{\mathrm{j}}=\left(1-\emptyset_{1}^{\mathrm{I}}\right) \cdot\left(\mathrm{c}_{\mathrm{D}}+\mathrm{c}_{\mathrm{M}}+\mathrm{c}_{\mathrm{R}}\right)=\left(1-\emptyset_{1}^{\mathrm{II}}-\emptyset_{2}^{\mathrm{II}}\right) \cdot\left(\mathrm{c}_{\mathrm{D}}+\mathrm{c}_{\mathrm{M}}+\mathrm{c}_{\mathrm{R}}\right) .
$$

And the lower bound and the upper bound of the refund parameter $b_{2}^{j}$ ( $j=I$ or II) become

$$
\begin{aligned}
& \underline{\mathrm{b}_{2}^{\mathrm{j}}}=\max \left\{0,\left(1-\emptyset_{1}^{\mathrm{I}}\right) \cdot\left(\mathrm{c}_{\mathrm{R}}+\mathrm{c}_{\mathrm{D}}+\mathrm{c}_{\mathrm{M}}\right)+\emptyset_{1}^{\mathrm{I}} \cdot\left(1-\emptyset_{2}^{\mathrm{I}}\right) \cdot\left(\mathrm{p}-\left(\mathrm{p}-\mathrm{c}_{\mathrm{R}}-\mathrm{c}_{\mathrm{D}}-\mathrm{c}_{\mathrm{M}}\right) \cdot \frac{\left(\mathrm{Q}-\mathrm{Q}^{\mathrm{I}}\right)}{\int_{\mathrm{Q}^{\mathrm{I}} \mathrm{F}(\mathrm{x}) \mathrm{dx}}}\right)\right. \\
& \left.\left(1-\emptyset_{1}^{I}\right)\left(c_{D}+c_{M}+c_{R}\right)+\emptyset_{1}^{I I} \cdot\left(p-\left(p-c_{R}-c_{D}-c_{M}\right) \cdot \frac{\left(Q-Q^{I *}\right)}{\int_{Q^{I *}}^{Q} F(x) d x}\right)\right\}
\end{aligned}
$$

and

$$
\begin{gathered}
\overline{b_{2}^{j}}=\min \left\{\left(1-\emptyset_{2}^{I}\right) \cdot\left(c_{D}+c_{M}\right), \emptyset_{1}^{I} \emptyset_{2}^{I} \cdot\left(p-c_{R}-c_{D}-c_{M}\right) \cdot \frac{\left(Q-Q^{I *}\right)}{\int_{Q^{I *}}^{Q} F(x) d x}-\emptyset_{1}^{I} \emptyset_{2}^{I} p, c_{D}+c_{M}-\emptyset_{2}^{I I}\right. \\
\left.\left(c_{R}+c_{D}+c_{M}\right), \emptyset_{2}^{I I} \cdot\left(p-c_{R}-c_{D}-c_{M}\right) \cdot \frac{\left(Q-Q^{I *}\right)}{\int_{Q^{I *}}^{Q} F(x) d x}-\emptyset_{2}^{I I} p\right\}^{I I}
\end{gathered}
$$

respectively. 
If $b_{1}^{\mathrm{I}}=b_{1}^{\mathrm{II}}$ and $\mathrm{b}_{2}^{\mathrm{I}}=\mathrm{b}_{2}^{\mathrm{II}}$, the comparative analysis of the two risk sharing contracts can represent that of the two revenue sharing contracts. According to Equation (33), $\emptyset_{1}^{\mathrm{I}}=\emptyset_{1}^{\mathrm{II}}+\emptyset_{2}^{\mathrm{II}}$ holds, furthermore $\mathrm{Q}^{\mathrm{I}^{*}}=\mathrm{Q}^{\mathrm{I}{ }^{*}}$ holds. Then we get the following proposition.

Proposition 13. If the risk-aversion level $\left(a_{R}, \beta_{R}\right)$ satisfies $F\left(Q^{j 0}\right)<\beta_{R}<F\left(\gamma^{j}\right)$, the comparative results of the two revenue sharing contracts are shown in Table 5, where $b_{1}^{j}$ satisfies Equation (33) and $\mathrm{b}_{2}^{\mathrm{j}} \in\left[\underline{\mathrm{b}_{2}^{\mathrm{j}}}, \overline{\mathrm{b}_{2}^{\mathrm{j}}}\right](\mathrm{j}=\mathrm{I}$ or II $)$.

According to Proposition 13, the comparison between the two revenue sharing contracts is very intuitive through executing the designed risk sharing contract. The conditions (1), (2), (3) in Table 5 are the conditions (4), (10) and (13) in Table 1, respectively. Moreover, Table 5 is also a small part of Table 2, Table 3 and Table 4.

\begin{tabular}{|c|c|c|c|}
\hline Results Item & $\begin{array}{c}\text { Compare } \\
\Pi_{\mathrm{R}}^{\mathrm{L}} \text { with } \Pi_{\mathrm{R}}^{\mathrm{II}}\end{array}$ & $\begin{array}{l}\text { Compare } \\
\Pi_{\mathrm{D}}^{\mathrm{I}} \text { with } \Pi_{\mathrm{D}}^{\mathrm{II}}\end{array}$ & $\begin{array}{c}\text { Compare } \\
\Pi_{\mathrm{M}}^{\mathrm{L}} \text { with } \Pi_{\mathrm{M}}^{\mathrm{II}}\end{array}$ \\
\hline (1) $\left\{\begin{array}{c}\emptyset_{1}^{\mathrm{I}}=\emptyset_{1}^{\mathrm{II}}+\emptyset_{2}^{\mathrm{II}} \\
0<\emptyset_{2}^{\mathrm{II}}<\emptyset_{1}^{\mathrm{I}} \cdot \emptyset_{2}^{\mathrm{I}}\end{array}\right.$ & $\Pi_{\mathrm{R}}^{\mathrm{I}}=\Pi_{\mathrm{R}}^{\mathrm{II}}$ & $\Pi_{\mathrm{D}}^{\mathrm{I}}<\Pi_{\mathrm{D}}^{\mathrm{II}}$ & $\Pi_{\mathrm{M}}^{\mathrm{I}}>\Pi_{\mathrm{M}}^{\mathrm{II}}$ \\
\hline (2) $\left\{\begin{array}{l}\emptyset_{1}^{\mathrm{I}}=\emptyset_{1}^{\mathrm{II}}+\emptyset_{2}^{\mathrm{II}} \\
\emptyset_{1}^{\mathrm{I}} \emptyset_{2}^{\mathrm{I}}<\emptyset_{2}^{\mathrm{II}}<1\end{array}\right.$ & $\Pi_{\mathrm{R}}^{\mathrm{I}}=\Pi_{\mathrm{R}}^{\mathrm{II}}$ & $\Pi_{D}^{I}>\Pi_{D}^{I I}$ & $\Pi_{\mathrm{M}}^{\mathrm{I}}<\Pi_{\mathrm{M}}^{\mathrm{II}}$ \\
\hline (3) $\left\{\begin{array}{c}\emptyset_{1}^{\mathrm{I}}=\emptyset_{1}^{\mathrm{II}}+\emptyset_{2}^{\mathrm{II}} \\
\emptyset_{2}^{\mathrm{II}}=\emptyset_{1}^{\mathrm{I}} \cdot \emptyset_{2}^{\mathrm{I}}\end{array}\right.$ & $\Pi_{\mathrm{R}}^{\mathrm{I}}=\Pi_{\mathrm{R}}^{\mathrm{II}}$ & $\Pi_{\mathrm{D}}^{\mathrm{I}}=\Pi_{\mathrm{D}}^{\mathrm{II}}$ & $\Pi_{\mathrm{M}}^{\mathrm{I}}=\Pi_{\mathrm{M}}^{\mathrm{II}}$ \\
\hline
\end{tabular}

Table 5. Comparisons $\Pi_{\mathrm{R}}^{\mathrm{Ir}}$ with $\Pi_{\mathrm{R}}^{\mathrm{IIr}}, \Pi_{\mathrm{D}}^{\mathrm{Ir}}$ with $\Pi_{\mathrm{D}}^{\mathrm{IIr}}$ and $\Pi_{\mathrm{M}}^{\mathrm{Ir}}$ with $\Pi_{\mathrm{M}}^{\mathrm{IIr}}$ if $b_{1}^{\mathrm{I}}=b_{1}^{\mathrm{Il}}$ and $b_{2}^{\mathrm{I}}=b_{2}^{\mathrm{II}}$

From Table 5, the retailer's preference is the same between the two revenue sharing contracts. But for the distributor and the manufacturer, their preferences between the two contracts are different. The distributor prefers the revenue sharing contract I (II) if her profit share in the revenue sharing contract I (II) is higher than that in the revenue sharing contract II (I). Moreover, the manufacturer's preference is also positively related to her profit share in the supply chain. Therefore, we have a corollary as follows.

Corollary 7. Based on the risk sharing contracts and $\emptyset_{1}^{\mathrm{I}}=\emptyset_{1}^{\mathrm{II}}+\emptyset_{2}^{\mathrm{II}}$

(1) if $\emptyset_{2}^{\text {II }}=\emptyset_{1}^{\mathrm{I}} \cdot \emptyset_{2}^{\mathrm{I}}$, all the member gets the same profit between the two revenue sharing contracts; and 
(2) if $\emptyset_{2}^{\mathrm{II}} \neq \emptyset_{1}^{\mathrm{I}} \cdot \emptyset_{2}^{\mathrm{I}}$, the retailer gets the same profit between the two revenue sharing contracts, and the distributor's preference between the two revenue sharing contracts are opposite to the manufacturer's.

\section{Conclusion}

We have analyzed two revenue sharing contracts for a three-echelon supply chain with the retailer's different risk attitude. Both the two revenue sharing contracts can coordinate this supply chain with a risk-neutral retailer. They are not always able to coordinate the supply chain with a risk-averse retailer. However, the supply chain with a risk-averse retailer can be coordinated by executing any risk sharing contracts, which are based on any kind of revenue sharing contracts.

After that, we have established the analytical relationships between the two revenue sharing contracts. (1) If the retailer is risk-neutral, any kind of revenue sharing contracts is not absolutely better than another for each member. (2) If the retailer is risk-averse, her downside-risk is related to her profit share in the supply chain with any kind of revenue sharing contracts. For the whole supply chain, the efficiencies of the two revenue sharing contracts are different, which is related to the retailer's profit share and the upper bound of the retailer's downside risk. For all the supply chain members, the efficiencies of the two revenue sharing contracts are also different, which is related to the each member's profit share, the retailer's target profit level, and the upper bound of the retailer's downside-risk. (3) If the retailer is risk-averse and the risk sharing contract is executed, for the whole supply chain and the retailer, the efficiencies of the two revenue sharing contracts are the same; for the distributor and the manufacturer, the efficiencies of the two revenue sharing contracts are different, except when $\emptyset_{2}^{\mathrm{II}}=\emptyset_{1}^{\mathrm{I}} \cdot \emptyset_{2}^{\mathrm{I}}$, the distributor's preference between the two revenue sharing contracts are opposite to and the manufacturer's.

In practice, which kind of revenue sharing contract is employed in the supply chain, depends on the indicator of the supply chain decision-maker concerned, such as the profit of supply chain, the profit of each member, the risk of the retailer faced. From the different perspective, the comparative results between the two revenue sharing contracts are different. If the decisionmaker concerns total profit of the supply chain, any revenue-sharing contract can be used. If the decision-maker is a member in the supply chain, she would like to execute a revenue-sharing contract which gives her a higher profit, and this may be hurting the other members' benefits. Specially, if the retailer is risk-averse, the decision-maker should consider the risk of the retailer faced expect the profit in the supply chain. So the best way is executing the risk-sharing contract both to coordinate the supply chain and to satisfy the retailer's risk constraint. Moreover, it is also beneficial to the decision-maker that the comparative results of the two revenue sharing contracts under the risk-sharing contract are intuitive (See Corollary 7). 
In a nutshell, this study provides an accurate and comprehensive guide for the supply chain decision-maker about how to coordinate the conflict of interest among the members. Future research can incorporate the other supply chain contracts, such as buyback contract, sale-rebate contract, and option contract.

\section{Acknowledgment}

This work was supported by the National Natural Sciences Foundation of China [No. 71071134, 71202114]; Natural Science Foundation of Hebei Province, China [No. G2013203169]; Shandong Independent Innovation and Achievement Transformation Special Fund of China [No. 2014ZZCX03302]; Shanghai Industry-University-Research Institute Collaboration Fund of China [No. HU-CXY-2014-014]; Foundation of High-level personnel projects in Hebei province [No. C201400157].

\section{References}

Agrawal, V., \& Seshadri, S. (2000). Risk intermediation in supply chains. IIE Transactions, 32(9), 819-831. http://dx.doi.org/10.1023/A:1007630925625

Bahinipati, B.K., Kanda, A., \& Deshmukh, S.G. (2009). Revenue sharing in semiconductor industry supply chain: Cooperative game theoretic approach. Sadhana, 34(3), 501-527. http://dx.doi.org/10.1007/s12046-009-0018-9

Cachon, G.P. (2003). Supply chain coordination with contracts. Handbooks in operations research and management science, 11: 227-339. http://dx.doi.org/10.1016/S0927-0507(03)11006-7

Cachon, G.P., \& Lariviere, M.A. (2005). Supply chain coordination with revenue sharing contracts: strengths and limitations. Management Science, 51(1), 30-44. http://dx.doi.org/10.1287/mnsc. 1040.0215

Dana, J., \& Spier, K. (2001). Revenue sharing and vertical control in the video rental industry. The Journal of Industrial Economics, 49(3): 223-245. http://dx.doi.org/10.1111/1467-6451.00147

Feng, X., Moon, I., \& Ryu, K. (2014). Revenue sharing contracts in an N-stage supply chain with reliability considerations. International Journal of Production Economics, 147, 20-29. http://dx.doi.org/10.1287/mnsc.1040.0215

Fishburn, P.C. (1977). Mean-risk analysis with risk associated with below-target returns. The American Economic Review, 67(2), 116-126. http://www.jstor.org/stable/1807225 
Gan, X., Sethi, S.P., \& Yan, H. (2004). Coordination of Supply Chains with Risk-Averse Agents. Production and Operations Management, 13(2), 135-149. http://dx.doi.org/10.1007/978-3-64219257-9 1

Gan, X., Sethi, S.P., \& Yan, H. (2005). Channel Coordination with a Risk-Neutral Supplier and a Risk-averse Retailer. Production and Operations Management, 14(1), 80-89. http://dx.doi.org/10.1111/j.1937-5956.2005.tb00011.x

Gerchak, Y., \& Wang, Y. (2004). Revenue sharing vs. Wholesale-Price Contracts in Assembly Systems with Random Demand. Production and Operations Management, 13(1), 23-33. http://dx.doi.org/10.1111/j.1937-5956.2004.tb00142.x

Giannoccaro, I., \& Pontrandolfo, P. (2004). Supply chain coordination by revenue sharing contracts. International journal of production economics, 89(2), 131-139. http://dx.doi.org/10.1016/S0925-5273(03)00047-1

Govindan, K., Popiuc, M. N., \& Diabat, A. (2013). Overview of coordination contracts within forward and reverse supply chains. Journal of Cleaner Production, 47, 319-334. http://dx.doi.org/10.1016/j.jclepro.2013.02.001

Hu, X., Caldentey, R., \& Vulcano, G. (2013). Revenue sharing in airline alliances. Management Science, 59(5), 1177-1195. http://dx.doi.org/10.1287/mnsc.1120.1591

Hsueh, C.F. (2014). Improving corporate social responsibility in a supply chain through a new revenue sharing contract. International Journal of Production Economics, 151, 214-222. http://dx.doi.org/10.1016/j.ijpe.2013.10.017

Jaber, M.Y., Bonney, M., \& Guiffrida, A.L. (2010). Coordinating a three-level supply chain with learning-based continuous improvement. International Journal of Production Economics, 127(1), 27-38. http://dx.doi.org/10.1016/j.ijpe.2010.04.010

Ji, S., Liu, M., \& Han, L. (2007). The three-stage supply chain coordination by revenue sharing contracts. IEEE International Conference on Grey Systems and Intelligent Services, IEEE. 1216-1220. http://dx.doi.org/10.1109/GSIS.2007.4443466

Jiang, L., Wang, Y., Yan, X., \& Dai, W. (2014). Coordinating a three-stage supply chain with competing manufacturers. Central European Journal of Operations Research, 22(1), 53-72. http://dx.doi.org/10.1007/s10100-012-0267-2

Lu, Y., Lin, J., \& Wang, B. (2010). Mobile service supply chain coordination with revenue sharing contracts. International Journal of Logistics Systems and Management, 6(3), 267-278. http://dx.doi.org/10.1504/IJLSM.2010.031981

Mortimer, J.H. (2008). Vertical contracts in the video rental industry. The Review of Economic Studies, 75(1), 165-199. http://dx.doi.org/10.1111/j.1467-937X.2007.00462.x 
Pang, Q., Chen, Y., \& Hu, Y. (2014). Coordinating Three-Level Supply Chain by Revenue sharing Contract with Sales Effort Dependent Demand. Discrete Dynamics in Nature and Society. http://dx.doi.org/10.1109/CSO.2011.112

Qian, G.X., Zhang, Y.P., Wu, J.G., \& Pan, Y.H. (2013). Revenue Sharing in Dairy Industry Supply Chain-A Case Study of Hohhot, China. Journal of Integrative Agriculture, 12(12), 2300-2309. http://dx.doi.org/10.1016/S2095-3119(13)60585-7

Rhee, B. van der, Veen, J.A. van der, Venugopal, V., \& Nalla, V.R. (2010). A new revenue sharing mechanism for coordinating multi-echelon supply chains. Operations research letters, 38(4), 296-301. http://dx.doi.org/10.1016/j.orl.2010.03.004

Xu, X., Meng, Z., \& Shen, R. (2013). A tri-level programming model based on Conditional Value-at-Risk for three-stage supply chain management. Computers and Industrial Engineering, 66(2), 470-475. http://dx.doi.org/10.1016/j.cie.2013.07.012

Zhang, J., \& Chen, J. (2014). Information sharing in a make-to-stock supply chain. Journal of Industrial and Management Optimization, 10(4), 1169-1189. http://dx.doi.org/10.1016/j.jom.2004.08.007

\section{Appendix}

Proof of Proposition 2. Based on the revenue sharing contract I with parameters $w_{1}^{\mathrm{I}}$ and $\mathrm{w}_{2}^{\mathrm{I}}$ the target profit of the retailer is $a_{R}$. So there is a critical order quantity $\mathrm{Q}^{\mathrm{I0}}$, which satisfies the equality as follows, $\mathrm{a}_{\mathrm{R}}=\left(1-\emptyset_{1}^{\mathrm{I}}\right) \mathrm{p} \cdot \mathrm{Q}^{\mathrm{I0}}-\mathrm{w}_{1}^{\mathrm{I}} \cdot \mathrm{Q}^{\mathrm{IO}}-\mathrm{c}_{\mathrm{R}} \cdot \mathrm{Q}^{\mathrm{I0}}$. It means that

$$
Q^{I 0}=\frac{a_{R}}{\left(1-\emptyset_{1}^{I}\right) p-w_{1}^{I}-c_{R}} .
$$

Noting Equation (7a), we have

$$
Q^{I 0}=\frac{a_{R}}{\left(1-\phi_{1}^{I}\right) \cdot\left(p-c_{D}-c_{M}-c_{R}\right)} .
$$

According to Equation (A.1), the downside-risk of the retailer is analyzed as follows.

(1) If $Q \leq Q^{I 0}$, then $\Pi_{R}^{I}(Q, X)=\left(1-\emptyset_{1}^{I}\right) \cdot p \cdot \min (X, Q)-w_{1}^{I} \cdot Q-c_{R} \cdot Q \leq\left(1-\emptyset_{1}^{I}\right) \cdot p \cdot Q^{I 0}-w_{1}^{I} \cdot Q^{I 0}-c_{R} \cdot Q^{I 0}=a_{R}$. Therefore, $P\left\{n_{R}^{I}(Q, X) \leq a_{R}\right\}=1$.

(2) If $\mathrm{Q}>\mathrm{Q}^{\mathrm{I0}}$, two situations are discussed.

First, if $Q>Q^{I 0}$ and $X>Q, \Pi_{R}^{I}(Q, X)=\left(1-\emptyset_{1}^{I}\right) \cdot p \cdot Q-w_{1}^{I} \cdot Q-c_{R} \cdot Q>\left(1-\emptyset_{1}^{I}\right) \cdot p \cdot Q^{I 0}-w_{1}^{I} \cdot Q^{I 0}-c_{R} \cdot Q^{I 0}=a_{R}$. Therefore, $P\left\{\left\{\Pi_{\mathrm{R}}^{\mathrm{I}}(\mathrm{Q}, \mathrm{X}) \leq \mathrm{a}_{\mathrm{R}}\right\} \cap\{\mathrm{X}>\mathrm{Q}\}\right\}=0$.

Second, if $Q>Q^{10}$ and $X \leq Q, \Pi_{R}^{I}(Q, X)=\left(1-\emptyset_{1}^{I}\right) \cdot p \cdot X-w_{1}^{I} \cdot Q-c_{R} \cdot Q$. So 


$$
\begin{gathered}
P\left\{\left\{\Pi_{R}^{I}(Q, X) \leq a_{R}\right\} \cap\{X \leq Q\}\right\}=P\left\{\left(1-\emptyset_{1}^{I}\right) \cdot p \cdot X-w_{1}^{I} \cdot Q-c_{R} \cdot Q \leq a_{R}\right\} \\
=P\left\{X \leq \frac{a_{R}+w_{1}^{I} \cdot Q+c_{R} \cdot Q}{\left(1-\phi_{1}^{I}\right) \cdot p}\right\}=F\left(\frac{a_{R}+w_{1}^{I} \cdot Q+c_{R} \cdot Q}{\left(1-\phi_{1}^{I}\right) \cdot p}\right) .
\end{gathered}
$$

In summary, if $\mathrm{Q}>\mathrm{Q}^{\mathrm{I}}$,

$$
P\left\{\Pi_{R}^{I}(Q, X) \leq a_{R}\right\}=F\left(\frac{a_{R}+\left(1-\emptyset_{1}^{1}\right) \cdot\left(c_{D}+c_{M}+c_{R}\right) \cdot Q}{\left(1-\emptyset_{1}^{I}\right) \cdot p}\right) .
$$

It is obvious that the downside-risk of the retailer in Equation (A.2) increases with $\mathrm{Q}$.

Hence, we have

$$
P\left\{\Pi_{R}^{I}(Q, X) \leq a_{R}\right\}=\left\{\begin{array}{cl}
1 & Q \leq Q^{I 0} \\
F\left(\frac{a_{R}+\left(1-\phi_{1}^{I}\right) \cdot\left(c_{D}+c_{M}+c_{R}\right) \cdot Q}{\left(1-\phi_{1}^{I}\right) \cdot p}\right) & Q>Q^{I 0}
\end{array}\right.
$$

This completes the proof.

Proof of Lemma 1. We discuss the range of $\mathrm{Q}^{\mathrm{I}^{*}}$ in the supply chain with revenue sharing contract I with $\mathrm{w}_{1}^{\mathrm{I}}$ and $\mathrm{w}_{2}^{\mathrm{I}}$.

First, according to Equation (16), the risk-averse retailer must make an order quantity such that it is greater than $\mathrm{Q}^{10}$. Otherwise, her downside-risk constraint is one. So we have $\mathrm{Q}^{\mathrm{I}^{*}}>\mathrm{Q}^{\mathrm{I0}}$.

Second, the retailer would not make an order quantity greater than $\mathrm{Q}^{\mathrm{C}}$, because her expected profit is concave with respect to $Q$ and the optimal solution is $Q^{c}$. So we have $\mathrm{Q}^{\mathrm{I}^{*}} \leq \mathrm{Q}^{\mathrm{C}}$.

Last, the target profit of the risk-averse retailer is equal to or less than $\Pi_{R}^{I}$ for the downside-risk constraint. According to Equations (8a) and (15), we have

$$
\begin{gathered}
\left(\left(1-\emptyset_{1}^{I}\right) \cdot\left(p-c_{D}-c_{M}-c_{R}\right)\right) Q^{I 0} \leq\left(1-\emptyset_{1}^{I}\right) \cdot\left(\left(p-c_{R}-c_{D}-c_{M}\right) \cdot Q^{C}-p \cdot \int_{0}^{Q^{C}} F(x) d x\right) \\
<\left(1-\emptyset_{1}^{I}\right) \cdot\left(p-c_{R}-c_{D}-c_{M}\right) \cdot Q^{C} .
\end{gathered}
$$

It means that $\mathrm{Q}^{\mathrm{I}}<\mathrm{Q}^{\mathrm{C}}$. Hence, the optimal order quantity of the risk-averse retailer satisfy $\mathrm{Q}^{\mathrm{I}^{*}} \in\left(\mathrm{Q}^{\mathrm{I0}}, \mathrm{Q}^{\mathrm{C}}\right]$.

This completes the proof.

Proof of Proposition 3. According to Lemma 1, because $Q^{I 0}<Q^{C}, F\left(Q^{I 0}\right)<F\left(Y^{I}\right)$ holds. We discuss the value of $\mathrm{Q}^{\mathrm{I}^{*}}$ from three cases as follows. 
If $\beta_{R} \leq F\left(Q^{10}\right)$, then

$$
F\left(\frac{a_{R}+\left(1-\phi_{1}^{I}\right) \cdot\left(c_{D}+c_{M}+c_{R}\right) \cdot Q}{\left(1-\emptyset_{1}^{I}\right) \cdot p}\right) \leq F\left(Q^{I 0}\right)
$$

holds. Because of Equation (15), the inequality (A.3) is equivalent to $Q \leq Q^{10}$, which is opposite to $Q>Q^{10}$. So the problem (14) has no feasible solution if $\beta_{R} \leq F\left(Q^{10}\right)$.

If $F\left(Q^{I 0}\right)<\beta_{R}<F\left(Y^{I}\right)$, the retailer make an optimal order quantity for the problem (14). The optimal order quantity $\mathrm{Q}^{\mathrm{I}^{*}}$ satisfies

$$
P\left\{\Pi_{R}^{\mathrm{I}}\left(Q^{\mathrm{I} *}, \mathrm{X}\right) \leq \mathrm{a}_{\mathrm{R}}\right\}=\beta_{\mathrm{R}}
$$

This is because the retailer's expected profit increases with $\mathrm{Q}$ for $\mathrm{Q}^{\mathrm{I}}<\mathrm{Q} \leq \mathrm{Q}^{\mathrm{C}}$ and the retailer's downside-risk is also increases with $\mathrm{Q}$ for $\mathrm{Q}^{\mathrm{I0}}<\mathrm{Q}$. Hence, the optimal order quantity of the retailer is

$$
\mathrm{Q}^{\mathrm{I} *}=\frac{\left(1-\emptyset_{1}^{\mathrm{I}}\right) \mathrm{p} \cdot \mathrm{F}^{-1}\left(\beta_{\mathrm{R}}\right)-\mathrm{a}_{\mathrm{R}}}{\left(1-\emptyset_{1}^{\mathrm{I}}\right) \cdot\left(\mathrm{c}_{\mathrm{D}}+\mathrm{c}_{\mathrm{M}}+\mathrm{c}_{\mathrm{R}}\right)}
$$

And if $F\left(Y^{I}\right) \leq \beta_{R}$, then

$$
P\left\{n_{R}^{I}\left(Q^{C}, X\right) \leq a_{R}\right\} \leq \beta_{R}
$$

The order quantity $\mathrm{Q}^{C}$ not only maximizes the retailer's expected profit but also satisfies the retailer's downside-risk constraint. Hence, the retailer's optimal order quantity is $\mathrm{Q}^{\mathrm{C}}$ in this situation.

This completes the proof.

Proof of Theorem 1. According to Proposition 3, if $F\left(Y^{I}\right) \leq \beta_{R}, Q^{I^{*}}=Q^{C}$ Based on the definition of the supply chain coordination given by Cachon (2003), the three-echelon supply chain can be coordinated by the revenue sharing contract I with the wholesale prices $\left(w_{1}^{\mathrm{I}}, \mathrm{w}_{2}^{\mathrm{I}}\right)$.

If $F\left(Q^{I 0}\right)<\beta_{R}<F\left(Y^{I}\right), Q^{I *}=\frac{\left(1-\phi_{1}^{I}\right) p \cdot F^{-1}\left(\beta_{R}\right)-a_{R}}{\left(1-\emptyset_{1}^{I}\right) \cdot\left(c_{D}+c_{M}+c_{R}\right)}$. We have $Q^{I^{*}<Q^{C}}$ because $\beta_{R}<F\left(Y^{I}\right)$. In this case, the retailer's optimal order quantity cannot maximize the supply chain profit and the supply chain cannot be coordinated by the revenue sharing contract I.

If $\beta_{R} \leq F\left(Q^{10}\right)$, the retailer would not order any product. Hence, the supply chain also cannot be coordinated by the revenue sharing contract $\mathrm{I}$ in this case.

This completes the proof. 
Proof of Proposition 4. In the supply chain governed by the revenue sharing contract I with $\mathrm{w}_{1}^{\mathrm{I}}$ and $\mathrm{w}_{2}^{\mathrm{I}}$, we discuss the members' expected profit from three cases as follows:

(1) if $F\left(Y^{I}\right) \leq \beta_{R}$, the optimal order quantity of the risk-averse retailer is equal to that of the risk-neutral retailer, i.e., $\mathrm{Q}^{\mathrm{I}^{*}}=\mathrm{Q}^{\mathrm{C}}$. It means that $\mathrm{E}\left[\mathrm{n}_{\mathrm{SC}}\left(\mathrm{Q}^{\mathrm{I*}}\right)\right]=\mathrm{n}_{\mathrm{SC}}^{\mathrm{C}}$. So according to Equations (1-3), (7a) and (7b), the optimal profits of the retailer, the distributor and the manufacturer are also Equations $(8 a),(8 b)$ and $(8 c)$, respectively.

(2) if $F\left(Q^{I 0}\right)<\beta_{R}<F\left(Y^{I}\right)$, then $Q^{I^{*}}<Q^{C}$. The total expected profit of the supply chain profit is less than $\Pi_{S C}^{C}$, i.e., $E\left[\Pi_{S C}\left(Q^{I *}\right)\right]<\Pi_{S C}^{C}$, because the total expected profit of the supply chain increases with $\mathrm{Q}$ for $\mathrm{Q}^{\mathrm{I}}<\mathrm{Q} \leq \mathrm{Q}^{\mathrm{C}}$. So according to Equations (1), (2), (3), (7a) and (7b), the optimal expected profits of the retailer, the distributor and the manufacturer become Equations (18a), (18b) and (18c), respectively;

(3) if $\beta_{R} \leq F\left(Q^{I 0}\right)$, according to Proposition 3, the retailer does not order a quantity and each member's expected profits are zero.

This completes the proof.

Proof of Proposition 5. Similar to the proof of Proposition 2, based on the revenue sharing contract II with parameters $\mathrm{w}_{1}^{\mathrm{II}}$ and $\mathrm{w}_{2}^{\mathrm{II}}$, there is a critical order quantity $\mathrm{Q}^{\mathrm{II}}$, which satisfies

$$
\mathrm{Q}^{\mathrm{II} 0}=\frac{\mathrm{a}_{\mathrm{R}}}{\left(1-\emptyset_{1}^{\mathrm{II}}-\emptyset_{2}^{\mathrm{II}}\right) \mathrm{p}-\mathrm{w}_{1}^{\mathrm{II}}-\mathrm{c}_{\mathrm{R}}} .
$$

Because $w_{1}^{I}=\left(1-\emptyset_{1}^{I}\right) \cdot\left(c_{D}+c_{M}+c_{R}\right)-c_{R}$, we have

$$
\mathrm{Q}^{\mathrm{II0}}=\frac{\mathrm{a}_{\mathrm{R}}}{\left(1-\emptyset_{1}^{\mathrm{II}}-\emptyset_{2}^{\mathrm{II}}\right) \cdot\left(\mathrm{p}-c_{\mathrm{D}}-\mathrm{c}_{\mathrm{M}}-c_{\mathrm{R}}\right)} .
$$

According to Equation (A.4), the downside-risk of the retailer is analyzed as follows:

(1) if $Q \leq Q^{I I 0}$, then $\Pi_{R}^{I I}(Q, X)=\left(1-\emptyset_{1}^{I I}-\emptyset_{2}^{I I}\right) \cdot p \cdot \min (X, Q)-w_{1}^{I I} \cdot Q^{36} c_{R} \cdot Q \leq\left(1-\emptyset_{1}^{I I}-\emptyset_{2}^{I I}\right) \cdot p \cdot Q^{I I 0}-$ $\mathrm{w}_{1}^{\mathrm{II}} \cdot \mathrm{Q}^{\mathrm{II} 0}-\mathrm{c}_{\mathrm{R}} \cdot \mathrm{Q}^{\mathrm{II0}}=\mathrm{a}_{\mathrm{R}}$. Therefore, $\mathrm{P}\left\{\mathrm{n}_{\mathrm{R}}^{\mathrm{II}}(\mathrm{Q}, \mathrm{X}) \leq \mathrm{a}_{\mathrm{R}}\right\}=1$.

(2) if $Q>Q^{I I 0}$, two situation are discussed. First, if $X>Q, \Pi_{R}^{I I}(Q, X)=\left(1-\emptyset_{1}^{\mathrm{II}}-\emptyset_{2}^{\mathrm{II}}\right) \cdot \mathrm{p} \cdot \mathrm{Q}-\mathrm{w}_{1}^{\mathrm{II}} \cdot \mathrm{Q}-$ $c_{R} \cdot Q>\left(1-\emptyset_{1}^{I I}-\emptyset_{2}^{I I}\right) \cdot p \cdot Q^{I I 0}-w_{1}^{I I} \cdot Q^{I I 0}-c_{R} \cdot Q^{I I 0}=a_{R}$. Therefore, $\quad P\left\{\left\{\Pi_{R}^{I I}(Q, X) \leq a_{R}\right\} \cap\{X>Q\}\right\}=0$. Second, if $X \leq Q, \quad \Pi_{R}^{I I}(Q, X)=\left(1-\emptyset_{1}^{I I}-\emptyset_{2}^{I I}\right) \cdot p \cdot X-w_{1}^{I I} \cdot Q-c_{R} \cdot Q$. So $P\left\{\left\{\Pi_{R}^{I I}(Q, X) \leq a_{R}\right\} \cap\{X \leq Q\}\right\}=$ $P\left\{\left(1-\emptyset_{1}^{\mathrm{II}}-\emptyset_{2}^{\mathrm{II}}\right) \cdot \mathrm{p} \cdot \mathrm{X}-\mathrm{w}_{1}^{\mathrm{II}} \cdot \mathrm{Q}-\mathrm{c}_{\mathrm{R}} \cdot \mathrm{Q} \leq \mathrm{a}_{\mathrm{R}}\right\}=\mathrm{P}\left\{\mathrm{X} \leq \frac{\mathrm{a}_{\mathrm{R}}+\mathrm{w}_{1}^{\mathrm{II}} \cdot \mathrm{Q}+\mathrm{c}_{\mathrm{R}} \cdot \mathrm{Q}}{\left(1-\phi_{1}^{\mathrm{II}}-\phi_{2}^{\mathrm{II}}\right) \cdot \mathrm{p}}\right\}=\mathrm{F}\left(\frac{\mathrm{a}_{\mathrm{R}}+\left(1-\emptyset_{1}^{\mathrm{II}}-\phi_{2}^{\mathrm{II}}\right) \cdot\left(c_{\mathrm{D}}+c_{\mathrm{M}}+c_{\mathrm{R}}\right) \cdot \mathrm{Q}}{\left(1-\phi_{1}^{\mathrm{II}}-\emptyset_{2}^{\mathrm{II}}\right) \cdot \mathrm{p}}\right) \cdot$

In summary, if $Q>Q^{I I 0}$, 


$$
P\left\{\Pi_{R}^{\mathrm{II}}(Q, X) \leq a_{R}\right\}=F\left(\frac{a_{R}+\left(1-\emptyset_{1}^{I I}-\emptyset_{2}^{I I}\right) \cdot\left(c_{D}+c_{M}+c_{R}\right) \cdot Q}{\left(1-\emptyset_{1}^{I I}-\emptyset_{2}^{I I}\right) \cdot p}\right) .
$$

It is obvious that the downside-risk of the retailer in Equation (A.5) increases with Q.

Hence we have

$$
P\left\{\Pi_{R}^{I I}(Q, X) \leq a_{R}\right\}=\left\{\begin{array}{ll}
1 & Q \leq Q^{I I 0} \\
F\left(\frac{a_{R}+\left(1-\phi_{1}^{I I}-\phi_{2}^{I I}\right) \cdot\left(c_{D}+c_{M}+c_{R}\right) \cdot Q}{\left(1-\phi_{1}^{I I}-\phi_{2}^{I I}\right) \cdot p}\right) & Q>Q^{I I 0}
\end{array} .\right.
$$

This completes the proof.

Proof of Lemma 2. Similar to the proof of Lemma 1, we discuss the range of $\mathrm{Q}^{\mathrm{II}}$.

First, according to Equation (20), the retailer must make an order quantity such that $\mathrm{Q}^{\mathrm{II}}>\mathrm{Q}^{\mathrm{II} 0}$, otherwise her downside-risk is one.

Second, the retailer would not make an order quantity greater than $\mathrm{Q}^{\mathrm{C}}$ because her expected profit is concave with respect to $Q$ and the optimal solution is $Q^{C}$. So we have $Q^{I I^{*}} \leq Q^{C}$.

Last, for the retailer, $a_{R} \leq \Pi_{R}^{I I}$ must be satisfied for the downside-risk constraint. According to Equations (13a) and (19), we have

$$
\begin{gathered}
\left(\left(1-\emptyset_{1}^{\mathrm{II}}-\emptyset_{2}^{\mathrm{II}}\right) \cdot\left(p-c_{D}-c_{M}-c_{R}\right)\right) Q^{\mathrm{II} 0} \leq\left(1-\emptyset_{1}^{\mathrm{II}}-\emptyset_{2}^{\mathrm{II}}\right) \cdot\left(\left(p-c_{R}-c_{D}-c_{M}\right) \cdot Q^{\mathrm{C}}-p \cdot \int_{0}^{\mathrm{Q}^{\mathrm{C}}} \mathrm{F}(\mathrm{x}) \mathrm{dx}\right) \\
<\left(1-\emptyset_{1}^{\mathrm{II}}-\emptyset_{2}^{\mathrm{II}}\right) \cdot\left(\mathrm{p}-\mathrm{c}_{\mathrm{R}}-\mathrm{c}_{\mathrm{D}}-\mathrm{c}_{\mathrm{M}}\right) \cdot \mathrm{Q}^{\mathrm{C}} .
\end{gathered}
$$

It means that $\mathrm{Q}^{\mathrm{II}}<\mathrm{Q}^{\mathrm{C}}$. Hence, the optimal order quantity of the risk-averse retailer satisfies $\mathrm{Q}^{\mathrm{II}} \in\left(\mathrm{Q}^{\mathrm{II} 0}, \mathrm{Q}^{\mathrm{C}}\right]$.

This completes the proof.

Proof of Proposition 6. Similar to the proof of Proposition 3, according to Lemma 2, $\mathrm{F}\left(\mathrm{Q}^{\mathrm{IIO}}\right)<\mathrm{F}\left(\mathrm{Y}^{\mathrm{II}}\right)$ holds. We discuss the value of $\mathrm{Q}^{\mathrm{II}}$ from three cases.

If $\beta_{R} \leq F\left(Q^{I I 0}\right)$, then

$$
F\left(\frac{\alpha_{R}+\left(1-\phi_{1}^{I I}-\phi_{2}^{I I I}\right) \cdot\left(c_{D}+c_{M}+c_{R}\right) \cdot Q}{\left(1-\emptyset_{1}^{I I}-\emptyset_{2}^{I I I}\right) \cdot p}\right) \leq F\left(Q^{I I 0}\right)
$$

holds. Because of Equation (19), the inequality (A.6) is equivalent to $Q \leq Q^{I I 0}$, which is opposite to $Q>Q^{\text {IIO }}$. So the problems (14) has no feasible solution if $\beta_{R} \leq F\left(Q^{I 10}\right)$.

If $\mathrm{F}\left(\mathrm{Q}^{\mathrm{II} 0}\right)<\beta_{\mathrm{R}}<\mathrm{F}\left(\mathrm{Y}^{\mathrm{II}}\right)$, the optimal order quantity of the risk-averse retailer $\mathrm{Q}^{\mathrm{II} *}$ satisfies 


$$
\mathrm{P}\left\{\pi_{\mathrm{R}}^{\mathrm{II}}\left(\mathrm{Q}^{\mathrm{II} *}, \mathrm{X}\right) \leq \alpha_{\mathrm{R}}\right\}=\beta_{\mathrm{R}}
$$

This is because the retailer's expected profit increases with $\mathrm{Q}$ for $\mathrm{Q}^{\mathrm{II} 0}<\mathrm{Q} \leq \mathrm{Q}^{\mathrm{C}}$ and the retailer's downside-risk increases with $\mathrm{Q}$ for $\mathrm{Q}^{\mathrm{IIO}}<\mathrm{Q}$. Hence, the optimal order quantity of the retailer is

$$
Q^{\mathrm{II} *}=\frac{\left(1-\emptyset_{1}^{\mathrm{II}}-\emptyset_{2}^{\mathrm{II}}\right) p \cdot \mathrm{F}^{-1}\left(\beta_{\mathrm{R}}\right)-\alpha_{\mathrm{R}}}{\left(1-\emptyset_{1}^{\mathrm{II}}-\emptyset_{2}^{\mathrm{II}}\right) \cdot\left(c_{\mathrm{D}}+c_{\mathrm{M}}+c_{\mathrm{R}}\right)}
$$

And if $F\left(Y^{\text {II }}\right) \leq \beta_{R}$, then

$$
P\left\{\pi_{R}^{\mathrm{II}}\left(Q^{\mathrm{C}}, X\right) \leq \alpha_{\mathrm{R}}\right\} \leq \beta_{\mathrm{R}} .
$$

The order quantity $\mathrm{Q}^{\mathrm{C}}$ not only maximizes the retailer's expected profit but also satisfy the retailer's downside-risk constraint, so $\mathrm{Q}^{\mathrm{II}}=\mathrm{Q}^{\mathrm{C}}$.

This completes the proof.

Proof of Theorem 2. Similar to the proof of Theorem 1, according to Proposition 6, if $F\left(Y^{I I}\right) \leq \beta_{R}, Q^{I{ }^{*}}=Q^{C}$. Based on the definition of the supply chain coordination given by Cachon (2003), the supply chain can be coordinated by the revenue sharing contract II with the wholesale prices $\left(w_{1}^{\mathrm{II}}, \mathrm{w}_{2}^{\mathrm{II}}\right)$.

If $F\left(Q^{I I 0}\right)<\beta_{R}<F\left(Y^{I I}\right), Q^{I I *}=\frac{\left(1-\phi_{1}^{I I}-\phi_{2}^{I I}\right) p \cdot F^{-1}\left(\beta_{R}\right)-\alpha_{R}}{\left(1-\emptyset_{1}^{I I}-\emptyset_{2}^{I I}\right) \cdot\left(c_{D}+c_{M}+c_{R}\right)}$. Because $\beta_{R}<F\left(Y^{I I}\right)$, we have $Q^{I I *}<Q^{C}$. In this case, the retailer's optimal order quantity cannot maximize the supply chain profit, so the supply chain cannot be coordinated by the revenue sharing contract II.

If $\beta_{R} \leq F\left(Q^{I I 0}\right)$, the retailer would not order any product. Hence, the supply chain cannot be coordinated by the revenue sharing contract II in this case.

This completes the proof.

Proof of Proposition 7. In the three-echelon supply chain governed by the revenue sharing contract II with $\mathrm{w}_{1}^{\mathrm{II}}$ and $\mathrm{w}_{2}^{\mathrm{II}}$, we discuss the members' expected profit from three cases.

(1) if $F\left(Y^{I I}\right) \leq \beta_{R}, Q^{I I *}=Q^{C}$. It means that $E\left[\Pi_{S C}\left(Q^{I I *}\right)\right]=\Pi_{S C}^{C}$. So according to Equations (9)-(12b), the optimal profits of the retailer, the distributor and the manufacturer are also Equations (13a)-(13c), respectively.

(2) if $\mathrm{F}\left(\mathrm{Q}^{\mathrm{II} 0}\right)<\beta_{\mathrm{R}}<\mathrm{F}\left(\mathrm{Y}^{\mathrm{II}}\right)$, then $\mathrm{Q}^{\mathrm{II} *}<\mathrm{Q}^{\mathrm{C}} . \mathrm{E}\left[\mathrm{n}_{\mathrm{SC}}\left(\mathrm{Q}^{\mathrm{II} *}\right)\right]<\mathrm{\Pi}_{\mathrm{SC}}^{\mathrm{C}}$ is obtained because the total expected profit of the supply chain increases with $Q$ for $Q^{I I 0}<Q \leq Q^{C}$. So according to Equations (9)-(12b), the optimal expected profits of the retailer, the distributor and the manufacturer become Equations (22a)-(22c), respectively; 
(3) if $\beta_{R} \leq F\left(Q^{I 0}\right)$, according to Proposition 6 , the retailer does not order a quantity. So all the member's expected profits are zero.

This completes the proof.

\section{Proof of Proposition 8}

(1) According to Equations (16) and (20), because $\emptyset_{1}^{\mathrm{I}}, \emptyset_{2}^{\mathrm{I}} \in[0,1]$ and $\left(\emptyset_{1}^{\mathrm{II}}+\emptyset_{2}^{\mathrm{II}}\right) \in[0,1]$, it is obvious that the retailer's downside-risk increases with the order quantity $\mathrm{Q}$ both in the two revenue sharing contracts if $\mathrm{Q}>\mathrm{Q}^{\mathrm{I0}}$ and $\mathrm{Q}>\mathrm{Q}^{\mathrm{II} 0}$.

(2) According to Lemma 3 and Equations (15), (16), (19) and (20), we comparative analyze the retailer's downside risk from three cases. If $\emptyset_{1}^{\mathrm{I}}=\emptyset_{1}^{\mathrm{II}}+\emptyset_{2}^{\mathrm{II}}, \mathrm{Q}^{\mathrm{I0}}=\mathrm{Q}^{\mathrm{II}}$ holds, so $\mathrm{P}\left\{\Pi_{\mathrm{R}}^{\mathrm{I}}(\mathrm{Q}, \mathrm{X}) \leq \mathrm{a}_{\mathrm{R}}\right\}=\mathrm{P}\left\{\Pi_{\mathrm{R}}^{\mathrm{II}}(\mathrm{Q}, \mathrm{X}) \leq \mathrm{a}_{\mathrm{R}}\right\}$; if $\emptyset_{1}^{\mathrm{I}}>\emptyset_{1}^{\mathrm{II}}+\emptyset_{2}^{\mathrm{Il}}, \mathrm{Q}^{\mathrm{I0}}>\mathrm{Q}^{\mathrm{II} 0}$, we have

$$
F\left(\frac{a_{R}+\left(1-\phi_{1}^{I}\right) \cdot\left(c_{D}+c_{M}+c_{R}\right) \cdot Q}{\left(1-\emptyset_{1}^{\mathrm{I}}\right) \cdot p}\right)>F\left(\frac{a_{R}+\left(1-\phi_{1}^{I I}-\phi_{2}^{I I I}\right) \cdot\left(c_{D}+c_{M}+c_{R}\right) \cdot Q}{\left(1-\emptyset_{1}^{\mathrm{II}}-\phi_{2}^{\mathrm{II}}\right) \cdot p}\right),
$$

so $P\left\{\Pi_{R}^{\mathrm{I}}(\mathrm{Q}, \mathrm{X}) \leq \mathrm{a}_{\mathrm{R}}\right\} \geq \mathrm{P}\left\{\Pi_{\mathrm{R}}^{\mathrm{II}}(\mathrm{Q}, \mathrm{X}) \leq \mathrm{a}_{\mathrm{R}}\right\}$; and if $\emptyset_{1}^{\mathrm{I}}<\emptyset_{1}^{\mathrm{II}}+\emptyset_{2}^{\mathrm{II}}, \mathrm{Q}^{\mathrm{I0}}<\mathrm{Q}^{\mathrm{IIO}}$, we have

$$
F\left(\frac{a_{R}+\left(1-\phi_{1}^{I}\right) \cdot\left(c_{D}+c_{M}+c_{R}\right) \cdot Q}{\left(1-\emptyset_{1}^{I}\right) \cdot p}\right)<F\left(\frac{a_{R}+\left(1-\phi_{1}^{I I}-\phi_{2}^{I I}\right) \cdot\left(c_{D}+c_{M}+c_{R}\right) \cdot Q}{\left(1-\emptyset_{1}^{I I}-\emptyset_{2}^{I I}\right) \cdot p}\right)
$$

so $P\left\{\Pi_{R}^{\mathrm{I}}(\mathrm{Q}, \mathrm{X}) \leq \mathrm{a}_{\mathrm{R}}\right\} \leq \mathrm{P}\left\{\boldsymbol{n}_{\mathrm{R}}^{\mathrm{II}}(\mathrm{Q}, \mathrm{X}) \leq \mathrm{a}_{\mathrm{R}}\right\}$.

This completes the proof.

\section{Proof of Proposition 9}

First, if $\emptyset_{1}^{\mathrm{I}}=\emptyset_{1}^{\mathrm{II}}+\emptyset_{2}^{\mathrm{II}}$, noting Equations (17) and (21), it is obviously that $\mathrm{Q}^{\mathrm{I}^{*}}=\mathrm{Q}^{\mathrm{II}}$.

Second, if $\emptyset_{1}^{\mathrm{I}}>\emptyset_{1}^{\mathrm{II}}+\emptyset_{2}^{\mathrm{II}}$, we have $F\left(Q^{\mathrm{I0}}\right)>F\left(Q^{\mathrm{II}}\right)$ and $F\left(Y^{\mathrm{I}}\right)>F\left(Y^{\mathrm{II}}\right)$.

(1) If $F\left(Q^{I 0}\right)<\beta_{R} \leq F\left(Q^{10}\right)$, the retailer's optimal order quantity is zero in the revenue sharing contract I and is $\frac{\left(1-\phi_{1}^{\mathrm{II}}-\phi_{2}^{\mathrm{II}}\right) \cdot \mathrm{p} \cdot \mathrm{F}^{-1}\left(\beta_{\mathrm{R}}\right)-\mathrm{a}_{\mathrm{R}}}{\left(1-\emptyset_{1}^{\mathrm{II}}-\phi_{2}^{\mathrm{II}}\right) \cdot\left(c_{\mathrm{D}}+c_{\mathrm{M}}+c_{\mathrm{R}}\right)}$ in the revenue sharing contract II. So we have $\mathrm{Q}^{\mathrm{I}^{*}}<\mathrm{Q}^{\mathrm{II}}$.

(2) If $F\left(Q^{I 0}\right)<\beta_{R}<F\left(Y^{I I}\right)$, the retailer's optimal order quantity is $\frac{\left(1-\phi_{1}^{I}\right) p \cdot F^{-1}\left(\beta_{R}\right)-a_{R}}{\left(1-\phi_{1}^{I}\right) \cdot\left(c_{D}+c_{M}+c_{R}\right)}$ in the revenue sharing contract I and is $\frac{\left(1-\phi_{1}^{\mathrm{II}}-\phi_{2}^{\mathrm{II}}\right) \cdot p \cdot \mathrm{F}^{-1}\left(\beta_{R}\right)-a_{R}}{\left(1-\phi_{1}^{\mathrm{II}}-\phi_{2}^{\mathrm{II}}\right) \cdot\left(c_{D}+c_{M}+c_{R}\right)}$ in the revenue sharing contract II. Because $\emptyset_{1}^{\mathrm{I}}>\emptyset_{1}^{\mathrm{II}}+\emptyset_{2}^{\mathrm{II}}$ implies

$$
\frac{\left(1-\phi_{1}^{\mathrm{I}}\right) p \cdot \mathrm{F}^{-1}\left(\beta_{R}\right)-a_{R}}{\left(1-\phi_{1}^{\mathrm{I}}\right) \cdot\left(c_{D}+c_{M}+c_{R}\right)}<\frac{\left(1-\emptyset_{1}^{\mathrm{II}}-\phi_{2}^{\mathrm{II}}\right) \cdot \mathrm{p} \cdot \mathrm{F}^{-1}\left(\beta_{R}\right)-a_{R}}{\left(1-\phi_{1}^{\mathrm{II}}-\phi_{2}^{\mathrm{II}}\right) \cdot\left(c_{D}+c_{M}+c_{R}\right)}
$$


we have $\mathrm{Q}^{\mathrm{I}^{*}}<\mathrm{Q}^{\mathrm{II}}$;

(3) If $F\left(\gamma^{I I}\right) \leq \beta_{R}<F\left(\gamma^{I}\right)$, the retailer's optimal order quantity is $\frac{\left(1-\phi_{1}^{I}\right) p \cdot F^{-1}\left(\beta_{R}\right)-a_{R}}{\left(1-\emptyset_{1}^{I}\right) \cdot\left(c_{D}+c_{M}+c_{R}\right)}$ in the revenue sharing contract $I$ and is $Q^{C}$ in the revenue sharing contract II. Because $\frac{\left(1-\phi_{1}^{I}\right) p \cdot F^{-1}\left(\beta_{R}\right)-a_{R}}{\left(1-\varnothing_{1}^{I}\right) \cdot\left(c_{D}+c_{M}+c_{R}\right)}<Q^{C}$, $\mathrm{Q}^{\mathrm{I} *}<\mathrm{Q}^{\mathrm{II}}$ holds;

(4) If $F\left(Y^{I}\right) \leq \beta_{R}$, the retailer's optimal order quantity is $Q^{C}$ both in the revenue sharing contract $\mathrm{I}$ and in the revenue sharing contract II. So $\mathrm{Q}^{\mathrm{I}^{*}}=\mathrm{Q}^{\mathrm{I}{ }^{*}}$ holds.

Third, if $\emptyset_{1}^{\mathrm{I}}<\emptyset_{1}^{\mathrm{II}}+\emptyset_{2}^{\mathrm{II}}, \mathrm{F}\left(\mathrm{Q}^{\mathrm{IO}}\right)<\mathrm{F}\left(\mathrm{Q}^{\mathrm{II}}\right)$ and $\mathrm{F}\left(\mathrm{Y}^{\mathrm{I}}\right)<\mathrm{F}\left(\mathrm{Y}^{\mathrm{II}}\right)$.

(1) If $F\left(Q^{I 0}\right)<\beta_{R} \leq F\left(Q^{I 10}\right)$, the retailer's optimal order quantity is $\frac{\left(1-\phi_{1}^{I}\right) \cdot p \cdot F^{-1}\left(\beta_{R}\right)-a_{R}}{\left(1-\phi_{1}^{I}\right) \cdot\left(c_{D}+c_{M}+c_{R}\right)}$ in the revenue sharing contract I, but it's zero in the revenue sharing contract II. So we have $\mathrm{Q}^{\mathrm{I}^{*}}>\mathrm{Q}^{\mathrm{II}}$.

(2) If $F\left(Q^{I I 0}\right)<\beta_{R}<F\left(\gamma^{I}\right)$, the retailer's optimal order quantity is $\frac{\left(1-\phi_{1}^{I}\right) p \cdot F^{-1}\left(\beta_{R}\right)-a_{R}}{\left(1-\emptyset_{1}^{I}\right) \cdot\left(c_{D}+c_{M}+c_{R}\right)}$ in the revenue sharing contract I and is $\frac{\left(1-\varnothing_{1}^{\mathrm{II}}-\emptyset_{2}^{\mathrm{II}}\right) \cdot \mathrm{p} \cdot \mathrm{F}^{-1}\left(\beta_{R}\right)-a_{R}}{\left(1-\phi_{1}^{\mathrm{II}}-\varnothing_{2}^{\mathrm{II}}\right) \cdot\left(c_{D}+c_{M}+c_{R}\right)}$ in the revenue sharing contract II. Because $\emptyset_{1}^{\mathrm{I}}<\emptyset_{1}^{\mathrm{II}}+\emptyset_{2}^{\mathrm{II}}$ implies

$$
\frac{\left(1-\phi_{1}^{\mathrm{I}}\right) p \cdot \mathrm{F}^{-1}\left(\beta_{\mathrm{R}}\right)-a_{\mathrm{R}}}{\left(1-\phi_{1}^{\mathrm{I}}\right) \cdot\left(\mathrm{c}_{\mathrm{D}}+\mathrm{c}_{\mathrm{M}}+\mathrm{c}_{\mathrm{R}}\right)}>\frac{\left(1-\phi_{1}^{\mathrm{II}}-\oint_{2}^{\mathrm{II}}\right) \cdot \mathrm{p} \cdot \mathrm{F}^{-1}\left(\beta_{\mathrm{R}}\right)-\mathrm{a}_{\mathrm{R}}}{\left(1-\phi_{1}^{\mathrm{II}}-\phi_{2}^{\mathrm{II}}\right) \cdot\left(\mathrm{c}_{\mathrm{D}}+\mathrm{c}_{\mathrm{M}}+\mathrm{c}_{\mathrm{R}}\right)}
$$

we have $\mathrm{Q}^{\mathrm{I}^{*}}>\mathrm{Q}^{\mathrm{II}}$;

(3) If $F\left(Y^{I}\right) \leq \beta_{R}<F\left(Y^{\text {II }}\right)$, the retailer's optimal order quantity is $Q^{C}$ in the revenue sharing contract I and is $\frac{\left(1-\phi_{1}^{\mathrm{II}}-\phi_{2}^{\mathrm{II}}\right) \cdot \mathrm{p} \cdot \mathrm{F}^{-1}\left(\beta_{R}\right)-a_{R}}{\left(1-\phi_{1}^{\mathrm{II}}-\phi_{2}^{\mathrm{II}}\right) \cdot\left(c_{D}+c_{M}+c_{R}\right)}$ in the revenue sharing contract II. Because $\frac{\left(1-\phi_{1}^{\mathrm{II}}-\phi_{2}^{\mathrm{II}}\right) \cdot \mathrm{p} \cdot \mathrm{F}^{-1}\left(\beta_{R}\right)-a_{R}}{\left(1-\phi_{1}^{\mathrm{II}}-\phi_{2}^{\mathrm{II}}\right) \cdot\left(c_{D}+c_{M}+c_{R}\right)}<Q^{C}$, we have $\mathrm{Q}^{\mathrm{I}^{*}}>\mathrm{Q}^{\mathrm{I}{ }^{*}}$;

(4) If $F\left(Y^{I I}\right) \leq \beta_{R}$, no matter in the revenue sharing contract I or in the revenue sharing contract II, the retailer's optimal order quantity is $\mathrm{Q}^{\mathrm{C}}$. So $\mathrm{Q}^{\mathrm{I}^{*}}=\mathrm{Q}^{\mathrm{II}{ }^{*}}$ holds.

This completes the proof.

\section{Proof of Proposition 10}

First, if $\emptyset_{1}^{\mathrm{I}}=\emptyset_{1}^{\mathrm{II}}+\emptyset_{2}^{\mathrm{II}}$, we have $\mathrm{E}\left[\mathrm{n}_{\mathrm{SC}}\left(\mathrm{Q}^{\mathrm{I}}\right)\right]=\mathrm{E}\left[\mathrm{n}_{\mathrm{SC}}\left(\mathrm{Q}^{\mathrm{II} *}\right)\right]$ because $\mathrm{Q}^{\mathrm{I}^{*}}=\mathrm{Q}^{\mathrm{II}}$. Moreover, since $\mathrm{F}\left(\mathrm{Q}^{\mathrm{I0}}\right)=\mathrm{F}\left(\mathrm{Q}^{\mathrm{II}}\right)$ and $\mathrm{F}\left(\mathrm{Y}^{\mathrm{I}}\right)=\mathrm{F}\left(\mathrm{Y}^{\mathrm{II}}\right)$, we have the following discussion.

(1) If $\beta_{R} \leq F\left(Q^{10}\right)$, all the member's profit is zero in the two revenue sharing contracts. 
(2) If $F\left(Q^{10}\right)<\beta_{R}<F\left(Y^{I}\right)$, the members' optimal expected profit in the revenue sharing contract I are Equations (18a)-(18c), and the member's optimal expected profit in the revenue sharing contract II are Equations (22a)-(22c).

For the retailer, $\mathrm{E}\left[\Pi_{\mathrm{R}}^{\mathrm{I}}\left(\mathrm{Q}^{\mathrm{I} *}\right)\right]=\mathrm{E}\left[\Pi_{\mathrm{R}}^{\mathrm{II}}\left(\mathrm{Q}^{\mathrm{II}}\right)\right]$.

For the distributor, $\mathrm{E}\left[\Pi_{\mathrm{D}}^{\mathrm{I}}\left(\mathrm{Q}^{\mathrm{I} *}\right)\right]<\mathrm{E}\left[\Pi_{\mathrm{D}}^{\mathrm{II}}\left(\mathrm{Q}^{\mathrm{II} *}\right)\right] \quad$ if $\quad \emptyset_{1}^{\mathrm{I}} \cdot\left(1-\emptyset_{2}^{\mathrm{I}}\right)<\emptyset_{1}^{\mathrm{II}}, \quad \mathrm{E}\left[\Pi_{\mathrm{D}}^{\mathrm{I}}\left(\mathrm{Q}^{\mathrm{I} *}\right)\right]=\mathrm{E}\left[\Pi_{\mathrm{D}}^{\mathrm{II}}\left(\mathrm{Q}^{\mathrm{I} *}\right)\right] \quad$ if $\emptyset_{1}^{\mathrm{I}} \cdot\left(1-\emptyset_{2}^{\mathrm{I}}\right)=\emptyset_{1}^{\mathrm{II}}$, and $\mathrm{E}\left[\pi_{\mathrm{D}}^{\mathrm{I}}\left(\mathrm{Q}^{\mathrm{I} *}\right)\right]>\mathrm{E}\left[\pi_{\mathrm{D}}^{\mathrm{II}}\left(\mathrm{Q}^{\mathrm{II} *}\right)\right]$ if $\emptyset_{1}^{\mathrm{I}} \cdot\left(1-\emptyset_{2}^{\mathrm{I}}\right)>\emptyset_{1}^{\mathrm{II}}$.

For the manufacturer, $\mathrm{E}\left[\pi_{\mathrm{M}}^{\mathrm{I}}\left(\mathrm{Q}^{\mathrm{I} *}\right)\right]<\mathrm{E}\left[\pi_{\mathrm{M}}^{\mathrm{II}}\left(\mathrm{Q}^{\mathrm{II} *}\right)\right]$ if $\emptyset_{1}^{\mathrm{I}} \cdot \emptyset_{2}^{\mathrm{I}}<\emptyset_{2}^{\mathrm{II}}, \mathrm{E}\left[\pi_{\mathrm{M}}^{\mathrm{I}}\left(\mathrm{Q}^{\mathrm{I} *}\right)\right]=\mathrm{E}\left[\pi_{\mathrm{M}}^{\mathrm{II}}\left(\mathrm{Q}^{\mathrm{II} *}\right)\right]$ if $\emptyset_{1}^{\mathrm{I}} \cdot \emptyset_{2}^{\mathrm{I}}=\emptyset_{2}^{\mathrm{II}}$, and $\mathrm{E}\left[\pi_{\mathrm{M}}^{\mathrm{I}}\left(\mathrm{Q}^{\mathrm{I} *}\right)\right]>\mathrm{E}\left[\pi_{\mathrm{M}}^{\mathrm{II}}\left(\mathrm{Q}^{\mathrm{II}}\right)\right]$ if $\emptyset_{1}^{\mathrm{I}} \cdot \emptyset_{2}^{\mathrm{I}}>\emptyset_{2}^{\mathrm{II}}$.

(3) If $\mathrm{F}\left(\mathrm{Y}^{\mathrm{I}}\right) \leq \beta_{\mathrm{R},} \quad \mathrm{E}\left[\pi_{\mathrm{SC}}\left(\mathrm{Q}^{\mathrm{I} *}\right)\right]=\mathrm{E}\left[\pi_{\mathrm{SC}}\left(\mathrm{Q}^{\mathrm{II} *}\right)\right], \quad \mathrm{E}\left[\pi_{\mathrm{R}}^{\mathrm{I}}\left(\mathrm{Q}^{\mathrm{I} *}\right)\right]=\mathrm{E}\left[\pi_{\mathrm{R}}^{\mathrm{II}}\left(\mathrm{Q}^{\mathrm{II} *}\right)\right], \quad \mathrm{E}\left[\pi_{\mathrm{D}}^{\mathrm{I}}\left(\mathrm{Q}^{\mathrm{I} *}\right)\right]=\mathrm{E}\left[\pi_{\mathrm{D}}^{\mathrm{II}}\left(\mathrm{Q}^{\mathrm{II} *}\right)\right] \quad$ and $\mathrm{E}\left[\pi_{\mathrm{M}}^{\mathrm{I}}\left(\mathrm{Q}^{\mathrm{I} *}\right)\right]=\mathrm{E}\left[\pi_{\mathrm{M}}^{\mathrm{II}}\left(\mathrm{Q}^{\mathrm{II} *}\right)\right]$ hold because $\mathrm{Q}^{\mathrm{I}^{*}}=\mathrm{Q}^{\mathrm{II}}=\mathrm{Q}^{\mathrm{C}}$.

Second, if $\emptyset_{1}^{\mathrm{I}}>\emptyset_{1}^{\mathrm{II}}+\emptyset_{2}^{\mathrm{II}}$, since $\mathrm{F}\left(\mathrm{Q}^{\mathrm{I0}}\right)>\mathrm{F}\left(\mathrm{Q}^{\mathrm{II0}}\right)$ and $\mathrm{F}\left(\mathrm{Y}^{\mathrm{I}}\right)>\mathrm{F}\left(\mathrm{Y}^{\mathrm{II}}\right)$, we have the following discussion.

(1) If $\mathrm{F}\left(\mathrm{Q}^{\mathrm{II0}}\right)<\beta_{\mathrm{R}} \leq \mathrm{F}\left(\mathrm{Q}^{\mathrm{I0}}\right)$, then $\mathrm{E}\left[\pi_{\mathrm{SC}}\left(\mathrm{Q}^{\mathrm{I}}\right)\right]<\mathrm{E}\left[\pi_{\mathrm{SC}}\left(\mathrm{Q}^{\mathrm{II}}\right)\right]$ because $\mathrm{Q}^{\mathrm{I}^{*}}<\mathrm{Q}^{\mathrm{II} *}$. Moreover, all the member's optimal expected profits in the revenue sharing contract I are zero, and the member's optimal expected profit in the revenue sharing contract II are Equations (22a)-(22c). Hence, $\mathrm{E}\left[\pi_{\mathrm{R}}^{\mathrm{I}}\left(\mathrm{Q}^{\mathrm{I} *}\right)\right]<\mathrm{E}\left[\pi_{\mathrm{R}}^{\mathrm{II}}\left(\mathrm{Q}^{\mathrm{II} *}\right)\right], \mathrm{E}\left[\pi_{\mathrm{D}}^{\mathrm{I}}\left(\mathrm{Q}^{\mathrm{I} *}\right)\right]<\mathrm{E}\left[\pi_{\mathrm{D}}^{\mathrm{II}}\left(\mathrm{Q}^{\mathrm{II} *}\right)\right]$ and $\mathrm{E}\left[\pi_{\mathrm{M}}^{\mathrm{I}}\left(\mathrm{Q}^{\mathrm{I} *}\right)\right]<\mathrm{E}\left[\pi_{\mathrm{M}}^{\mathrm{II}}\left(\mathrm{Q}^{\mathrm{II} *}\right)\right]$.

(2) If $\mathrm{F}\left(\mathrm{Q}^{\mathrm{I0}}\right)<\beta_{\mathrm{R}}<\mathrm{F}\left(\mathrm{Y}^{\mathrm{II}}\right)$, then $\mathrm{E}\left[\pi_{\mathrm{SC}}\left(\mathrm{Q}^{\mathrm{I} *}\right)\right]<\mathrm{E}\left[\pi_{\mathrm{SC}}\left(\mathrm{Q}^{\mathrm{II} *}\right)\right]$ because $\mathrm{Q}^{\mathrm{I}^{*}}<\mathrm{Q}^{\mathrm{II}}$. Moreover, the member's optimal expected profit in the revenue sharing contract I are Equations (18a)-(18c), and the member's optimal expected profit in the revenue sharing contract II are Equations (22a)-(22c).

For the retailer, we have $\mathrm{E}\left[\pi_{\mathrm{R}}^{\mathrm{I}}\left(\mathrm{Q}^{\mathrm{I*}}\right)\right]<\mathrm{E}\left[\pi_{\mathrm{R}}^{\mathrm{II}}\left(\mathrm{Q}^{\mathrm{II} *}\right)\right]$.

For the distributor, if $\emptyset_{1}^{\mathrm{I}} \cdot\left(1-\emptyset_{2}^{\mathrm{I}}\right) \leq \emptyset_{1}^{\mathrm{II}}$, we have $\mathrm{E}\left[\pi_{\mathrm{D}}^{\mathrm{I}}\left(\mathrm{Q}^{\mathrm{I} *}\right)\right]<E\left[\pi_{\mathrm{D}}^{\mathrm{II}}\left(\mathrm{Q}^{\mathrm{II} *}\right)\right]$, however, we could not get a clear comparison between $\mathrm{E}\left[\pi_{\mathrm{D}}^{\mathrm{I}}\left(\mathrm{Q}^{\mathrm{I} *}\right)\right]$ and $\mathrm{E}\left[\pi_{\mathrm{D}}^{\mathrm{II}}\left(\mathrm{Q}^{\mathrm{II} *}\right)\right]$ if $\emptyset_{1}^{\mathrm{I}} \cdot\left(1-\emptyset_{2}^{\mathrm{I}}\right)>\emptyset_{1}^{\mathrm{II}}$.

For the manufacturer, if $\emptyset_{1}^{\mathrm{I}} \cdot \emptyset_{2}^{\mathrm{I}} \leq \emptyset_{2}^{\mathrm{II}}$, we have $\mathrm{E}\left[\pi_{\mathrm{M}}^{\mathrm{I}}\left(\mathrm{Q}^{\mathrm{I} *}\right)\right]<\mathrm{E}\left[\pi_{\mathrm{M}}^{\mathrm{II}}\left(\mathrm{Q}^{\mathrm{II*}}\right)\right]$, however, we could not get a clear comparison between $\mathrm{E}\left[\pi_{\mathrm{M}}^{\mathrm{I}}\left(\mathrm{Q}^{\mathrm{I} *}\right)\right]$ and $\mathrm{E}\left[\pi_{\mathrm{M}}^{\mathrm{II}}\left(\mathrm{Q}^{\mathrm{II} *}\right)\right]$ if $\emptyset_{1}^{\mathrm{I}} \cdot \emptyset_{2}^{\mathrm{I}}>\emptyset_{2}^{\mathrm{II}}$.

(3) If $\mathrm{F}\left(\mathrm{Y}^{\mathrm{II}}\right) \leq \beta_{\mathrm{R}}<\mathrm{F}\left(\mathrm{Y}^{\mathrm{I}}\right)$, then $\mathrm{E}\left[\pi_{\mathrm{SC}}\left(\mathrm{Q}^{\mathrm{I} *}\right)\right]<\mathrm{E}\left[\pi_{\mathrm{SC}}\left(\mathrm{Q}^{\mathrm{II} *}\right)\right]=\pi_{\mathrm{SC}}^{\mathrm{C}}$ because $\mathrm{Q}^{\mathrm{I}^{*}}<\mathrm{Q}^{\mathrm{II} *}=\mathrm{Q}^{\mathrm{C}}$. Moreover, the member's optimal expected profit in the revenue sharing contract I are Equations (18a)-(18c), and the member's optimal expected profit in the revenue sharing contract II are Equations (13a)-(13c). Through a simple analyzing, the comparative results in this situation are the same as the results in the situation of $F\left(Q^{I 0}\right)<\beta_{R}<F\left(Y^{I I}\right)$.

(4) If $\mathrm{F}\left(\mathrm{Y}^{\mathrm{I}}\right) \leq \beta_{\mathrm{R}}, \mathrm{E}\left[\pi_{\mathrm{R}}^{\mathrm{I}}\left(\mathrm{Q}^{\mathrm{I} *}\right)\right]=\mathrm{E}\left[\pi_{\mathrm{R}}^{\mathrm{II}}\left(\mathrm{Q}^{\mathrm{II} *}\right)\right], \mathrm{E}\left[\pi_{\mathrm{D}}^{\mathrm{I}}\left(\mathrm{Q}^{\mathrm{I} *}\right)\right]=\mathrm{E}\left[\pi_{\mathrm{D}}^{\mathrm{II}}\left(\mathrm{Q}^{\mathrm{II} *}\right)\right]$ and $\mathrm{E}\left[\pi_{\mathrm{M}}^{\mathrm{I}}\left(\mathrm{Q}^{\mathrm{I} *}\right)\right]=\mathrm{E}\left[\pi_{\mathrm{M}}^{\mathrm{II}}\left(\mathrm{Q}^{\mathrm{II} *}\right)\right]$ hold because $\mathrm{Q}^{\mathrm{I}^{*}}=\mathrm{Q}^{\mathrm{I}{ }^{*}}=\mathrm{Q}^{\mathrm{C}}$. 
Third, if $\emptyset_{1}^{\mathrm{I}}<\emptyset_{1}^{\mathrm{II}}+\emptyset_{2}^{\mathrm{II}}$, since $\mathrm{F}\left(\mathrm{Q}^{\mathrm{I0}}\right)<\mathrm{F}\left(\mathrm{Q}^{\mathrm{II}}\right)$ and $\mathrm{F}\left(\mathrm{Y}^{\mathrm{I}}\right)<\mathrm{F}\left(\mathrm{Y}^{\mathrm{II}}\right)$, we have the following discussion.

(1) if $\mathrm{F}\left(\mathrm{Q}^{\mathrm{I0}}\right)<\beta_{\mathrm{R}} \leq \mathrm{F}\left(\mathrm{Q}^{\mathrm{II0}}\right)$, then $\mathrm{E}\left[\pi_{\mathrm{SC}}\left(\mathrm{Q}^{\mathrm{I} *}\right)\right]>\mathrm{E}\left[\pi_{\mathrm{SC}}\left(\mathrm{Q}^{\mathrm{II} *}\right)\right]$ because $\mathrm{Q}^{\mathrm{I}^{*}}>\mathrm{Q}^{\mathrm{II} *}$. Moreover, the member's optimal expected profits in the revenue sharing contract I are Equations (18a)-(18c), and all the member's optimal expected profits in the revenue sharing contract II are zero. Hence, we have $\mathrm{E}\left[\pi_{\mathrm{R}}^{\mathrm{I}}\left(\mathrm{Q}^{\mathrm{I} *}\right)\right]>\mathrm{E}\left[\pi_{\mathrm{R}}^{\mathrm{II}}\left(\mathrm{Q}^{\mathrm{II} *}\right)\right], \mathrm{E}\left[\pi_{\mathrm{D}}^{\mathrm{I}}\left(\mathrm{Q}^{\mathrm{I} *}\right)\right]>\mathrm{E}\left[\pi_{\mathrm{D}}^{\mathrm{II}}\left(\mathrm{Q}^{\mathrm{II} *}\right)\right]$ and $\mathrm{E}\left[\pi_{\mathrm{M}}^{\mathrm{I}}\left(\mathrm{Q}^{\mathrm{I} *}\right)\right]>\mathrm{E}\left[\pi_{\mathrm{M}}^{\mathrm{II}}\left(\mathrm{Q}^{\mathrm{II} *}\right)\right]$.

(2) if $\mathrm{F}\left(\mathrm{Q}^{\mathrm{II} 0}\right)<\beta_{\mathrm{R}}<\mathrm{F}\left(\mathrm{Y}^{\mathrm{I}}\right)$, then $\mathrm{E}\left[\pi_{\mathrm{SC}}\left(\mathrm{Q}^{\mathrm{I*}}\right)\right]>\mathrm{E}\left[\pi_{\mathrm{SC}}\left(\mathrm{Q}^{\mathrm{II*}}\right)\right]$ because $\mathrm{Q}^{\mathrm{I}^{*}}>\mathrm{Q}^{\mathrm{II}}$. Moreover, the member's optimal expected profit in the revenue sharing contract I are Equations (18a)-(18c), and the member's optimal expected profit in the revenue sharing contract II are Equations (22a)-(22c).

For the retailer, we have $\mathrm{E}\left[\pi_{\mathrm{R}}^{\mathrm{I}}\left(\mathrm{Q}^{\mathrm{I} *}\right)\right]>\mathrm{E}\left[\pi_{\mathrm{R}}^{\mathrm{II}}\left(\mathrm{Q}^{\mathrm{II*}}\right)\right]$.

For the distributor, we have $\mathrm{E}\left[\pi_{\mathrm{D}}^{\mathrm{I}}\left(\mathrm{Q}^{\mathrm{I} *}\right)\right]>\mathrm{E}\left[\pi_{\mathrm{D}}^{\mathrm{II}}\left(\mathrm{Q}^{\mathrm{II} *}\right)\right]$ if $\emptyset_{1}^{\mathrm{I}} \cdot\left(1-\emptyset_{2}^{\mathrm{I}}\right) \geq \emptyset_{1}^{\mathrm{II}}$, however, we could not get a clear comparison between $\mathrm{E}\left[\pi_{\mathrm{D}}^{\mathrm{I}}\left(\mathrm{Q}^{\mathrm{I} *}\right)\right]$ and $\mathrm{E}\left[\pi_{\mathrm{D}}^{\mathrm{II}}\left(\mathrm{Q}^{\mathrm{II}}\right)\right]$ if $\emptyset_{1}^{\mathrm{I}} \cdot\left(1-\emptyset_{2}^{\mathrm{I}}\right)<\emptyset_{1}^{\mathrm{II}}$.

For the manufacturer, we have $\mathrm{E}\left[\pi_{\mathrm{M}}^{\mathrm{I}}\left(\mathrm{Q}^{\mathrm{I} *}\right)\right]>\mathrm{E}\left[\pi_{\mathrm{M}}^{\mathrm{II}}\left(\mathrm{Q}^{\mathrm{II} *}\right)\right]$ if $\emptyset_{1}^{\mathrm{I}} \cdot \emptyset_{2}^{\mathrm{I}} \geq \emptyset_{2}^{\mathrm{II}}$, however, we also could not get a clear comparison between $\mathrm{E}\left[\pi_{\mathrm{M}}^{\mathrm{I}}\left(\mathrm{Q}^{\mathrm{I} *}\right)\right]$ and $\mathrm{E}\left[\pi_{\mathrm{M}}^{\mathrm{II}}\left(\mathrm{Q}^{\mathrm{II} *}\right)\right]$ if $\emptyset_{1}^{\mathrm{I}} \cdot \emptyset_{2}^{\mathrm{I}}<\emptyset_{2}^{\mathrm{Il}}$.

(3) if $\mathrm{F}\left(\mathrm{Y}^{\mathrm{I}}\right) \leq \beta_{\mathrm{R}}<\mathrm{F}\left(\mathrm{Y}^{\mathrm{II}}\right)$, then $\mathrm{E}\left[\pi_{\mathrm{SC}}\left(\mathrm{Q}^{\mathrm{I} *}\right)\right]>\mathrm{E}\left[\pi_{\mathrm{SC}}\left(\mathrm{Q}^{\mathrm{II} *}\right)\right]$ because $\mathrm{Q}^{\mathrm{C}}=\mathrm{Q}^{\mathrm{I}^{*}}>\mathrm{Q}^{\mathrm{II}}$. Moreover, the member's optimal expected profit in the revenue sharing contract I are Equations (8a)-(8c), and the member's optimal expected profit in the revenue sharing contract II are Equations (22a)-(22c). Through a simple analyzing, the comparative results in this situation are the same as the results in the situation of $F\left(Q^{\mathrm{II}}\right)<\beta_{R}<F\left(Y^{I}\right)$.

(4) if $\mathrm{F}\left(\mathrm{Y}^{\mathrm{II}}\right) \leq \beta_{\mathrm{R}}$, so $\mathrm{E}\left[\pi_{\mathrm{R}}^{\mathrm{I}}\left(\mathrm{Q}^{\mathrm{I} *}\right)\right]=\mathrm{E}\left[\pi_{\mathrm{R}}^{\mathrm{II}}\left(\mathrm{Q}^{\mathrm{II} *}\right)\right]$, $\mathrm{E}\left[\pi_{\mathrm{D}}^{\mathrm{I}}\left(\mathrm{Q}^{\mathrm{I} *}\right)\right]=\mathrm{E}\left[\pi_{\mathrm{D}}^{\mathrm{II}}\left(\mathrm{Q}^{\mathrm{II} *}\right)\right]$ and $\mathrm{E}\left[\pi_{\mathrm{M}}^{\mathrm{I}}\left(\mathrm{Q}^{\mathrm{I} *}\right)\right]=\mathrm{E}\left[\pi_{\mathrm{M}}^{\mathrm{II}}\left(\mathrm{Q}^{\mathrm{II} *}\right)\right]$ because $\mathrm{Q}^{\mathrm{I}^{*}}>\mathrm{Q}^{\mathrm{I}{ }^{*}}=\mathrm{Q}^{\mathrm{C}}$.

According to the above discussion, we can draw the comparative results about the members' optimal expected profit.

This completes the proof.

Proof of Proposition 11. To ensure that the retailer's downside-risk constraint is met when $\mathrm{Q}^{\mathrm{I}^{*}}<\mathrm{Q} \leq \mathrm{Q}^{\mathrm{C}}$ according to Equation (25), we have $\mathrm{b}_{1}^{\mathrm{I}}=\left(1-\emptyset_{1}^{\mathrm{I}}\right)\left(\mathrm{c}_{\mathrm{D}}+\mathrm{c}_{\mathrm{M}}+\mathrm{c}_{\mathrm{R}}\right)$.

If the retailer orders a quantity $\mathrm{Q}$ such that $\mathrm{Q}^{\mathrm{I}^{*}}<\mathrm{Q} \leq \mathrm{Q}^{\mathrm{C}}$, then the expected profits of the retailer, the distributor and the manufacturer change by the amount

$$
\Delta \pi_{R}^{\mathrm{Ir}}(\mathrm{Q})=\left(1-\emptyset_{1}^{\mathrm{I}}\right)\left(\mathrm{p}-\mathrm{c}_{\mathrm{R}}-\mathrm{c}_{\mathrm{D}}-\mathrm{c}_{\mathrm{M}}\right)\left(\left(\mathrm{Q}-\mathrm{Q}^{\mathrm{I} *}\right)-\int_{\mathrm{Q}^{\mathrm{I}}}^{\mathrm{Q}} \mathrm{F}(\mathrm{x}) \mathrm{dx}\right)
$$




$$
\begin{gathered}
\Delta \pi_{D}^{\mathrm{Ir}}(\mathrm{Q})=\emptyset_{1}^{\mathrm{I}} \cdot\left(1-\emptyset_{2}^{\mathrm{I}}\right) \cdot\left(\mathrm{p}-\mathrm{c}_{\mathrm{R}}-\mathrm{c}_{\mathrm{D}}-\mathrm{c}_{\mathrm{M}}\right) \cdot\left(\mathrm{Q}-\mathrm{Q}^{\mathrm{I} *}\right)-\left(\emptyset_{1}^{\mathrm{I}}\left(1-\emptyset_{2}^{\mathrm{I}}\right) \cdot \mathrm{p}+\left(1-\emptyset_{1}^{\mathrm{I}}\right) \cdot\right. \\
\left.\left(\mathrm{c}_{\mathrm{D}}+\mathrm{c}_{\mathrm{M}}+\mathrm{c}_{\mathrm{R}}\right)-\mathrm{b}_{2}^{\mathrm{I}}\right) \cdot \int_{\mathrm{Q}^{\mathrm{I}}}^{\mathrm{Q}} \mathrm{F}(\mathrm{x}) \mathrm{dx}
\end{gathered}
$$

and

$$
\Delta \pi_{M}^{\mathrm{Ir}}(\mathrm{Q})=\emptyset_{1}^{\mathrm{I}} \emptyset_{2}^{\mathrm{I}} \cdot\left(\mathrm{p}-\mathrm{c}_{\mathrm{R}}-\mathrm{c}_{\mathrm{D}}-\mathrm{c}_{\mathrm{M}}\right)\left(\mathrm{Q}-\mathrm{Q}^{\mathrm{I} *}\right)-\left(\emptyset_{1}^{\mathrm{I}} \emptyset_{2}^{\mathrm{I}} \mathrm{p}+\mathrm{b}_{2}^{\mathrm{I}}\right) \cdot \int_{\mathrm{Q}^{\mathrm{I}}}^{\mathrm{Q}} \mathrm{F}(\mathrm{x}) \mathrm{dx}
$$

respectively. To encourage all the members to participate into the risk sharing contract I, the value of $\Delta \pi_{i}^{I r}(Q)(i=R, D, M)$ must be equal to or greater than zero. According to Equation (A.7a), $\Delta \pi_{R}^{\mathrm{Ir}}(\mathrm{Q})>0$ holds because $\mathrm{p}>\mathrm{C}_{R}+\mathrm{C}_{\mathrm{D}}+\mathrm{C}_{M}$ and $\mathrm{Q}^{\mathrm{I}^{*}}<\mathrm{Q}$. According to Equation (A.7b), $\Delta \pi_{\mathrm{D}}^{\mathrm{Ir}}(\mathrm{Q}) \geq 0$ means that

$$
\mathrm{b}_{2}^{\mathrm{I}} \geq \emptyset_{1}^{\mathrm{I}}\left(1-\emptyset_{2}^{\mathrm{I}}\right) \cdot \mathrm{p}+\left(1-\emptyset_{1}^{\mathrm{I}}\right) \cdot\left(\mathrm{c}_{\mathrm{D}}+\mathrm{c}_{\mathrm{M}}+\mathrm{c}_{\mathrm{R}}\right)-\emptyset_{1}^{\mathrm{I}} \cdot\left(1-\emptyset_{2}^{\mathrm{I}}\right) \cdot\left(\mathrm{p}-\mathrm{c}_{\mathrm{R}}-\mathrm{c}_{\mathrm{D}}-\mathrm{c}_{\mathrm{M}}\right) \cdot \frac{\left(\mathrm{Q}-\mathrm{Q}^{\mathrm{I} *}\right)}{\left.\int_{\mathrm{Q}^{\mathrm{I}} \mathrm{F}}^{\mathrm{F}} \mathrm{x}\right) \mathrm{dx}}
$$

According to Equation (A.7c), $\Delta \pi_{\mathrm{M}}^{\mathrm{Ir}}(\mathrm{Q}) \geq 0$ means that

$$
\mathrm{b}_{2}^{\mathrm{I}} \leq \emptyset_{1}^{\mathrm{I}} \emptyset_{2}^{\mathrm{I}} \cdot\left(\mathrm{p}-\mathrm{c}_{\mathrm{R}}-\mathrm{c}_{\mathrm{D}}-\mathrm{c}_{\mathrm{M}}\right) \frac{\left(\mathrm{Q}-\mathrm{Q}^{\mathrm{I}}\right)}{\int_{\mathrm{Q}^{*}}^{\mathrm{Q}} \mathrm{F}(\mathrm{x}) \mathrm{dx}}-\emptyset_{1}^{\mathrm{I}} \emptyset_{2}^{\mathrm{I}} \mathrm{p}
$$

According to Equations (23b) and (A.8), the lower bound of $b_{2}^{I}$ is

$$
\max \left\{0, \emptyset_{1}^{\mathrm{I}} \cdot\left(1-\emptyset_{2}^{\mathrm{I}}\right) \cdot \mathrm{p}+\left(1-\emptyset_{1}^{\mathrm{I}}\right) \cdot\left(\mathrm{c}_{\mathrm{R}}+\mathrm{c}_{\mathrm{D}}+\mathrm{c}_{\mathrm{M}}\right)-\emptyset_{1}^{\mathrm{I}} \cdot\left(1-\emptyset_{2}^{\mathrm{I}}\right) \cdot\left(\mathrm{p}-\mathrm{c}_{\mathrm{R}}-\mathrm{c}_{\mathrm{D}}-\mathrm{c}_{\mathrm{M}}\right) \cdot \frac{\left(\mathrm{Q}-\mathrm{Q}^{\mathrm{I}}\right)}{\int_{\mathrm{Q}^{\mathrm{I}} \mathrm{F}(\mathrm{x}) \mathrm{dx}}}\right\}
$$

According to Equations (23b) and (A.9), the upper bound of $b_{2}^{I}$ is

$$
\min \left\{\left(1-\emptyset_{2}^{I}\right) \cdot\left(c_{D}+c_{M}\right), \emptyset_{1}^{I} \emptyset_{2}^{I} \cdot\left(p-c_{R}-c_{D}-c_{M}\right) \cdot \frac{\left(Q-Q^{I *}\right)}{\int_{Q^{I *}}^{Q} F(x) d x}-\emptyset_{1}^{I} \emptyset_{2}^{I} p\right\}
$$

This completes the proof.

Proof of Theorem 3. We prove that three conditions of Definition 1 are satisfied.

(1) According to Proposition 12, all the members get an expected profit more than themselves reservation profit when $\mathrm{Q}^{\mathrm{I}^{*}}<\mathrm{Q} \leq \mathrm{Q}^{\mathrm{C}}$;

(2) If Equation (25) is set up, the retailer's downside-risk constraint is met when $\mathrm{Q}^{\mathrm{I}^{*}}<\mathrm{Q} \leq \mathrm{Q}^{\mathrm{C}}$;

(3) From Equation (26a), the expected profit of the retailer increases with $Q$ for $Q^{I^{*}}<Q \leq Q^{c}$. In addition, the retailer's ordering a quantity exceeding $\mathrm{Q}^{c}$ violates her downside-risk constraint, since the contract specifies the maximum return quantity as $\left(\mathrm{Q}^{\mathrm{C}}-\mathrm{Q}^{\mathrm{I}^{*}}\right)$. Therefore, the retailer would order $\mathrm{Q}^{\mathrm{C}}$ which maximizes her expected profit subject to her downside-risk constraint. Thus the supply chain's profit is maximized. 
According to Definition1, the supply chain is coordinated.

This completes the proof.

Proof of Proposition 12. Similar to the proof of Proposition 11, to ensure that the retailer's downside-risk constraint is met when $\mathrm{Q}^{\mathrm{I}{ }^{*}}<\mathrm{Q} \leq \mathrm{Q}^{\mathrm{C}}$, according to Equation (30), we have $b_{1}^{\mathrm{II}}=\left(1-\emptyset_{1}^{\mathrm{II}}-\emptyset_{2}^{\mathrm{II}}\right) \cdot\left(\mathrm{c}_{\mathrm{D}}+\mathrm{c}_{\mathrm{M}}+\mathrm{c}_{\mathrm{R}}\right)$.

If the retailer orders a quantity $Q$ such that $\mathrm{Q}^{\mathrm{II} *}<\mathrm{Q} \leq \mathrm{Q}^{\mathrm{C}}$, then the expected profits of the retailer, the distributor and the manufacturer change by the amount

$$
\begin{gathered}
\Delta \pi_{R}^{I I r}(Q)=\left(1-\emptyset_{1}^{I I}-\emptyset_{2}^{I I}\right) \cdot\left(p-c_{R}-c_{D}-c_{M}\right) \cdot\left(\left(Q-Q^{I I *}\right)-\int_{Q^{I I *}}^{Q} F(x) d x\right), \\
\Delta \pi_{D}^{I I r}(Q)=\emptyset_{1}^{I I} \cdot\left(p-c_{R}-c_{D}-c_{M}\right) \cdot\left(Q-Q^{I I *}\right)-\left(\emptyset_{1}^{I I} p+\left(1-\emptyset_{1}^{I I}-\emptyset_{2}^{I I}\right)\left(c_{D}+c_{M}+c_{R}\right)-b_{2}^{I I}\right) \cdot \int_{Q^{I I *}}^{Q} F(x) d x
\end{gathered}
$$

and

$$
\Delta \pi_{M}^{\mathrm{IIr}}(\mathrm{Q})=\emptyset_{2}^{\mathrm{II}} \cdot\left(\mathrm{p}-\mathrm{c}_{\mathrm{R}}-\mathrm{c}_{\mathrm{D}}-\mathrm{c}_{\mathrm{M}}\right)\left(\mathrm{Q}-\mathrm{Q}^{\mathrm{II} *}\right)-\left(\emptyset_{2}^{\mathrm{II}} \mathrm{p}+\mathrm{b}_{2}^{\mathrm{II}}\right) \cdot \int_{\mathrm{Q}^{\mathrm{II}} \mathrm{F}}^{\mathrm{Q}} \mathrm{F}(\mathrm{x}) \mathrm{dx}
$$

respectively. To encourage all the members to participate into the risk sharing contract II, $\Delta \pi_{i}^{\mathrm{IIr}}(Q) \geq 0$ must be satisfied ( $\left.\mathrm{i}=\mathrm{R}, \mathrm{D}, \mathrm{M}\right)$. According to Equation (A.10a), $\Delta \pi_{R}^{\mathrm{IIr}}(\mathrm{Q})>0$ holds because $p>C_{R}+C_{D}+C_{M}$ and $Q>Q^{I I^{*}}$. According to Equation (A.10b), $\Delta \pi_{D}^{I I r}(Q) \geq 0$ means that

$$
\mathrm{b}_{2}^{\mathrm{II}} \geq \emptyset_{1}^{\mathrm{II}} \mathrm{p}+\left(1-\emptyset_{1}^{\mathrm{II}}-\emptyset_{2}^{\mathrm{II}}\right)\left(\mathrm{c}_{\mathrm{D}}+\mathrm{c}_{\mathrm{M}}+\mathrm{c}_{\mathrm{R}}\right)-\emptyset_{1}^{\mathrm{II}} \cdot\left(\mathrm{p}-\mathrm{c}_{\mathrm{R}}-\mathrm{c}_{\mathrm{D}}-\mathrm{c}_{\mathrm{M}}\right) \cdot \frac{\left(\mathrm{Q}-\mathrm{Q}^{\mathrm{II} *}\right)}{\int_{\mathrm{Q}^{\mathrm{II}} \mathrm{F}(\mathrm{x}) \mathrm{d}}}
$$

According to Equation (A.10c), $\Delta \pi_{\mathrm{M}}^{\mathrm{IIr}}(\mathrm{Q}) \geq 0$ means that

$$
b_{2}^{\mathrm{II}} \leq \emptyset_{2}^{\mathrm{II}} \cdot\left(\mathrm{p}-\mathrm{c}_{\mathrm{R}}-\mathrm{c}_{\mathrm{D}}-\mathrm{c}_{\mathrm{M}}\right) \cdot \frac{\left(\mathrm{Q}-\mathrm{Q}^{\mathrm{II}}\right)}{\int_{\mathrm{Q}^{\mathrm{II}} \mathrm{F}}^{\mathrm{Q}} \mathrm{F}(\mathrm{x}) \mathrm{dx}}-\emptyset_{2}^{\mathrm{II}} \mathrm{p}
$$

According to Equations (28b) and (A.11), the lower bound of $b_{2}^{\mathrm{II}}$ is

$$
\max \left\{0, \emptyset_{1}^{\mathrm{II}} \mathrm{p}+\left(1-\emptyset_{1}^{\mathrm{II}}-\emptyset_{2}^{\mathrm{II}}\right)\left(\mathrm{c}_{\mathrm{D}}+\mathrm{c}_{\mathrm{M}}+\mathrm{c}_{\mathrm{R}}\right)-\emptyset_{1}^{\mathrm{II}} \cdot\left(\mathrm{p}-\mathrm{c}_{\mathrm{R}}-\mathrm{c}_{\mathrm{D}}-\mathrm{c}_{\mathrm{M}}\right) \cdot \frac{\left(\mathrm{Q}-\mathrm{Q}^{\mathrm{II} *}\right)}{\int_{\mathrm{Q}^{\mathrm{II}} \mathrm{F}(\mathrm{x}) \mathrm{dx}}}\right\} .
$$

According to Equations (28b) and (A.12) the upper bound of $b_{2}^{I I}$ is

$$
\min \left\{c_{D}+c_{M}-\emptyset_{2}^{I I} \cdot\left(c_{R}+c_{D}+c_{M}\right), \emptyset_{2}^{I I} \cdot\left(p-c_{R}-c_{D}-c_{M}\right) \cdot \frac{\left(Q-Q^{I I *}\right)}{\int_{Q^{I *}}^{Q} F(x) d x}-\emptyset_{2}^{I I} p\right\} .
$$

This completes the proof. 
Proof of Theorem 4. We prove that three conditions of Definition 1 are satisfied.

(1) According to Proposition 9, all the members get an expected profit more than themselves reservation profit when $\mathrm{Q}^{\mathrm{II}}<\mathrm{Q} \leq \mathrm{Q}^{\mathrm{C}}$;

(2) If Equation (30) is set up, the retailer's downside-risk constraint is met when $\mathrm{Q}^{\mathrm{II} *}<\mathrm{Q} \leq \mathrm{Q}^{\mathrm{C}}$;

(3) From Equation (31a), the expected profit of the retailer increases with $Q$ for $Q^{I I^{*}}<Q \leq Q^{C}$. In addition, the retailer's ordering a quantity exceeding $\mathrm{Q}^{\mathrm{C}}$ violates her downside-risk constraint, since the contract specifies the maximum return quantity as $\left(\mathrm{Q}^{\mathrm{C}}-\mathrm{Q}^{\mathrm{II}}\right)$. Therefore, the retailer would order $\mathrm{Q}^{\mathrm{C}}$ which maximizes her expected profit subject to her downside-risk constraint. Thus, the supply chain's profit is maximized.

According to Definition 1 , the supply chain is coordinated.

This completes the proof.

Proof of Proposition 13. Under the condition of $b_{1}^{\mathrm{I}}=b_{1}^{\mathrm{II}}$ and $b_{2}^{\mathrm{I}}=b_{2}^{\mathrm{II}}$, we have $\emptyset_{1}^{\mathrm{I}}=\emptyset_{1}^{\mathrm{II}}+\emptyset_{2}^{\mathrm{II}}$ holds. According to Equations (27a) and (32a), if $\emptyset_{1}^{\mathrm{I}}=\emptyset_{1}^{\mathrm{II}}+\emptyset_{2}^{\mathrm{II}}$, the retailer has the same expected profit in the two risk sharing contracts.

Moreover, if $\emptyset_{1}^{\mathrm{I}}=\emptyset_{1}^{\mathrm{II}}+\emptyset_{2}^{\mathrm{II}}$, for the distributor, according to Equations (27b) and (32b), $\pi_{\mathrm{D}}^{\mathrm{Ir}}>\pi_{\mathrm{D}}^{\mathrm{IIr}}$ holds when $\emptyset_{1}^{\mathrm{I}}\left(1-\emptyset_{2}^{\mathrm{I}}\right)>\emptyset_{1}^{\mathrm{II}}, \pi_{\mathrm{D}}^{\mathrm{Ir}}=\pi_{\mathrm{D}}^{\mathrm{IIr}}$ holds when $\emptyset_{1}^{\mathrm{I}}\left(1-\emptyset_{2}^{\mathrm{I}}\right)=\emptyset_{1}^{\mathrm{Il}}$ and $\pi_{\mathrm{D}}^{\mathrm{Ir}}<\pi_{\mathrm{D}}^{\mathrm{IIr}}$ holds when $\emptyset_{1}^{\mathrm{I}}\left(1-\emptyset_{2}^{\mathrm{I}}\right)<\emptyset_{1}^{\mathrm{II}}$; for the manufacturer, according to Equations (27c) and (32c), $\pi_{\mathrm{M}}^{\mathrm{Ir}}>\pi_{\mathrm{M}}^{\mathrm{IIr}}$ holds when $\emptyset_{1}^{\mathrm{I}} \emptyset_{2}^{\mathrm{I}}>\emptyset_{2}^{\mathrm{II}}, \pi_{\mathrm{M}}^{\mathrm{Ir}}=\pi_{\mathrm{M}}^{\mathrm{IIr}}$ holds when $\emptyset_{1}^{\mathrm{I}} \emptyset_{2}^{\mathrm{I}}=\emptyset_{2}^{\mathrm{II}}$ and $\pi_{\mathrm{M}}^{\mathrm{Ir}}<\pi_{\mathrm{M}}^{\mathrm{IIr}}$ holds when $\emptyset_{1}^{\mathrm{I}} \emptyset_{2}^{\mathrm{I}}<\emptyset_{2}^{\mathrm{II}}$. Therefore, we have the comparative results shown in Table 5 .

This completes the proof.

Journal of Industrial Engineering and Management, 2015 (www.jiem.org)

Article's contents are provided on an Attribution-Non Commercial 3.0 Creative commons license. Readers are allowed to copy, distribute and communicate article's contents, provided the author's and Journal of Industrial Engineering and Management's names are included. It must not be used for commercial purposes. To see the complete license contents, please visit http://creativecommons.org/licenses/by-nc/3.0/. 